\title{
IMPACTS OF ENVIRONMENTAL CHANGES \\ ON THE USE OF CELLULAR STORAGE PRODUCTS \\ IN A TEMPERATE CNIDARIAN-DINOFLAGELLATE SYMBIOSIS
}

by

\section{LAUREN MICHELLE FRACASSO}

\author{
A thesis submitted to \\ Victoria University of Wellington \\ in partial fulfilment of the requirements for the degree of \\ Master of Science in Marine Biology
}

Victoria University of Wellington

2020 


\begin{abstract}
Members of the phylum Cnidaria, such as corals and sea anemones, often form mutualistic endosymbiotic relationships with photosynthetic dinoflagellates that are founded upon a reciprocal exchange of nutrients. In this exchange, the cnidarian host provides its symbionts with nutrients derived through respiration, heterotrophy, and the environment, while the symbionts provide their host with products of photosynthesis. The energy derived from this exchange is utilized for metabolism, growth, and reproduction; alternatively, it can be accumulated into storage bodies for use during nutritional shortages or stress. Cnidarian-algal symbioses can be found throughout the world and vary in their sensitivity to stress, with environmental changes playing a prominent role in inducing stress. Tropical cnidarian-dinoflagellate symbioses are particularly vulnerable to temperature change, with increases of just $1-2^{\circ} \mathrm{C}$ above their upper thermal limit often resulting in bleaching (the breakdown of symbiosis via symbiont expulsion). In contrast, temperate cnidarian-dinoflagellate symbioses exhibit far greater tolerance to such environmental stressors, and are rarely seen to bleach in the field. It is unclear how temperate cnidarian-dinoflagellate symbioses achieve this resilience and stability.
\end{abstract}

This thesis examines the effects of changes in temperature and irradiance on the content of energy-rich cellular storage products in the temperate sea anemone Anthopleura aureoradiata and its dinoflagellate endosymbionts (family: Symbiodiniaceae), in order to assess the potential of these compounds in contributing to the overall stability of the symbiosis. In particular, symbiont density and chlorophyll content (as well as photosynthetic efficiency, for experimental study only), in addition to both symbiont and host protein content, served as indicators of physiological health, and were then related to the accumulation of cellular storage products such as lipids and carbohydrates.

A field study was conducted in which a population of $A$. aureoradiata was sampled from Wellington Harbor, New Zealand, at monthly intervals for one year. Despite monthly and seasonal variability in the physiological parameters measured, the symbiosis remained functional and stable (i.e. no signs of bleaching) throughout the year. The greatest inter-seasonal variation occurred in the symbiont cell-specific carbohydrate content, which decreased significantly between spring and summer. In contrast, host lipid content exhibited less variation than all other symbiont and host storage products. These observations suggest that symbiont carbohydrate stores are primarily utilized to sustain the symbiosis during times of seasonal environmental change (in this case, correlating with increased light and temperature during summer), while lipids may be kept in reserve. The robustness of this field population is expected; being a native species, $A$. aureoradiata is likely highly acclimated to the conditions that were observed throughout the year of this field study. 
A separate population of $A$. aureoradiata was subsequently acclimated to a moderate regime of temperature and irradiance, and then exposed to one of six treatments of different combined temperatures and irradiances (based on seasonal conditions in the Wellington Harbour), to establish their interactive effects on cellular storage product content. Specifically, three thermal regimes (low: $9 \pm 1^{\circ} \mathrm{C}$, moderate: $14.5 \pm 1{ }^{\circ} \mathrm{C}$, high: $\left.21 \pm 1^{\circ} \mathrm{C}\right)$, each at a low $\left(70 \pm 10 \mu \mathrm{mol}\right.$ photons $\left.\mathrm{m}^{-2} \mathrm{~s}^{-1}\right)$ or high $\left(145 \pm 15 \mu \mathrm{mol}\right.$ photons $\left.\mathrm{m}^{-2} \mathrm{~s}^{-1}\right)$ irradiance, were maintained for a total of sixteen weeks. Unlike in the field, a breakdown in symbiosis was observed; photophysiological dysfunction of the symbiosis was observed within four weeks in all anemones exposed to low temperature at both irradiances, and bleaching was apparent by week eight. This response likely arose from a combination of the rapid decrease in temperature experienced upon distribution into the low-temperature tank, as well as the prolonged nature of the conditions in the experiment, which would not be experienced in the field. In contrast, the anemones maintained at both irradiances in the moderate and high temperature treatments maintained a stable symbiosis, suggesting that these conditions were not extreme enough to cause notable stress. In fact, anemones kept under both low and high irradiance within the moderate temperature treatment increased in symbiont density and exhibited the highest host lipid content relative to the other treatments, suggesting that this treatment was near-optimal for the symbiosis. Perhaps interestingly, both the moderate and high temperature treatments induced significant reductions in symbiont-specific protein, lipid, and carbohydrate content, while host storage products decreased less drastically. This observation suggests increased utilization of symbiont storage products to maintain a healthy symbiosis under these experimental conditions.

My findings are consistent with previous reports of seasonal stability in temperate cnidarian-dinoflagellate symbioses; moreover, I provide experimental evidence for the utilization of symbiont storage products as a means of maintaining symbiosis stability, though this was less apparent in the field. Although recent studies have made great progress in identifying patterns of stability in temperate cnidarian-dinoflagellate symbioses, additional studies are required to build a more comprehensive picture of the mechanisms involved. Future studies would benefit from increased frequency of field sampling, including assessments of nutrient availability and host reproductive cycles, to better understand the monthly and seasonal variability in the intracellular storage product use observed in the field. Nevertheless, results of this study contribute to an improved understanding of the physiology and remarkable stability of temperate cnidariandinoflagellate symbioses, with implications for predictions of how they might respond to future climate change scenarios. 


\section{Acknowledgements}

First and foremost, I want to express my immense gratitude toward my supervisor, Professor Simon Davy, who always managed to make time for me (as well as the rest of the lab group) amidst the plethora of additional responsibilities that were bestowed upon him. Without his insight and expertise (and patient emotional support) I have no doubt that I would not have been able to complete this project.

I am also highly appreciative of the support and advice provided by my fellow lab members and SBS colleagues, without whom I would still be frantically trying to learn 'how to science'. The solidarity and teamwork that this group emulates is key to its success, and I will be forever grateful for all of the advice and assistance that each and every one of them has provided me with. And to everyone who accompanied or drove me to the field for my monthly collections, I thank you to the end of the world and back; each trip was a little adventure in its own right and I hope you enjoyed the mid-day getaways.

I would be remiss if I did not acknowledge the SBS administrative staff and technician team, who all went out of their way on multiple occasions to assist me with anything from hole-punching my excessive lab notes, to managing my ever-unpredictable building access, to MacGyver-ing my experimental set-up (to the point where I'm sure we earned an engineering degree), to addressing my many equipment debacles.

Perhaps most importantly, to all the beautiful souls (friends and family alike) who gave me endless emotional support, shoulders to cry on, ears to vent to, and arms to wrap me up when I was feeling down... I cannot begin to express my sincerest gratitude toward you. Each and every one of you put up with far too many of my shenanigans, with unbelievable grace and patience. I wish you all nothing but the absolute best, and hope for the opportunity to return your support someday. 


\section{Table of Contents}

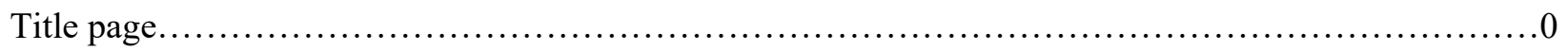

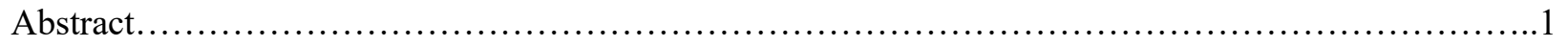

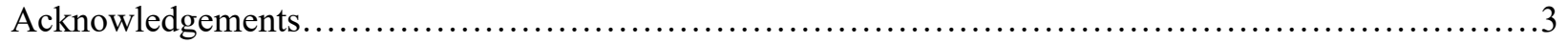

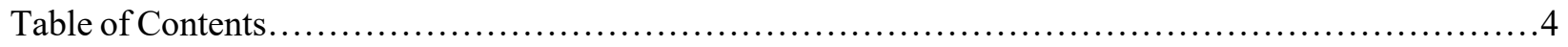

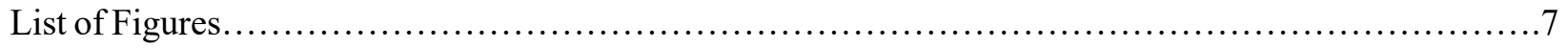

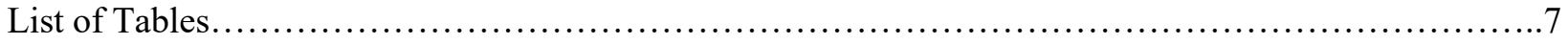

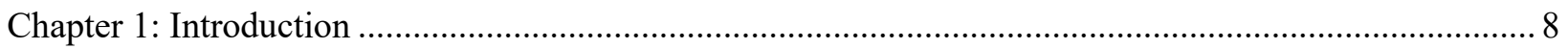

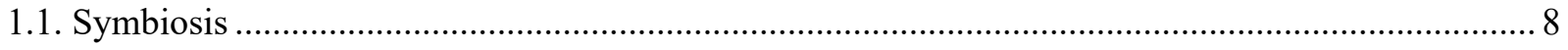

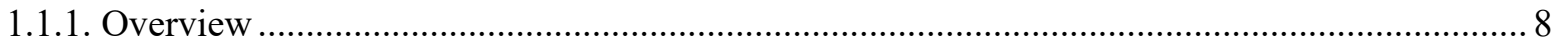

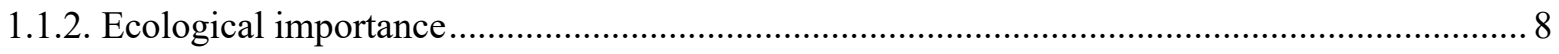

1.2. Cnidarian-dinoflagellate symbiosis ..............................................................................

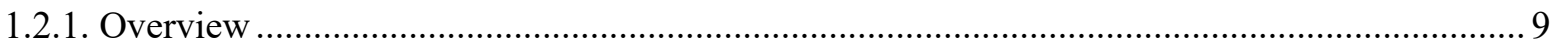

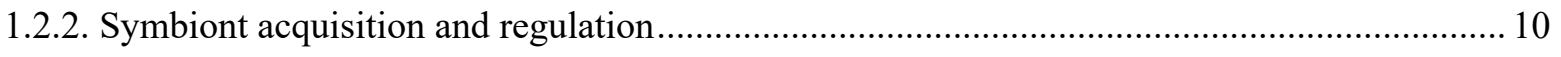

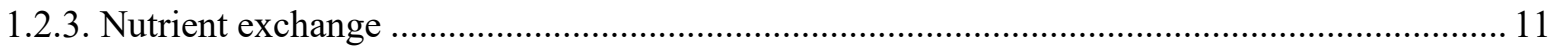

1.3. Environmental influences................................................................................................ 12

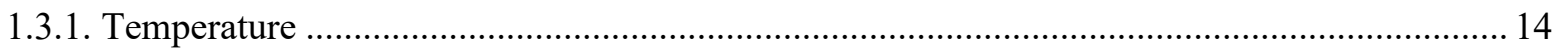

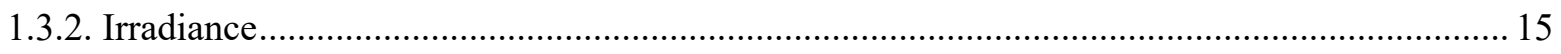

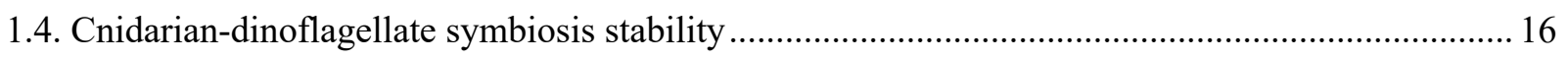

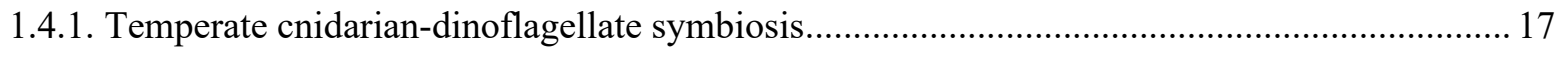

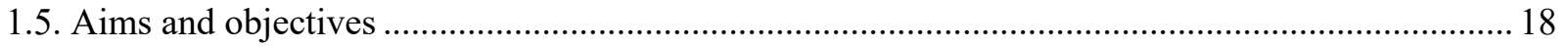

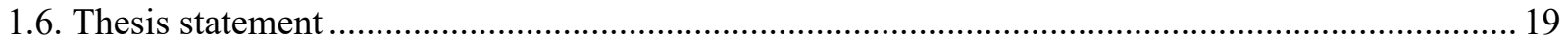

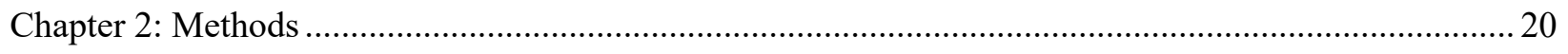

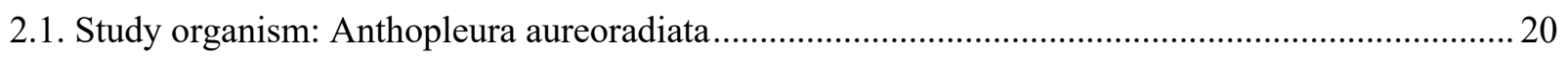

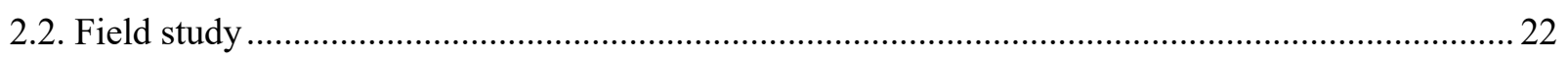

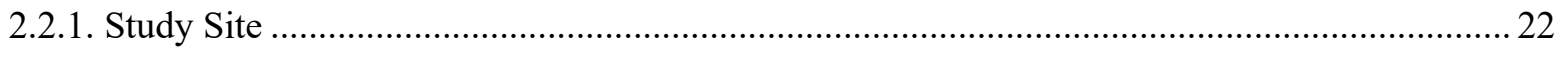




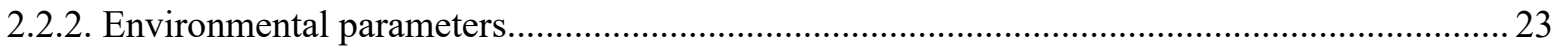

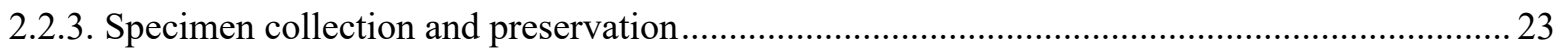

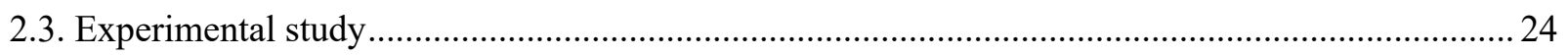

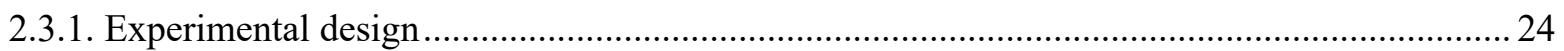

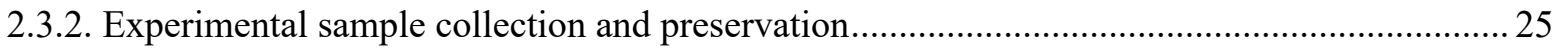

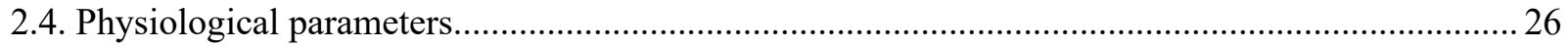

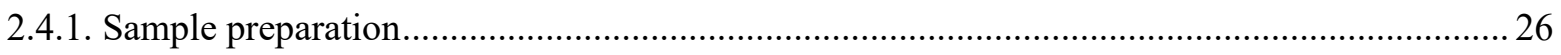

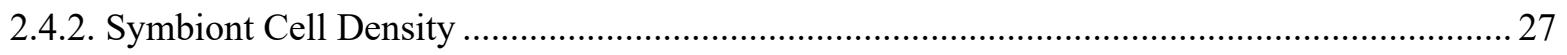

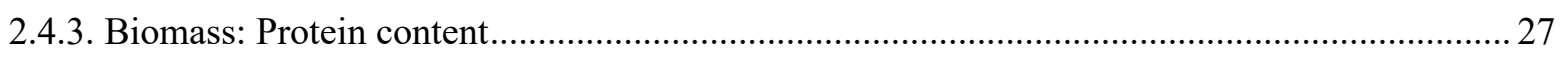

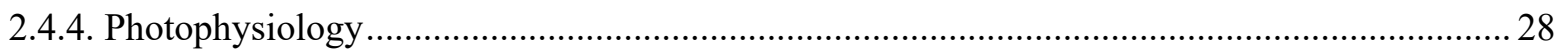

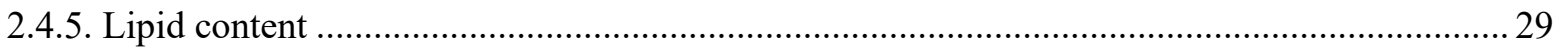

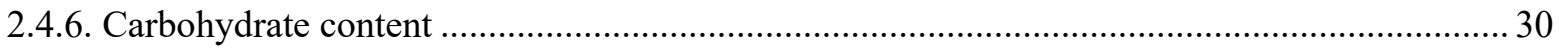

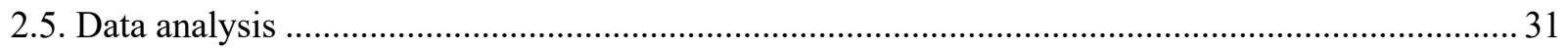

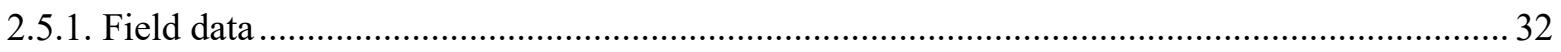

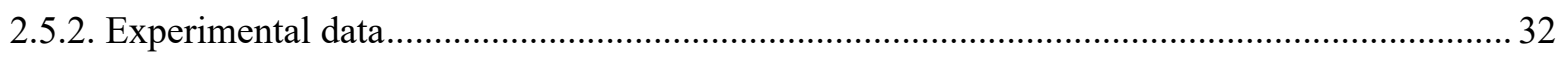

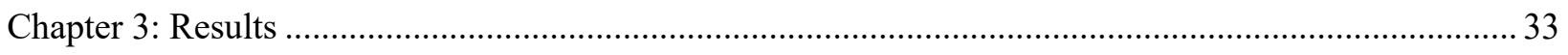

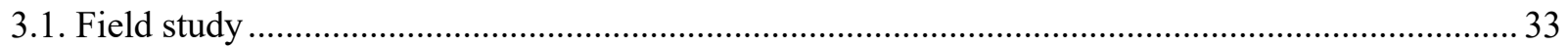

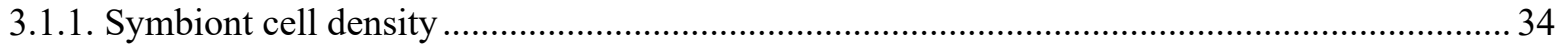

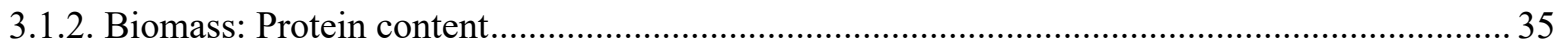

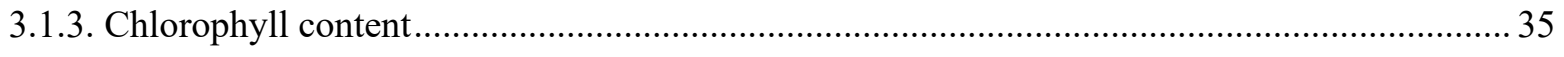

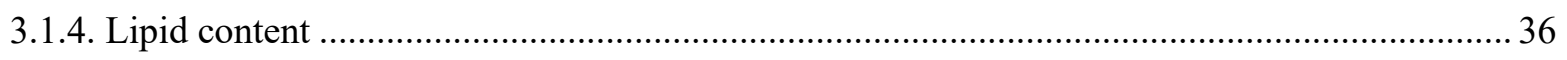

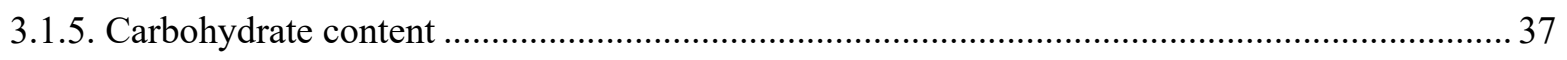

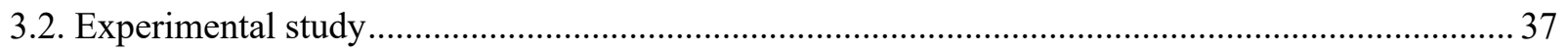

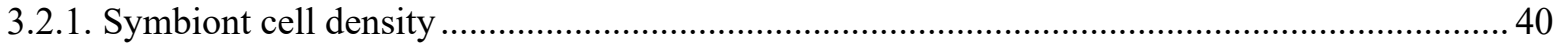

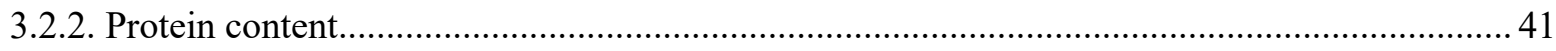

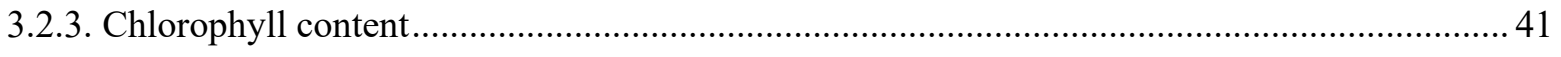

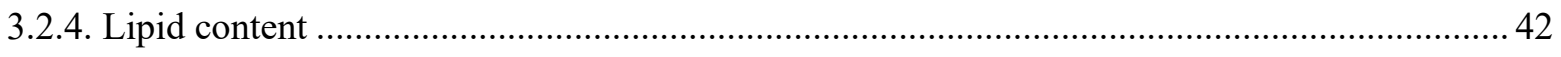




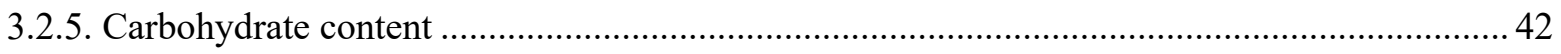

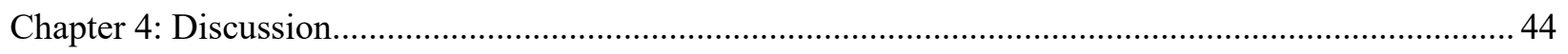

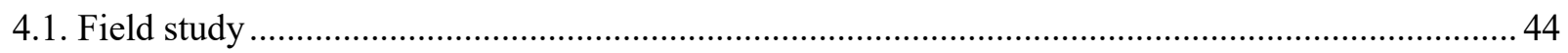

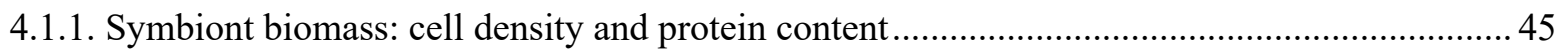

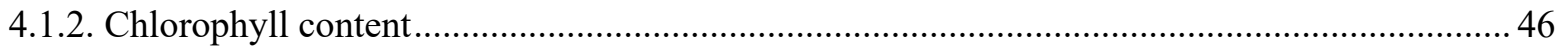

4.1.3. Symbiont and host storage products: lipid and carbohydrate content.................................. 48

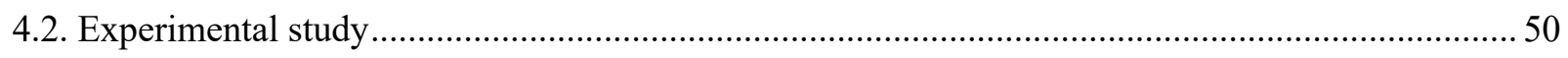

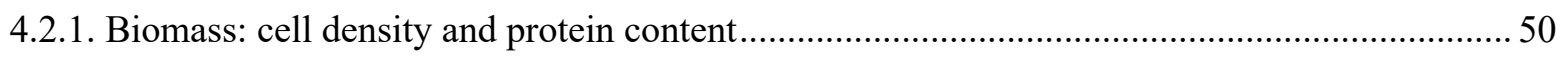

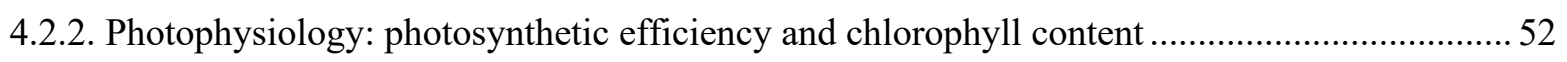

4.2.3. Symbiont and host storage products: lipid and carbohydrate content...................................5 54

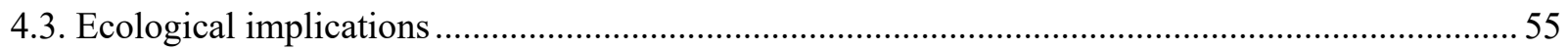

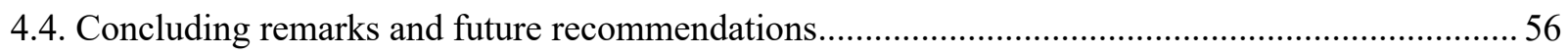

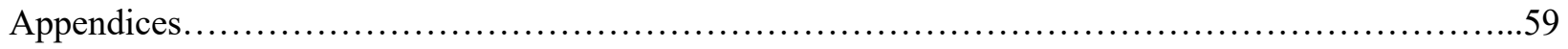

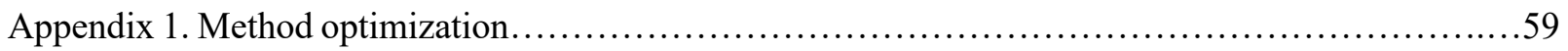

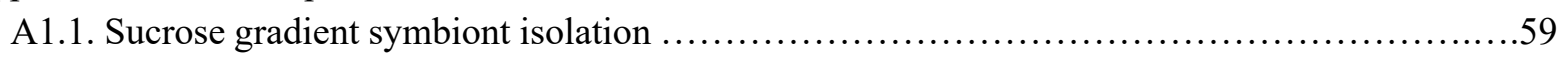

A1.2. Lipid assay optimization and standard development...............................60

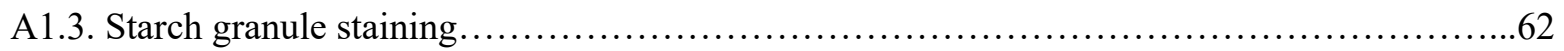

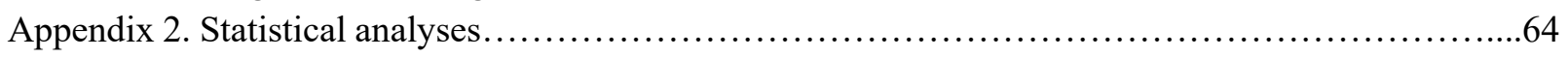

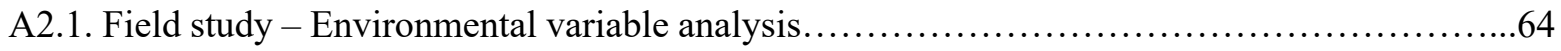

A2.2. Field study - Physiological response variable analysis................................65

A2.3. Experimental study - Physiological response variable analysis...........................66

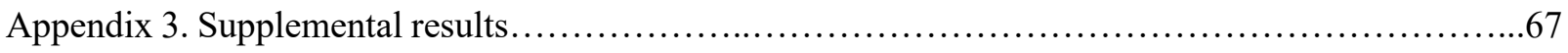

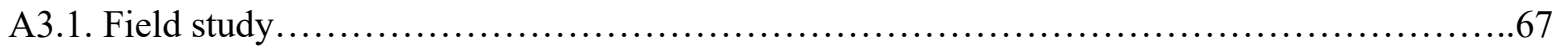

A3.1.1. Environmental conditions: temperature and irradiance............................67

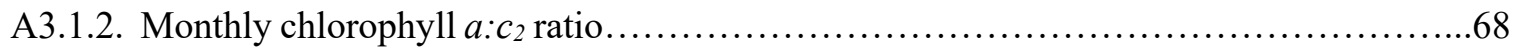

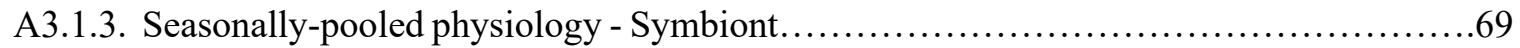

A3.1.4. Seasonally-pooled physiology - chlorophyll $a: c_{2}$ ratio............................. 70

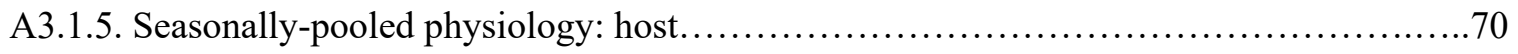

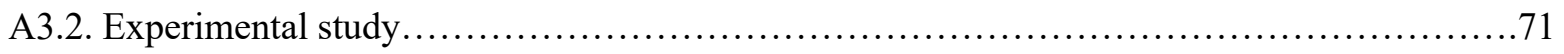

A3.2.1. Chlorophyll $a: c_{2}$ ratio................................................... 71

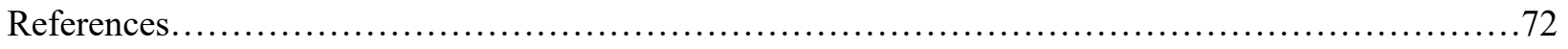




\section{List of Figures}

Figure 1.1: Anatomy of the cnidarian-dinoflagellate endosymbiosis .......................................

Figure 1.2: The cellular biology that enables the formation of vast reefs..................................... 12

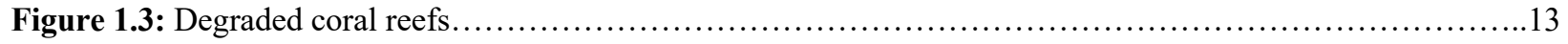

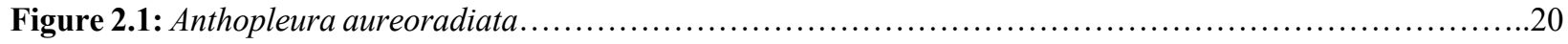

Figure 2.2: Symbiodiniaceae in-hospite and isolated from Anthopleura aureoradiata ..............................21

Figure 2.3: Project field site: Shelly Bay Lighthouse, Wellington New Zealand................................22

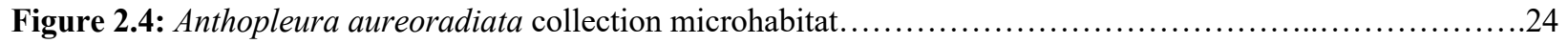

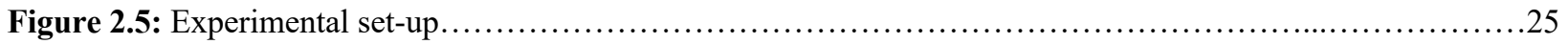

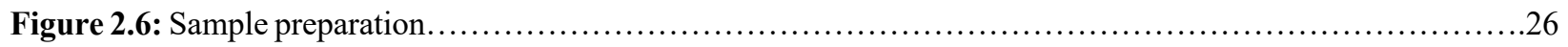

Figure 3.1: Monthly physiology of Symbiodiniaceae isolated from sea anemone Anthopleura aureoradiata.........33

Figure 3.2: Monthly physiological assessment of host for the sea anemone Anthopleura aureoradiata..............34

Figure 3.3: Photosynthetic efficiency of the intact Anthopleura aureoradiata-Symbiodiniaceae symbiosis under

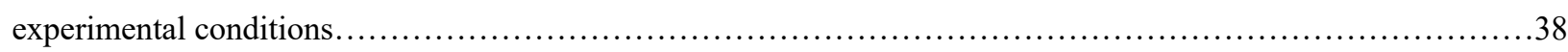

Figure 3.4: Physiology of Symbiodiniaceae isolated from the sea anemone Anthopleura aureoradiata maintained in

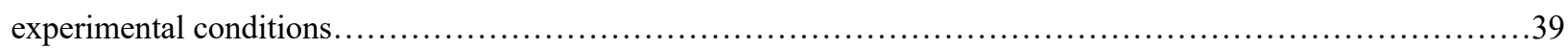

Figure 3.5: Physiology of host biomass for the sea anemone Anthopleura aureoradiata maintained in experimental

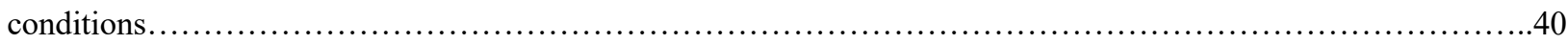

Figure A1.1: Comparison of symbiont isolation methods in the sea anemone Anthopleura aureoradiata..............59

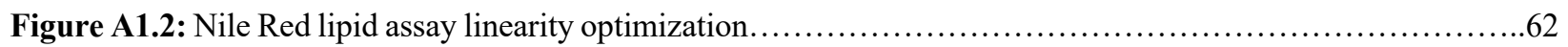

Figure A1.3: Attempts to identify starch bodies using Lugol's Iodine stain in the dinoflagellate Symbiodiniaceae...63

Figure A3.1.1: Average seasonal and monthly (inset) weather conditions for Wellington Harbour, New Zealand....68

Figure A3.1.2: Monthly chlorophyll a:c2 ratio of Symbiodiniaceae cells isolated from the sea anemone Anthopleura aureoradiata collected from Wellington Harbour, NZ ..........................................................

Figure A3.1.3: Seasonal physiology of symbionts isolated from Anthopleura aureoradiata .........................69

Figure A3.1.4: Seasonal chlorophyll $a: c_{2}$ ratio for symbionts isolated from Anthopleura aureoradiata ................70

Figure A3.1.5: Seasonal physiology of Anthopleura aureoradiata host material......................................70

Figure A3.2.1: Chlorophyll $a: c_{2}$ ratio of Symbiodiniaceae isolated from the sea anemone Anthopleura aureoradiata maintained in experimental conditions

\section{List of Tables}

Table A2.1: Statistical analyses of environmental variables for Wellington Harbour, New Zealand. .64

Table A2.2: Statistical analyses of physiological response variables for the sea anemone Anthopleura aureoradiata and its Symbiodiniaceae collected from the field.

Table A2.3: Statistical analyses of physiological response variables for the sea anemone Anthopleura aureoradiata and its Symbiodiniaceae maintained under experimental conditions........................................66

Table A3.1: Recorded observations of field site environmental parameters...................................67 


\section{Chapter 1: Introduction}

\subsection{Symbiosis}

\subsubsection{Overview}

"In the long history of humankind (and animal kind, too) those who learned to collaborate and improvise most effectively have prevailed" (Charles Darwin, according to popular belief). Collaboration is widespread throughout the various kingdoms of life, and when two or more organisms engage in a well-developed, long-lasting, and interactive association, they are referred to as being in "symbiosis" (Paracer, 2000). These symbiotic associations exist along a gradient of interactions that can be either obligatory or facultative, intracellular or extracellular, and range from parasitic to mutualistic. While symbiotic relationships can be found throughout the world, the oceans in particular are teeming with symbioses that take on remarkably different forms. Wellknown examples include anemones and their resident clownfish, sharks and remora, and eels and cleaner wrasses, while equally as remarkable are more unfamiliar symbioses such as those between gobies and pistol shrimp, bobtail squids and bioluminescent bacteria, and deep-sea hydrothermal vent tube worms and chemosynthetic bacteria. In fact, even humans are engaged in an obligatory mutualistic symbiosis with our gut microbiota, which receive shelter and constant nutrients from us in exchange for their ability to help digest our food (Yadav et al., 2018).

\subsubsection{Ecological importance}

Symbioses can be credited with supporting much of the vast array of life that exists on Earth, and they can be found throughout the world, even in some of the most extreme environments, with the partnership often enabling each participant to expand both its ecological range and fundamental niche. This is evident among many plant species which, with the aid of symbiotic mycorrhizal fungi, can occupy areas with more inconsistent moisture and nutrient levels than plants lacking mycorrhizal symbionts (Gerz et al., 2018). While the intimate exchange of nutrients and/or services between mutualistic partners can enhance the fitness of the individual organisms, symbiosis can

also promote greater contributions to overall ecosystem productivity, which becomes especially prevalent in low-nutrient environments. A prime example of this occurs in the light-deprived deep sea hydrothermal vents, where many residents form symbiotic relationships with chemosynthetic proteo-bacteria that fix inorganic carbon for their hosts, generating biomass, which acts as a source of organic carbon for exclusively heterotrophic consumers (Beinart et al., 2012; Dick, 2019). Indeed, symbiosis is responsible for the formation of what are arguably the world's most vibrant 
ecosystems (located in some of the world's most nutrient-poor waters): coral reefs. Cnidarians, such as corals and sea anemones, form tight-knit endosymbiotic (i.e. intracellular) relationships with photosynthetic dinoflagellates, a partnership which allows the holobiont (i.e. host and symbiont as one symbiotic unit)(Pietra, 1995) to grow and thrive in nutrient-depleted tropical seas. As the widely-recognized "backbone" of coral reef ecosystems, cnidarian-dinoflagellate symbioses have significant global importance, especially in coastal communities, where they generate income from tourism and resource industries, support diverse populations of marine species for fisheries, and act as a physical barrier to protect shorelines from hazardous waves and currents (Moberg and Folke, 1999; Pascal et al., 2016).

\subsection{Cnidarian-dinoflagellate symbiosis}

\subsubsection{Overview}

The symbiosis between cnidarians and dinoflagellate symbionts is thought to have originated in the Triassic period (Frankowiak et al., 2016); however, these early symbiotic species are thought to have disappeared during the End-Triassic mass extinction, and then re-emerged during the Jurassic period (LaJeunesse et al., 2018). These dinoflagellates, which have an infamously complicated phylogenetic lineage that has been re-evaluated many times since their discovery (Blank and Trench, 1985; LaJeunesse, 2001), are now formally assigned to the taxonomic family Symbiodiniaceae (LaJeunesse et al., 2018). This family includes seven genera (formerly clades), based on genetic differences - particularly in the internal transcribed spacer 2 (ITS2) region of rDNA - as well as morphological differences (Hunter et al., 2007; LaJeunesse et al., 2018). Symbiodiniaceae are classically described as round, unicellular organisms, ranging from 5-15 $\mu \mathrm{m}$ in diameter and varying from green to golden-brown in color. They can exist either as free-living individuals or as endosymbionts within a host organism. Anthozoan cnidarian hosts (i.e., corals and sea anemones), are coelenterates whose bodies are comprised of three layers: the outer epidermis, connective mesoglea, and inner gastrodermis. Symbionts typically inhabit cells within the host's gastrodermis, which lines the gastrovascular cavity, with typically 1-2 symbiont cells inhabiting a single host cell (Muscatine et al., 1998; Davy et al., 2012) (Figure 1.1). 


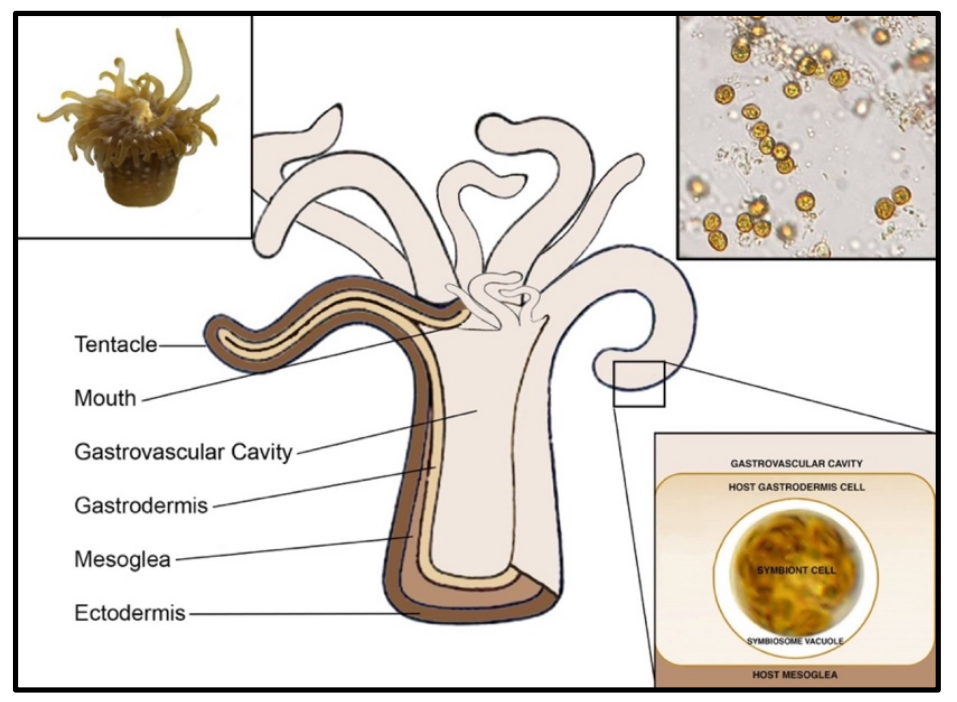

Figure 1.1: Anatomy of the cnidarian-dinoflagellate endosymbiosis. (A) Diagrammatic representation of holobiont anatomy, (B) dissection microscope image of a cnidarian (Anthopleura aureoradiata), (C) light microscope image of isolated Symbiodiniaceae (20x magnification), and (D) diagrammatic representation of symbiont cell within host gastrodermis cell.

\subsubsection{Symbiont acquisition and regulation}

A cnidarian host can acquire its symbionts in two ways, either horizontally (i.e. from the environment) or vertically (i.e. from the parent), although the former is more common (Davy and Turner, 2003). Horizontal transmission occurs when symbionts are taken in from the ambient seawater through the host's oral cavity and then phagocytized into host cells lining the gastrovascular cavity. Vertical transmission, on the other hand, occurs during offspring development as the symbionts are inherited from the maternal host cells (Davy et al., 2012). Regardless of transmission method, once the symbionts are within their host, each is housed by a "symbiosome membrane complex", a combination of symbiont cell membranes surrounded by an outer host-derived vacuolar membrane (Wakefield et al., 2000; Davy et al., 2012). Naturally, there are space limitations to consider when one organism is living within the cells of another organism. When symbiosis is functioning properly, symbiont cell growth and division are closely regulated and restricted by the host to prevent the symbiont population from either overgrowing or becoming too sparse (Dimond and Carrington, 2008; Davy et al., 2012). Mechanisms by which a host may regulate its symbiont population include nutrient restriction (Falkowski et al., 1993), cell cycle control (Smith and Muscatine, 1999; Tivey et al., 2020), cell degradation and digestion (Titlyanov et al., 1996), and expulsion (Hoegh-Guldberg et al., 1987; Dimond and Carrington, 2008). While several of these processes have received significant attention, there are many underlying mechanisms that have yet to be elucidated. 


\subsubsection{Nutrient exchange}

The mutualism between cnidarian host and dinoflagellate symbiont is founded upon the reciprocal exchange of both organic and inorganic nutrients between partners, thereby sustaining the holobiont (Figure 1.2). Both partners contribute in a healthy symbiosis, with the host supplying carbon dioxide through respiration and both organic and inorganic nutrients through heterotrophy, and the symbionts supplying organic carbon through autotrophy, the combination of which results in a holobiont that can be considered 'mixotrophic'. Inorganic nutrients such as phosphate and nitrate, and dissolved organic nutrients such as amino acids, can be derived directly from the environment, while other organic nutrients are obtained via prey consumption by the host. These nutrients, along with symbiont-derived photosynthetic carbon products such as glucose, glycerol, amino acids, and lipids, are allocated by the host toward growth, reproduction, and/or storage; the host also translocates some nutrients, such as amino acids, back to its resident symbionts as part of a nitrogen recycling process (Trench, 1971; Falkowski et al., 1993; Wang and Douglas, 1999; Davy et al., 2012). All nutritional exchange occurs through the symbiosome membrane complex; symbionts then transform the nutrients through photosynthesis into other organic compounds, and similarly to their host, allocate these compounds towards growth and division, respiration, storage, or translocation back to the host (Muscatine and Hand, 1958; Davy et al., 2012). In particular, lipids and carbohydrates are translocated between host and symbionts and/or used extensively by cells for many processes, which make them important biological indicators of a well-functioning symbiosis.

Lipids | Numerous studies report that lipids are an important energy storage molecule in cnidarian-dinoflagellate symbioses (Fitt and Pardy, 1981; Kellogg and Patton, 1983; Rossi et al., 2006), and have been observed accumulated into large "lipid bodies" within cells (Rosset et al., 2017). In addition to the storage and provision of energy, lipids also play a role in membrane structure and cell signaling (Davy et al., 2012) and can be useful indicators of cell division, nitrogen assimilation, and carbon to nitrogen ratios (Hillyer et al., 2016). It has been suggested that lipids are stored when energy can be generated in excess during optimal conditions, and are subsequently depleted in times of nutrient limitation or suboptimal conditions (Hinrichs et al., 2013). Lipids are also heavily utilized during reproductive processes, and have been observed to be released during coral spawning (Rossi et al., 2006). 
Carbohydrates | Glucose, a renowned carbohydrate, has been speculated to be one of the most prominent translocates between cnidarian hosts and symbiotic dinoflagellates (Whitehead and Douglas, 2003; Burriesci et al., 2012), while starches, also commonlyutilized carbohydrates, act similarly to lipids as primary energy storage reserves (Wang et al., 2013) and are relied on heavily during times of nutrient limitation, especially in algae and plants (Fitt and Pardy, 1981).

The photosynthetic products provided by a thriving symbiont population can satisfy a substantial amount, up to almost $90 \%$, of a host's nutritional demands, and are especially essential in the oligotrophic (low in nutrients) waters inhabited by coral reefs (Muscatine et al., 1984; Berkelmans and van Oppen, 2006). Even in nutrient-rich waters, the reciprocal exchange of nutrients between host and symbionts is essential toward maintenance of a stable holobiont.
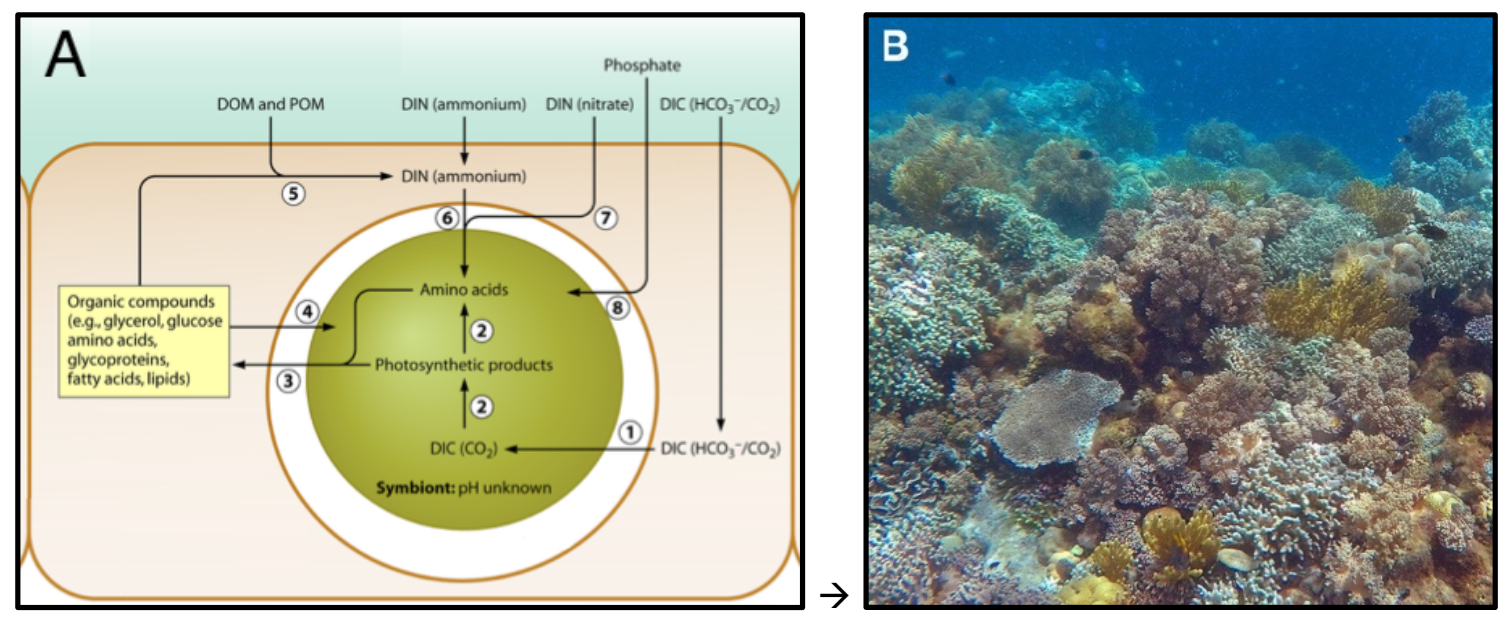

Figure 1.2: The cellular biology that enables the formation of vast reefs. (A) Schematic of the nutrient exchange between an intracellular algal symbiont and its cnidarian host (Davy et al., 2012). (B) Picture of a healthy coral reef in Wakatobi, Indonesia. Photograph by Lauren Fracasso.

\subsection{Environmental influences}

Cnidarian-dinoflagellate symbioses are especially vulnerable to environmental factors, such as irradiance, temperature, nutrient availability, salinity, and water quality. These variables can interact synergistically or antagonistically to induce physiological effects on resident organisms, though given this interconnectivity, their individual impacts can be difficult to discern. For example, turbidity, which is often considered an antagonistic condition for photosynthetic organisms, can benefit photosensitive organisms in areas that are exposed to excess heat and irradiance, as suggested in studies of 
tropical reef corals (Wagner et al., 2010; Cacciapaglia and Woesik, 2016). Given their typical distribution throughout the world's tropical and temperate shallow seas, cnidarian-dinoflagellate symbioses may be exposed to both aquatic and aerial conditions, increasing the range of extremities of environmental conditions they experience (Muller-Parker and Davy, 2001). Coral reefs are generally located in tropical waters that experience stable weather but are characteristically oligotrophic; temperate cnidarian-dinoflagellate symbioses, on the other hand, are exposed to variable and often cold conditions, with strong seasonal fluctuations in light, temperature, wind stress, and nutrient supply (Muller-Parker and Davy, 2001; Davy et al., 2006) (see section 1.4.1).

In addition to understanding the fundamental biology and biogeography of the cnidarian-dinoflagellate symbiosis, environmental factors and their variability are also an important consideration in the context of global change biology. Direct human activity (i.e. overfishing, pollution, invasive species introduction) as well as human-accelerated/induced environmental changes (i.e. ocean acidification and sea temperature increase) have had especially negative impacts on marine ecosystems, and particularly, on the cnidarian-dinoflagellate symbiosis. Widespread coral reef bleaching has become increasingly prevalent, with degraded reefs experiencing an entire ecosystem shift toward reduced biodiversity, sponge- and macroalgae-dominated structures, and trophic imbalance (Hughes et al., 2003) (Figure 1.3). While a multitude of environmental factors impact cnidarian-dinoflagellate symbioses in both temperate and tropical regions, constraints of this study required selecting the two most prominent and easily manipulated as focus drivers in respect to symbiosis stability: temperature and irradiance.
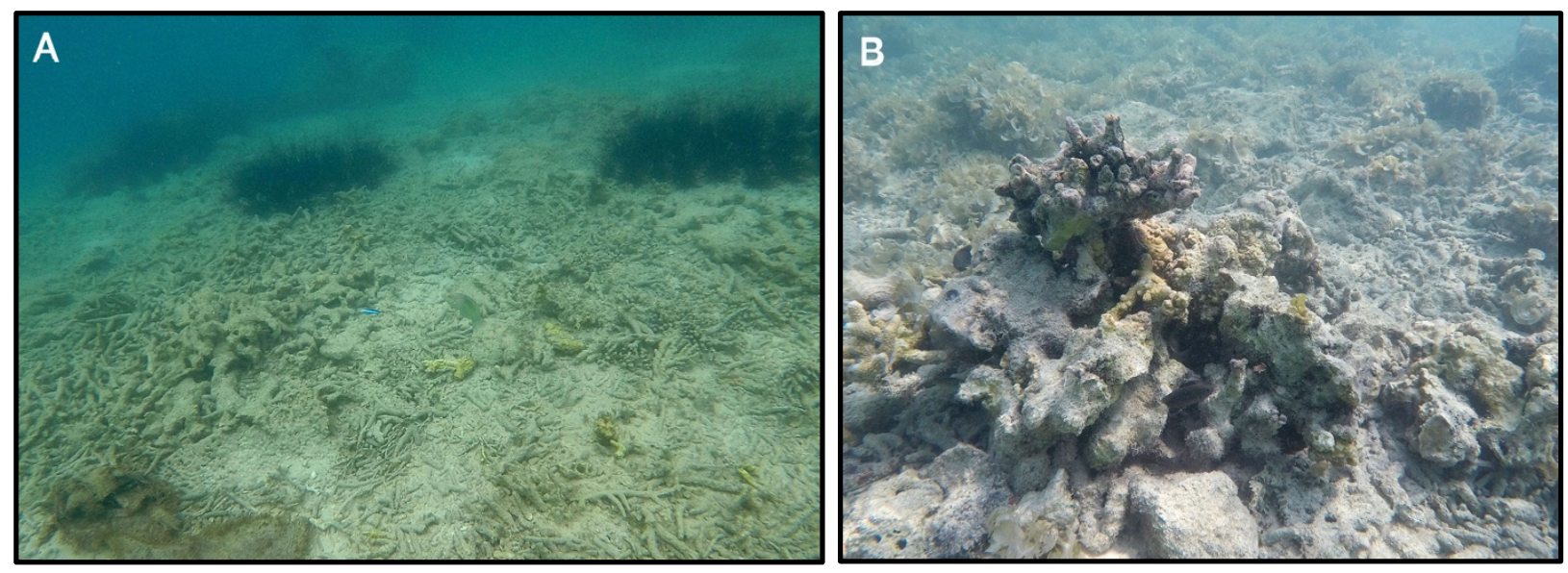

Figure 1.3: Degraded reefs. Highly degraded coral reefs in Sampela, Indonesia. Degradation indicators include rubble, (A) high population density of sea urchins, and (B) macroalgal cover. Photographs by Lauren Fracasso. 


\subsubsection{Temperature}

Cnidarian-dinoflagellate symbioses can inhabit a wide latitudinal distribution, and therefore may encounter a variety of temperature regimes. Symbioses that reside in tropical environments are often exposed to mild temperatures with minimal fluctuation throughout the year (aside from storms and environmental anomalies); however, temperate residents experience conditions that can differ within a day as much as they do between seasons, with both seasonal and diel temperature fluctuations increasing with latitude (Muller-Parker and Davy, 2001). For example, while the tropical reefs of Jamaica may experience mild annual fluctuations between $25^{\circ} \mathrm{C}$ and $31^{\circ} \mathrm{C}$, annual seawater temperatures in temperate regions experience a far greater range, fluctuating anywhere between a minimum of $9^{\circ} \mathrm{C}$ and a maximum of $23^{\circ} \mathrm{C}$ (Muller-Parker and Davy, 2001). While environmental stability is often preferred among many organisms, the consistently warm climates of the tropics can stress symbiotic cnidarians if temperatures increase even slightly above the usual thermal maximum, sometimes enough to cause the host to expel its symbionts, a process called "bleaching" (Weis, 2008), which can ultimately reduce a host's symbiont density to the point of elimination (Gates et al., 1992). The loss of symbionts occurs through a range of processes, including apoptosis ("programmed cell death"), expulsion, and detachment of host cells (reviewed in Weis, 2008). In fact, during the process of thermally-induced bleaching, viable host cells can detach, suggesting that increased temperature may impair host cell adhesion (Gates et al., 1992). It has been shown that temperature increases of just $1-2^{\circ} \mathrm{C}$ have the potential to induce bleaching among tropical cnidarian-dinoflagellate symbioses (Hoegh-Guldberg and Jones, 1999; Hughes et al., 2003).

Temperature can have a particularly severe effect on a symbiont's thylakoid membrane, which houses both photosystem I (PSI) and photosystem II (PSII), the cellular components capable of converting light energy via electron transport (Tchernov et al., 2004). Increased temperature can alter the structure of thylakoid membranes, as confirmed by Tchernov and colleagues (2004), who demonstrated that thermal sensitivity is correlated with lipid content of membranes, with higher concentrations of polyunsaturated fatty acids making them more permeable and fragile. High temperatures can also cause degradation of the D1 protein (which forms the reaction core of PSII) faster than its synthesis, the combination of which causes uncoupled electron transport, decreased energy transduction, and ultimately, reduced photosynthetic efficiency (Warner et al., 1999). Due to the evident effects of thermal stress on photosystem functioning, measurements of photosynthetic pigments are often used to assess holobiont condition (Apprill et al., 2007). In addition to degrading the aforementioned D1 protein, increased temperatures can instigate both the 
reduction of protein synthesis as well as the upregulation of stress-response proteins (Takahashi et al., 2008; Mayfield et al., 2016; McCauley et al., 2018).

Low temperatures can also have a deleterious effect on cnidarian-dinoflagellate symbioses. Studies on the effects of experimental cold shock have been performed on both tropical sea anemones (Exaiptasia pallida) and tropical reef corals (Pocillopora damicornis), demonstrating that experimental cold shock (with lower thermal limits variable between species) induces the expulsion of both symbionts and viable host cells (Steen and Muscatine, 1987; Muscatine et al., 1991; Gates et al., 1992). In addition, Gibbons (2009) reported that the symbionts of the temperate anemone Anthopleura aureoradiata contributed minimally, if at all, to carbon translocation within holobionts during the winter, suggesting that anemones may rely on other nutritional sources during times of low temperature. This finding is consistent with the knowledge that thermal stress often results in fewer nutrients being transformed through photosynthesis; therefore, symbionts are not able to translocate as much to their host, which must then rely on increased heterotrophy or draw upon stored reserves to meet its nutritional needs (Hillyer et al., 2016); similarly, the stressed symbionts need to mobilise their own storage products to survive thermal stress. If such stressresponse processes are insufficient, the holobiont could die within weeks (Berkelmans, 2002; Berkelmans et al., 2004).

\subsubsection{Irradiance}

Solar irradiance is an important environmental factor to consider, as it determines the amount of photic energy and carbon that is available to be transferred and transformed, respectively, during photosynthesis. Both the amount and intensity of irradiance received by photosynthetic endosymbionts depends on many factors, including depth, water turbidity, and sedimentation, as well as host-related aspects such as tissue density and body position (Pearse, 1974). For example, Anthopleura elegantissima has up to ten times more symbionts and chlorophyll in its tentacles than in its body column, and thus utilizes expansion and contraction of these tentacles to control how much light its symbionts are exposed to (Dykens and Shick, 1984). Additionally, while the amount of solar irradiance may not differ markedly between temperate and tropical surface waters on a

global scale, both daily and seasonal fluctuations are experienced far more acutely in temperate environments, and temperate cnidarian-dinoflagellate symbioses have been shown to exhibit about half of the photosynthetic potential of their tropical counterparts (Muller-Parker and Davy, 2001). Light attenuation is especially high in temperate regions during the winter, as waters are more frequently disturbed by storm activity and coastal nutrient run-off; solar irradiance is of course also 
lowest during the winter. Comparing irradiance at depth, however, reveals much greater differences between temperate and tropical regions, as less light attenuation occurs in the nutrient-poor water column of the tropics (Richardson et al., 1983; Muller-Parker and Davy, 2001). Excess irradiance can be a driver of photobleaching, which if not reduced will often result in the complete bleaching of a host's resident symbiont population (Iglesias-Prieto et al., 1992). Alternatively, insufficient irradiance can also negatively impact cnidarian-dinoflagellate symbiosis, with studies of photoacclimatory responses to dark stress suggesting that decreased photosynthetic output under low

light causes changes in cellular metabolism, growth rate, and antioxidant production (Falkowski et al., 1990; DeSalvo et al., 2012).

\subsection{Cnidarian-dinoflagellate symbiosis stability}

Coral reef cover throughout the world's oceans has been declining since the 1970's (Berkelmans et al., 2004; De'ath et al., 2012; Hughes et al., 2017), largely due to both global climate change and local environmental stressors. As discussed above, elevated seawater temperatures can trigger bleaching in tropical cnidarians; for example, the tropical sea anemone Exaiptasia pallida expels its symbionts upon exposure to minor temperature increases of just a few degrees above its thermal optimum of about $25^{\circ} \mathrm{C}$ (Muller-Parker and Davy, 2001). However, temperate symbiotic cnidarians (see Section 1.4.1) tend to be far more robust; for example, the sea anemone A. elegantissima can tolerate annual temperature fluctuations within a range of up to $15^{\circ} \mathrm{C}$ without experiencing symbiosis breakdown (Dimond et al., 2011). These temperate associations are similarly robust in the face of low light, with symbiotic anemones such as the New Zealand native $A$. aureoradiata spending much of its time under mud (Morar et al., 2011).

The attributes and mechanisms that underlie environmental tolerance are not fully understood, but likely relate to both the symbiont and host, as well as the potential interactions between the partners (Berkelmans and van Oppen, 2006; Fitt et al., 2009; Grégoire et al., 2017; Oakley and Davy, 2018). Furthermore, interactions with other microbial symbionts both within and on the host's tissues could play a role (Ainsworth et al., 2017; Rosado et al., 2019). Particular attention has focused on the potential for both symbiont and host to manage the reactive oxygen species (ROS) that are generated as a result of photosynthetic dysfunction, with more thermally-resistant symbionts, for example, being better equipped to deal with oxidative stress (Iglesias-Prieto and Trench, 1997; Lesser and Farrell, 2004; Oakley and Davy, 2018; Wietheger et al., 2018). In addition, other aspects of cellular physiology, such as heat shock proteins and thylakoid membrane composition of the symbionts, may also confer stress tolerance (Fitt et al., 2001; Tchernov et al., 2004). A considerable amount of attention has been paid to symbiont diversity in particular, with different symbiont species or genotypes possessing different physiologies and environmental 
tolerances (Robison and Warner, 2006; LaJeunesse et al., 2010; Díaz-Almeyda et al., 2011). For example, symbionts within the genus Durusdinium (LaJeunesse et al., 2018 novel genus, formerly referred to as "clade D") have been suggested to exhibit greater thermal tolerance than other symbionts, as well as conveying increased thermal tolerance to their host, expanding their thermal limit by up to $2^{\circ} \mathrm{C}$ (Fabricius et al., 2004; Rob, 2004); on the other hand, Cladocopium spp. (LaJeunesse et al., 2018 novel genus, formerly referred to as "clade C") is made up of both tolerant and sensitive members (Tchernov et al., 2004; Fisher et al., 2012; LaJeunesse et al., 2018). These phylogenetic inconsistencies in thermal tolerance suggest that many other factors are at play than genetics alone when it comes to the stability of cnidariandinoflagellate symbiosis, including but not limited to "respiratory physiology, cellular biochemistry, pigment concentrations, antioxidative compounds, heat shock proteins, and cell cycle regulation" (Baghdasarian et al., 2017). Less directly, the aforementioned ability to switch from a predominantly autotrophic nutritional state to a more heterotrophic one by the holobiont (Coma et al., 1999; Ferrier-Pagés et al., 2011), or the ability to utilize internal stores from both host and symbionts (Hughes et al., 2010; Hillyer et al., 2016; Grottoli et al., 2018), can help combat stress-induced nutritional deficits and aid in holobiont recovery.

\subsubsection{Temperate cnidarian-dinoflagellate symbiosis}

While we are much more familiar with tropical coral reefs, cnidarian-dinoflagellate symbioses are found in temperate regions too, where they can be conspicuous and important members of the benthic community (Davy et al., 1997; Muller-Parker and Davy, 2001). Examples include the soft coral Capnella gaboensis, the most abundant octocoral in Southeastern Australia (Farrant et al., 1987), the sea anemones A. elegantissima (USA) and Anemonia viridis (Europe), both locally abundant but harboring either heterogeneous or homogeneous symbiont populations, respectively, (Jacques et al., 1983; Verde and McCloskey, 2001, 2002, 2007; Revel et al., 2016); and Astrangia danae, abundant in Narragansett Bay (USA) and surviving in both symbiotic and non-symbiotic conditions (Jacques et al., 1983). As previously mentioned, temperate waters can undergo significant annual temperature fluctuations, which is relatively extreme compared with the milder fluctuations in the tropics. Temperate regions also experience greater irradiance fluctuations than tropical regions, as demonstrated by a comparison made by Muller-Parker and Davy (2001), who reported that their temperate field site in the Pacific Northwest experiences $80 \%$ more daily integrated irradiance flux than their tropical field site in the Caribbean Sea. Due to the inconsistent and seemingly undesirable environmental conditions, one would expect temperate symbiotic anemones to inhabit only shallow waters; however, this is not the case. For example, in Lough Hyne, Eire, symbiotic anemones reside at depths up to $21 \mathrm{~m}$, receiving only a small fraction of the 
light encountered at the surface (Davy et al., 1997). In fact, it has been suggested that temperate symbiotic cnidarians appear to be less dependent on light than their tropical counterparts for survival (Muller-Parker and Davy, 2001). Perhaps surprisingly, considering the reduced ambient irradiance compared to tropical regions, temperate symbiotic anemones tend to have a lower symbiont density than tropical counterparts, yet their symbionts persist at relatively high densities under low light conditions and may even increase during winter conditions (Muller-Parker and Davy, 2001). Moreover, despite their comparatively lower densities, temperate symbiont populations tend to maintain more stable numbers than tropical symbioses regardless of conditions experienced (Farrant et al., 1987; Muller-Parker and Davy, 2001; Verde and McCloskey, 2001, 2002, 2007), highlighting their remarkable stability relative to their tropical counterparts.

\section{Why are temperate cnidarian-dinoflagellate symbioses so stable?}

The previous sections highlight the evident disparity between the stability of temperate and tropical cnidarian-dinoflagellate symbioses; however, the reasons for this difference have yet to be fully elucidated. It has been suggested that the seasons experienced in temperate regions may play a role in acclimating the resident organisms to environmental condition changes (Fitt et al., 2000; MullerParker and Davy, 2001; Davy et al., 2006; Dimond et al., 2011; Hinrichs et al., 2013; McCauley et al., 2018), but there are many other factors that warrant exploration. Other mechanisms underlying stability differences likely relate to the physiology of both host and symbionts (Davy, 1994; Stat et al., 2008; Suggett et al., 2017; Sproles et al., 2018), with research suggesting that temperate symbioses utilize their stored resources differently than tropical symbioses when exposed to suboptimal conditions. To date, far more studies have been performed on tropical cnidariandinoflagellate symbioses, since they are currently under the greatest pressure from global climate changes; however, it is imperative that temperate symbioses be examined with equal scrutiny in order to develop more accurate generalizations about trends in holobiont stability.

\subsection{Aims and objectives}

This study aims to examine the stability of a temperate cnidarian-dinoflagellate symbiosis across seasons and in response to both temperature and irradiance changes, in order to determine the extent to which storage product accumulation/utilization might contribute to this stability. The symbiotic New Zealandnative sea anemone Anthopleura aureoradiata was used as a model organism for temperate cnidariandinoflagellate symbioses, with cell density, photo-physiology, protein content, and storage product content (specifically: lipids and carbohydrates) assessed as indicators of holobiont stability. 


\section{Objective 1: To establish the effects of seasonality on symbiosis stability and storage product} utilization in the temperate sea anemone $A$. aureoradiata and its Symbiodiniaceae population. To achieve this, anemones were sampled from the field at monthly intervals for one year, and a range of physiological response variables, including symbiont cell density, protein, and chlorophyll content, as well as host and symbiont lipid, and carbohydrate contents were determined. These physiological parameters were assessed with respect to seasonal fluctuations in temperature and irradiance.

Hypothesis: It was hypothesized that the symbiosis would remain stable throughout the year, irrespective of seasonal variations in temperature and irradiance, but that storage products would fluctuate in content during times of resource (i.e. light, nutrients) limitation or environmental extremes (i.e. summer highs and winter lows).

\footnotetext{
Objective 2: To experimentally determine the interactive effects of temperature and irradiance on symbiosis stability and storage product utilization in the temperate sea anemone $A$. aureoradiata and its Symbiodiniaceae population. To achieve this, anemones were experimentally exposed to low, moderate, and high temperatures (based on seasonal field data) and both low and high irradiance for a period of sixteen weeks, with the same physiological response variables measured as in Objective 1.

Hypothesis: It was hypothesized that the temperature and irradiance treatments would not influence symbiosis stability, but that storage products would be accumulated differently under thermal extremes or low irradiance to balance the reduced photosynthetic productivity of the symbionts.
}

\subsection{Thesis statement}

This thesis attempts to address knowledge gaps regarding the stability and tolerance of cnidariandinoflagellate symbioses by examining the relationship between $A$. aureoradiata and its symbionts, taking an eco-physiological approach toward studying cellular responses to fluctuations in temperature and irradiance. The field component of this thesis aims to examine the condition of symbioses exposed to nonmanipulated environmental conditions, while the experimental component aims to investigate whether temperature and irradiance specifically drive any of the patterns observed in the field. I expect that exposure to regular seasonal fluctuations in both temperature and irradiance has helped temperate cnidariandinoflagellate symbioses become more tolerant to environmental changes; additionally, I predict that the content of cellular storage products in host and symbiont fractions will change in relation to one another as each party works to sustain the holobiont under variable conditions. 


\section{Chapter 2: Methods}

\subsection{Study organism: Anthopleura aureoradiata}

More commonly referred to as the 'small brown sea anemone' or the 'mudflat anemone', Anthopleura aureoradiata (Figure 2.1) is a temperate intertidal cnidarian that, like its tropical cousins, harbours photosynthetic symbionts (Carlgren, 1950). Populations of A. aureoradiata are easily accessible, recognizable, and maintainable, making this species an exemplary model organism for studies of temperate cnidarian-dinoflagellate symbiosis. Although A. aureoradiata is native to the waters of southern Australia and New Zealand, fellow members of the genus Anthopleura can be found worldwide, with the exception of polar regions (Spano and Häussermann, 2017). A. aureoradiata often resides nestled within rock crevices, burrowed into fine sediment, or attached to the shells of cockles along intertidal coastlines (Mouritsen and Poulin, 2003). This anemone is easily identifiable due to the series of milky-white bumps that radiate down its golden-brown body column (Spano and Häussermann, 2017)(Figure 2.1B). In contrast to many other sea anemones, A. aureoradiata does not appear to utilize fission or budding for reproduction; rather, it has been classified as gonochoristic and reproduces via brooding and expulsion of offspring through the oral cavity (Larson, 2017; Spano and Häussermann, 2017). In addition to its role in contributing to ecosystem primary productivity, A. aureoradiata plays an important role in marine parasite transmission, as it has been shown to ingest parasitic trematode larvae, thereby reducing transmission between snail and crab hosts by up to four times (Hopper et al., 2008). This anemone also impedes larval infection of the bivalves they often reside upon by eating the approaching larvae (Mouritsen and Poulin, 2003).
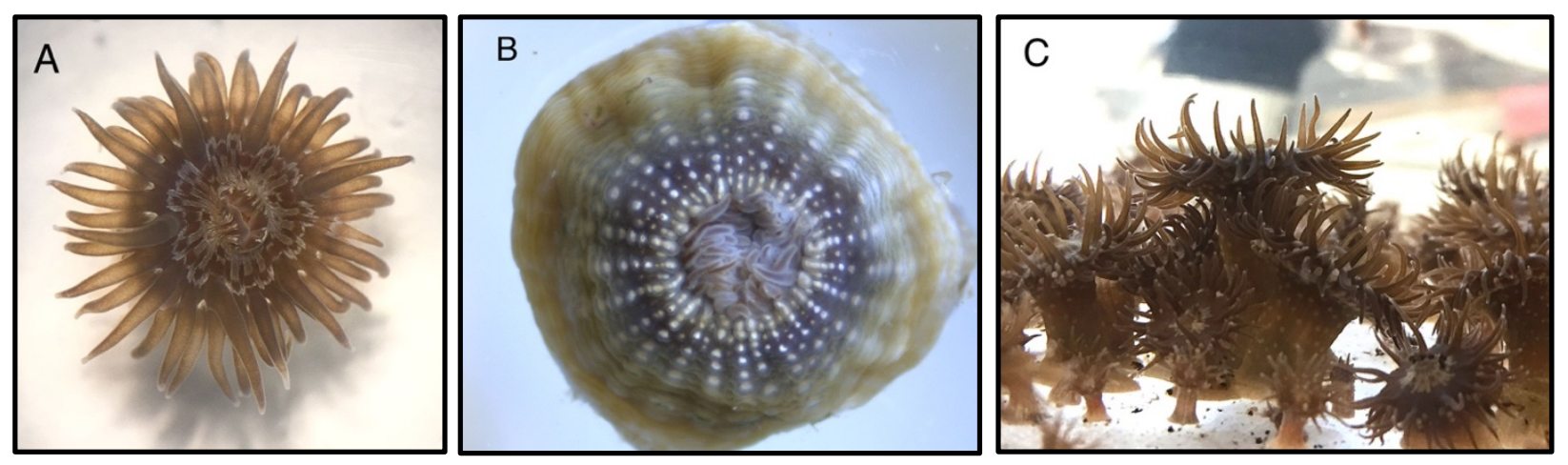

Figure 2.1: Anthopleura aureoradiata. Dissection microscope images of A. aureoradiata, with (A) expanded, and (B) retracted tentacles, magnification 4x; (C) side view of multiple individuals clustered together, as this species commonly aggregates. All photographs by Lauren Fracasso. 
As previously mentioned, A. aureoradiata forms an endosymbiotic relationship (Figure 2.2A-B) with photosynthetic dinoflagellates from the family Symbiodiniaceae (LaJeunesse et al., 2018). The symbionts housed by A. aureoradiata in New Zealand (Figure 2.2C-D) belong to the novel genus Philozoon (formerly referred to as "clade A"); in fact, it was recently suggested that $A$. aureoradiata simultaneously harbors two Philozoon species endemic to central New Zealand, distinguished from one another as well as other phylogenetic groups based on differences in their nucleotide sequences (LaJeunesse et al., in submission).
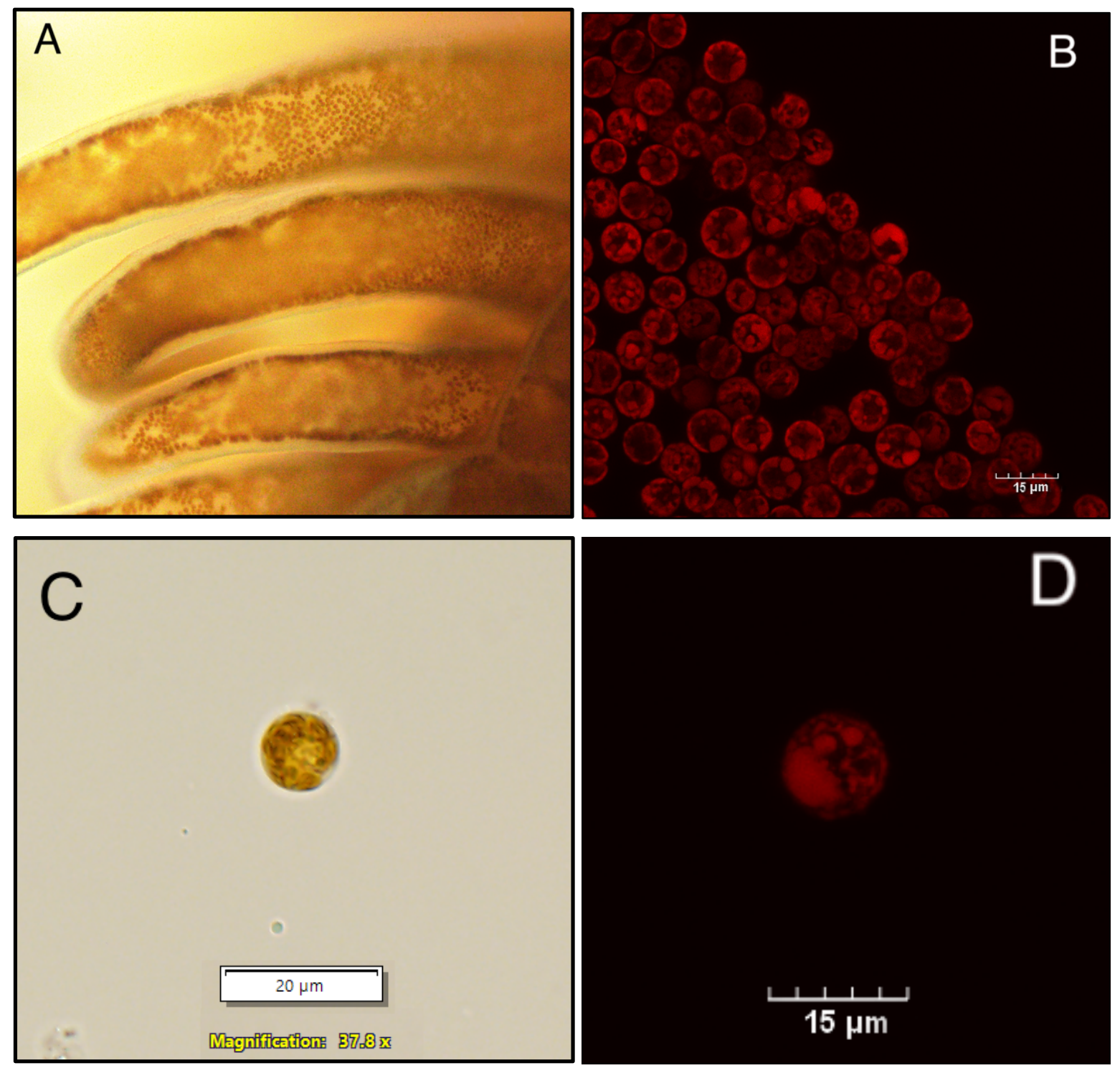

Figure 2.2: Symbiodiniaceae in-hospite and isolated from Anthopleura aureoradiata. (A) Brightfield image of symbionts within anemone tentacles; (B) confocal microscope image of a tentacle squash containing symbiont cells; (C) brightfield image of a symbiont cell isolated from host, magnification 40x; (D) confocal microscope image of a symbiont cell, magnification 100x. Red color in confocal images indicates chlorophyll autofluorescence. Photographs by Lauren Fracasso. 


\subsection{Field study}

\subsubsection{Study Site}

Anemones were collected from the mid-littoral zone of the rocky coastline bordering Shelly Bay Lighthouse, Wellington, New Zealand (GPS Coordinates: 4116'40”S 17449'48'E (-41.28, 174.83 (WGS84)))(Figure 2.3). While this area is exposed to regular tidal fluxes, it is relatively sheltered compared to other temperate coastal habitats, like the nearby Cook Strait. The microhabitats of individual anemones vary quite a bit at this site, and anemones could be found clustered on exposed rock surfaces, at the bottoms of shallow rock pools, nestled within deep rock crevices, or buried in the mud. It is important to note that the variety of microhabitats at this study site may introduce further variability in environmental factors that was not accounted for.

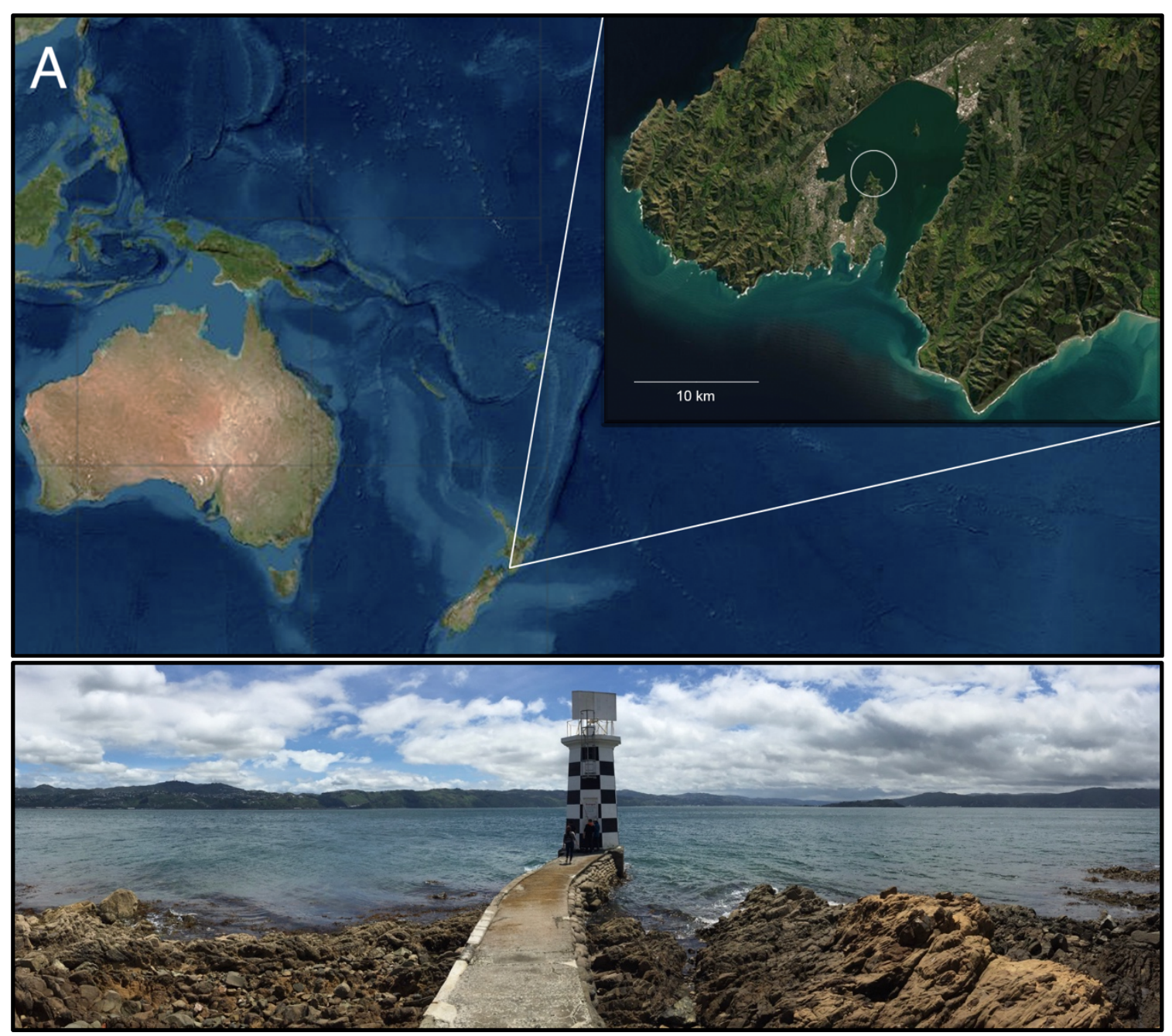

Figure 2.3: Project field site: Shelly Bay Lighthouse, Wellington New Zealand. (A) Map of global location obtained from Google Maps; (B) photo of the field site. Photograph by Lauren Fracasso. 


\subsubsection{Environmental parameters}

Sampling occurred monthly for one full year (November 2018 - November 2019). Collection date, time, tide level, air temperature, water temperature, and general weather conditions were recorded upon arrival to the site for each time point (Appendix 3, Table A3.1). As environmental parameters such as light and temperature are highly variable on a day-to-day basis, the measurements taken during each monthly collection are merely snapshots of a vast range of environmental conditions experienced by the study organism. Therefore, more detailed and ongoing additional recordings of environmental data were obtained from online databases (NIWA, 1981-2010; NOAA, 2020) and used to describe the trends in the conditions experienced by the local population during the sampling period. In addition to the above environmental parameters, seawater nutrient concentrations were measured during each collection. Nutrients analyzed were nitrates + nitrites $\left(\mathrm{NO}_{3}{ }^{-}+\mathrm{NO}_{2}{ }^{-}\right)$, ammonium $\left(\mathrm{NH}_{4}{ }^{+}\right)$, and dissolved reactive phosphorus (DRP), which were used as proxies for productivity and hence food availability. For these analyses, $150 \mathrm{~mL}$ of non-stagnant surface water closest to the anemones was collected into a sterile plastic container, $0.22 \mu \mathrm{m}$ syringefiltered upon return to the lab, and stored at $-20^{\circ} \mathrm{C}$ prior to being analyzed at a water quality analysis lab (NIWA, Hamilton). Determination of nutrient levels was performed using a SEAL AA3 nutrient auto-analyzer, which performed simultaneous analysis of nitrates and nitrites, ammonium, and dissolved reactive phosphorus. *It is important to note that due to inconsistencies in both filtration and preservation time, as well as manual error in analysis request forms, the nutrient measurements were not able to be compared with confidence and are therefore not presented.

\subsubsection{Specimen collection and preservation}

Each month, anemones $(n=7)$ were collected, with the exact date and time determined by when the lowest low tide coincided with the middle of the diel light cycle, thereby exposing anemones to air and making them easier to collect. Most anemone populations in this area reside within crevices or firmly attached to substrates (Figure 2.4) so individuals were removed using a blunt spatula. One or two anemones were collected every five to ten meters along the shoreline to increase the chances of maintaining genetic diversity among individuals and to avoid decimating local populations. Upon collection, anemones were deposited into a 1-L glass Schott bottle filled with fresh sea water to minimize additional environmental stress during transportation back to the lab (approximately a 20 -minute drive). Upon arrival at the lab, each anemone was rinsed of debris using $0.22-\mu \mathrm{m}$ filtered seawater (FSW), placed individually into a 2-mL Eppendorf tube with $500 \mu \mathrm{L}$ of $0.22-\mu \mathrm{m}$ FSW, flash frozen in liquid nitrogen $\left(-190^{\circ} \mathrm{C}\right)$, and stored at $-80^{\circ} \mathrm{C}$. 


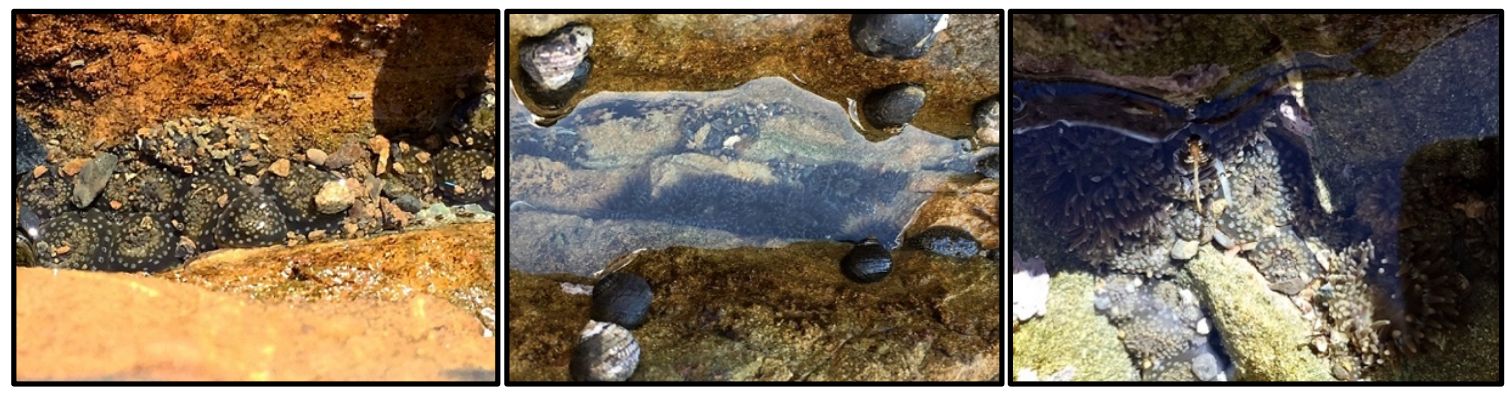

Figure 2.4: Anthopleura aureoradiata collection microhabitat. Anemones were collected from exposed crevices between rocks along the mid-littoral coast of Wellington Harbour, New Zealand.

\subsection{Experimental study}

\subsubsection{Experimental design}

A stock of several hundred A. aureoradiata was obtained in August 2018 and maintained for 12 months in $0.22-\mu \mathrm{m} \mathrm{FSW}$ at a temperature of $19 \pm 1{ }^{\circ} \mathrm{C}$ and an irradiance of $100 \pm 5 \mu \mathrm{mol}$ photons $\mathrm{m}^{-2} \mathrm{~s}^{-1}$ on a 12-hour light/dark cycle prior to experimental use. Anemones of similar size (pedal disk diameter $=2.5 \pm 0.5 \mathrm{~mm})$ were then distributed among plastic jars $(\mathrm{n}=20$ individuals per $\mathrm{jar})$ that were placed into one of six experimental treatments $(n=6$ jars per treatment) for a total of four months (Figure 2.5). The six experimental treatments were made up of three different temperature variants: $21 \pm 1^{\circ} \mathrm{C}$ (high "summer" temperature), $14.5 \pm 1^{\circ} \mathrm{C}$ (moderate "spring/autumn" temperature), and $9 \pm 1{ }^{\circ} \mathrm{C}$ (low "winter" temperature); each of which was divided into two light variants: $145 \pm 15$ $\mu \mathrm{mol}$ photons $\mathrm{m}^{-2} \mathrm{~s}^{-1}$ (high irradiance), and $70 \pm 10 \mu \mathrm{mol}$ photons $\mathrm{m}^{-2} \mathrm{~s}^{-1}$ (low irradiance), which were set to a 12-hour diel cycle. The temperatures used were selected based on reports from online environmental databases (NIWA, 1981-2010; NOAA, 2020) for the Wellington region from 1981 to present day, and irradiance variants were based upon the photosynthetic saturation curve of Symbiodiniaceae in A. aureoradiata reported by Cornwall (2017). To control the temperature, the jars containing anemones were placed into water baths regulated by circulating water heaters (HAAKE C10), with the addition of an immersion cooler (HAAKE EK20) in the low temperature treatments. The desired irradiance was obtained using lights (four 54W T5 bulbs) suspended from the ceiling, and a neutral density filter was applied over the low-irradiance treatments. Treatment conditions were monitored biweekly; temperature was measured in each water bath using a handheld thermometer, and irradiance was measured using a light meter (LI-COR LI-250A). Each jar of anemones was fed Artemia sp. nauplii twice per week, and the water in each jar was changed once per week. The jars within each experimental treatment were randomly re-positioned three 
times per week to account for intra-treatment variations in irradiance. Note that resource limitations prevented the replication of water baths.
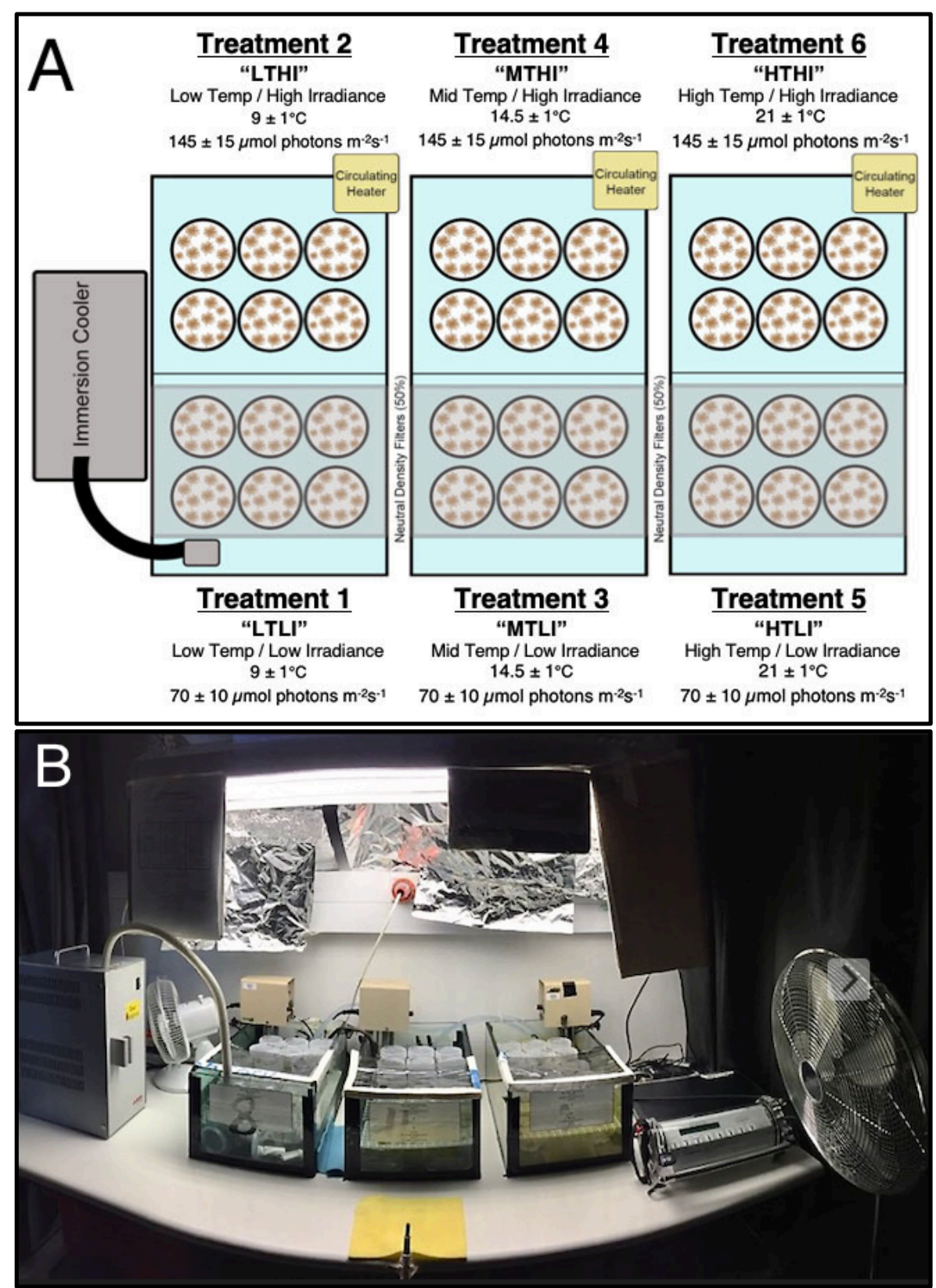

Figure 2.5: Experimental set-up. (A) Diagrammatic representation; (B) photograph of experimental set-up.

\subsubsection{Experimental sample collection and preservation}

Experimental treatment was performed across four months, with three sampling periods at 0,8 , and 16 weeks. Upon initial distribution of anemones from the stock tank into each of the six experimental treatments, anemones $(n=16)$ were set aside and used for the week 0 time point. For each subsequent sampling period, anemones ( $n=16$ per treatment, selected via jar randomization) 
were collected and immediately rinsed of any debris using $0.22-\mu \mathrm{m}$ filtered seawater. Anemones from the same treatment were then placed into 2-mL Eppendorf tubes with $500 \mu \mathrm{L}$ of $0.22-\mu \mathrm{m}$ FSW ( $\mathrm{n}=2$ anemones per tube; 8 tubes per treatment), flash frozen in liquid nitrogen $\left(-190^{\circ} \mathrm{C}\right)$, and stored at $-80^{\circ} \mathrm{C}$. One sample from each treatment was preserved as a back-up, while the other seven samples were processed and analysed as described below.

\subsection{Physiological parameters}

\subsubsection{Sample preparation}

Frozen sample tubes were thawed at $4{ }^{\circ} \mathrm{C}$ for one hour, and then were kept on ice to prevent cellular denaturation until processing. Anemones were homogenized in $1000 \mu \mathrm{L}$ of $0.22-\mu \mathrm{m}$ FSW using a IKA T10 Basic tissue homogenizer. The host and symbiont fractions were then separated via a series of centrifugations ( $1500 \mathrm{x}$ g for 10 minutes, $750 \mathrm{x}$ g for 7.5 minutes, $500 \mathrm{x}$ g for 5 minutes) and washes in FSW. The host-containing supernatant was carefully removed from the symbiontcontaining pellet, and transferred into a new tube following the first two centrifugations; after the second wash, all following supernatants were discarded as host material became negligibly diluted. Additional centrifugations ( $500 \mathrm{x} \mathrm{g}$ for 2 minutes) and subsequent washes were repeated until each pellet was satisfactorily cleaned of any remaining debris. The final symbiont pellet was then resuspended in $1000 \mu \mathrm{L}$ of $0.22-\mu \mathrm{m} \mathrm{FSW}$. A method of fraction isolation using a sucrose gradient was attempted (Chen et al., 2015); however, the process was far more precarious and timeconsuming and did not yield significantly cleaner fractions so it was not utilized in this study (see Appendix 1, Figure A1.1). Host fractions of each sample were assessed for protein, lipid, and carbohydrate content, and symbiont fractions were assessed for cell density, chlorophyll $a$ and $c_{2}$ content and ratio, and protein, lipid, and carbohydrate content (Figure 2.6).

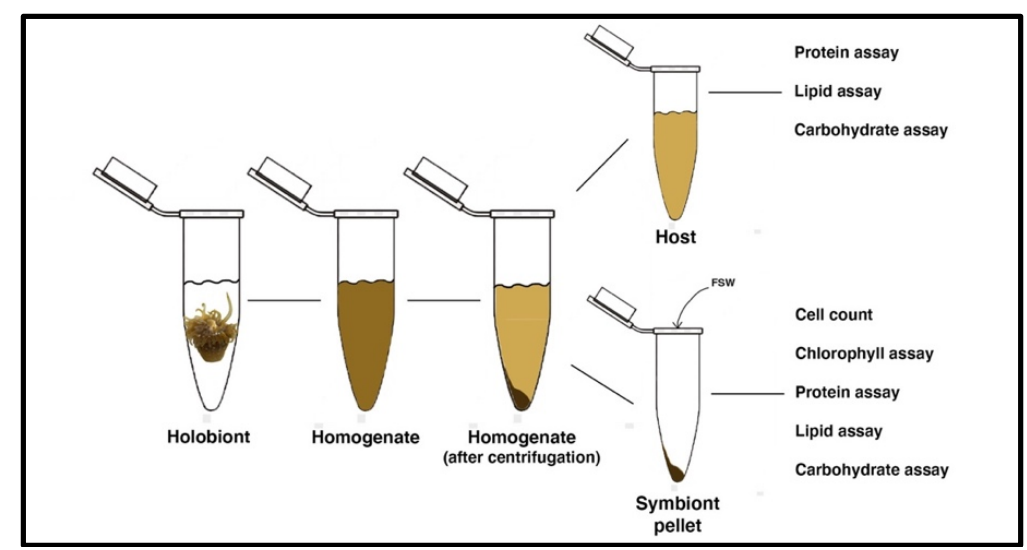

Figure 2.6: Sample preparation. Schematic diagram of the process of isolating host and symbiont fractions, and aliquoting them for physiological analysis. 


\subsubsection{Symbiont Cell Density}

Symbiont cell density (cell number per mg host protein) of each sample was estimated by automated counts performed on a high-throughput microscope (InCell Analyzer 6500). Each symbiont suspension was diluted (experiment sample DF $=10$, field sample DF $=25$ ), and then ten $15 \mu \mathrm{L}$ aliquots from each diluted cell suspension were pipetted individually into separate wells of a CellCarrier 384-ultrawell microplate ( $\mathrm{n}=10$ wells per sample). The plate was then inserted into the high-throughput microscope, and each well was scanned for cells based on their autofluorescence. The number of symbiont cells in each well was counted using a customized script in the INCarta software, and exported as an Excel file. Cell count was averaged across the ten replicates for each sample, and then normalized to host protein content (see below). Due to the occasional unavailability of the high-throughput microscope, some cell counts were performed manually using an Improved Neubauer haemocytometer. In this method, a glass micropipette was used to deposit approximately $1 \mu \mathrm{L}$ of diluted symbiont suspension onto the haemocytometer slide, which was placed under a photomicroscope to count the number of cells found within the slide's grid. This process was completed 10 times per sample, and results were averaged and then normalized to host protein content.

\subsubsection{Biomass: Protein content}

Proteins serve a variety of purposes, playing critical roles in signal transmission, molecular transport, and structural support; additionally, they are useful indicators of metabolic condition and overall biomass, and are frequently utilized as a basis for normalization of other cellular parameters (Buckley and Szmant, 2004; Dahlhoff, 2004; Davy et al., 2012). The protein content of both host and symbiont fractions was estimated using a colorimetric assay (Bradford, 1976), in which a reagent (Bradford Reagent, Sigma-Aldrich, NZ) binds to proteins in a sample, which is then spectrophotometrically assessed at a wavelength corresponding to various proteins. Throughout this assay, samples and reagents were kept on ice to limit protein denaturation. A standard curve of protein concentration was developed by adding $1,2,4,8,12$, and $16 \mu \mathrm{L}$ (each in duplicate) of 1 $\mathrm{mg} / \mathrm{mL}$ bovine serum albumin (BSA) in distilled water to the first row of wells of a clear $96-w e l l$ plate. Then, two aliquot volumes (between 1 and $16 \mu \mathrm{L}$ ) of each sample were pipetted into separate wells, in triplicate, filling the remainder of the plate (for a total of 6 wells per sample fraction). Each well, including those with the protein standard, was then topped up with Bradford Reagent to a total volume of $250 \mu \mathrm{L}$. The plate was then covered with foil and placed on a horizontal shaker (Ratek orbital mixer) at low speed for 15 minutes, to thoroughly mix the contents of each well. Following incubation, the plate was inserted into a spectrophotometer (Perkin Elmer Enspire 2300 
multi-label microplate reader), and absorbance was measured at an excitation wavelength of 595 $\mathrm{nm}$. Absorbance for each sample was converted into protein equivalents using the values generated by the standard curve, and these values were averaged across the technical replicates. Protein equivalents for symbiont fractions were normalized to symbiont cell number, and host fractions were normalized to host tissue homogenate volume.

\subsubsection{Photophysiology}

\subsubsection{Chlorophyll content}

The content of both chlorophylls $a$ and $c_{2}$ of symbiont fractions was estimated using a colorimetric assay (Jeffrey and Humphrey, 1975; Ritchie, 2006), in which ethanol extracts chlorophyll from cells, to be spectrophotometrically assessed at wavelengths corresponding to each pigment's absorption peak. A $100 \mu \mathrm{L}$ aliquot of each symbiont suspension was centrifuged at $5000 \mathrm{x} g$ for 3 minutes to pellet the cells, and the seawater supernatant was then discarded. $500 \mu \mathrm{L}$ of cold $\left(4^{\circ} \mathrm{C}\right) 100 \%$ ethanol were added to each tube, which were then vortexed to resuspend the pellet. The tubes were wrapped in foil to keep the contents in the dark and so prevent pigment degradation, and incubated at $4{ }^{\circ} \mathrm{C}$ for a minimum of one hour (range of 15-21 hrs used in this study) for chlorophyll extraction. Following incubation, samples were vortexed again and centrifuged at $15,000 \times \mathrm{g}$ for 5 minutes to pellet cellular debris. Two $200 \mu \mathrm{L}$ aliquots of the chlorophyll-containing supernatant from each sample were pipetted individually into separate wells (i.e. two technical replicates per sample) of a clear 96-well plate. An additional two wells were filled with $200 \mu \mathrm{L}$ of $100 \%$ ethanol each, as a negative control (i.e. blanks). Sample absorbance was then measured by a spectrophotometer (Perkin Elmer Enspire 2300 multi-label microplate reader) which recorded the absorbance emissions for each well at two different excitation wavelengths: $629 \mathrm{~nm}$ and $665 \mathrm{~nm}$. The relative absorbance for each well was corrected for by subtracting the average of the blanks, and then was applied to the following standard equations to calculate the concentration of both chlorophyll $a$ and chlorophyll $c_{2}$ in each well:

$$
\begin{aligned}
& \text { Chlorophyll a }(\mu \mathrm{g} / \mathrm{mL})=\left(-2.6094 \times \mathrm{A}_{629}\right)+\left(12.4380 \times \mathrm{A}_{665}\right) \\
& \text { Chlorophyll } c_{2}(\mu \mathrm{g} / \mathrm{mL})=\left(29.8208 \times \mathrm{A}_{629}\right)+\left(-5.6461 \times \mathrm{A}_{665}\right)
\end{aligned}
$$

The outputs from each equation were converted into picograms of chlorophyll per millilitre, and normalised to cell number to give the amount of chlorophyll per cell. 


\subsubsection{Photosynthetic efficiency}

From week 4 until the end of the experiment, twelve anemones from each treatment $(\sim 2$ anemones per jar) were randomly selected every week for an assessment of photophysiological health; these measurements could not be performed at earlier time points due to equipment unavailability. A Pulse Amplitude Modulation (PAM) fluorometer (Diving-PAM, Walz GmbH, Effeltrich, Germany) was used to measure both the light- and dark-adapted photosynthetic efficiency of experimental anemones, with relevant instrument settings as follows: measuring intensity $=3$, frequency $=1$, gain $=4$, damping $=3, \mathrm{NIR}=8$, saturation pulse intensity $=8$ (Howe, 2013). Prior to each PAM acquisition session, an autozero was performed on a jar filled with $300 \mu \mathrm{L}$ of $0.22-\mu \mathrm{m}$ FSW. Darkadapted PAM measurements were performed at 9:00am (one hour after the diel light cycle begins) following a 10-minute dark adaptation. Light-adapted PAM measurements were performed the same day at 2:00pm, after anemones had been exposed to light for half the day. Recorded values were minimum/initial fluorescence $\left(\mathrm{F}_{0}\right)$, maximum/final fluorescence $\left(\mathrm{F}_{\mathrm{m}}\right)$, and maximum PSII photochemical efficiency $\left(\mathrm{F}_{\mathrm{v}} / \mathrm{F}_{\mathrm{m}}\right)$. The maximum PSII photochemical efficiency was plotted and used to indicate whether holobionts were photosynthetically healthy throughout the experiment. [Note: Measures of photosynthetic efficiency were not performed on field study anemones due to equipment constraints.]

\subsubsection{Lipid content}

The lipid content of both host and symbiont fractions was estimated using Nile Red (Sigma Aldrich, NZ), a dye which binds to lipid bodies and fluoresces proportionately when excited at a wavelength specific to the type of lipid being analysed. The emission curve of Nile Red fluorescence "is blueshifted as the polarity of the surrounding environment decreases $[\ldots]$; therefore, it is possible to differentiate between neutral and polar lipids by accurate selection of excitation and emission wavelengths" (Bertozzini et al., 2011). Modifications to the protocol (i.e. excitation/emission wavelength, dimethyl sulfoxide "DMSO" concentration, Nile Red concentration, and linearity range) were made based on relevant publications (Chen et al., 2009; Kou et al., 2013; Rosset et al., 2017) and several rounds of optimization were performed to ensure reproducibility (Appendix 1, A1.2). This assay was performed in a fume hood with the lights off, as the Nile Red dye is photosensitive and decreases in fluorescence intensity with increased exposure to light; additionally, both the stain and all samples were kept on ice throughout the assay to limit degradation. Samples of both host and symbiont were first vortexed, and then four $95 \mu 1$ aliquots of each sample were added to separate wells of a black 96-well plate. To three of the four replicates 
of each sample, $5 \mu 1$ of dye ( $10 \mu \mathrm{g} / \mathrm{mL}$ Nile Red in DMSO) were added, for a final dye concentration of $0.5 \mu \mathrm{g} / \mathrm{mL}$ Nile Red and 5\% DMSO. The fourth replicate of each sample was used as an unstained control, with $5 \mu$ l of $99.9 \%$ DMSO added instead of the dye. The plate was then covered with foil and incubated in an oven at $37^{\circ} \mathrm{C}$ for 15 minutes to allow the dye to penetrate the cells and bind to the lipid bodies. The plate was then inserted into a spectrophotometer (Perkin Elmer Enspire 2300 multi-label microplate reader) which measured the fluorescence intensity of each well at an excitation wavelength of $530 \mathrm{~nm}$ and an emission wavelength of $580 \mathrm{~nm}$, corresponding to the emission wavelength of neutral lipids. A continuous emission scan was then performed for each plate, at an excitation wavelength of $530 \mathrm{~nm}$ and an emission range from $560-750 \mathrm{~nm}$ to see the full curve of fluorescence emission for each well in order to support the values obtained in the single-excitation scan. The fluorescence of the unstained sample was then subtracted from that of the stained samples to calculate the relative fluorescence intensity (R.F.I.) measured in arbitrary units (a.u.). The R.F.I. of each well was then converted into fluorescence per microliter based on volume, and then normalised to symbiont cell number or host protein content, depending on which fraction was analysed. The development of a standard curve for comparative neutral lipid quantification was attempted using Triolein oil (Sigma Aldrich, NZ); however, results were inconsistent and the method proved too time-consuming to pursue.

\subsubsection{Carbohydrate content}

It is important to note that this study did attempt several protocols to stain and quantify starch granules specifically; however, staining was unreliable and optimization was not able to be completed in time to utilize this method for the present study (see Appendix 1, A1.3). Instead, total carbohydrate content (which includes starches) was quantified for each sample.

The carbohydrate content of both host and symbiont fractions was estimated using a colorimetric assay (DuBois et al., 1956; Masuko et al., 2005) in which both simple and complex carbohydrates are reduced in acid and detected spectrophotometrically by measuring the solution's absorbance at a wavelength corresponding to that of hexoses, and then determined by calibration to a standard curve. This assay was performed in a fume hood while wearing appropriate PPE (gloves and safety goggles) as advised by the Material Safety Data Sheets for the highly toxic and corrosive chemicals required by in this procedure. A standard curve of glucose concentration was developed by adding $2,4,8,12,16$ and $20 \mu 1$ (each in duplicate) of $1 \mathrm{mg} / \mathrm{mL}$ pure D-Glucose standard solution in MilliQ water to the first row of wells in a clear 96-well plate; each well was then topped up with MilliQ to a final volume of $20 \mu \mathrm{l}$ per well. Two aliquot volumes (between 2 and $20 \mu \mathrm{L}$, depending on 
estimated sample concentration) of each sample were pipetted into separate wells, in triplicate (for a total of 6 wells per sample fraction), and again each well was topped up with MilliQ to a final volume of $20 \mu \mathrm{l}$ per well. To every well, $150 \mu \mathrm{L}$ of concentrated sulphuric acid were added, and the plate then covered with foil and incubated at $90^{\circ} \mathrm{C}$ for 15 minutes to encourage a reaction. Following incubation, concentrated phenol was diluted to $5 \%$ in MilliQ water and $30 \mu \mathrm{L}$ of this solution were added to each well and mixed via aspiration with a pipette. The plate was then placed on a horizontal shaker (Ratek orbital mixer) at low speed for 5 minutes to further mix the contents of the wells. Following this, the plate was inserted into a spectrophotometer (Perkin Elmer Enspire 2300 multi-label microplate reader) which measured the absorbance for each well at an excitation wavelength of $490 \mathrm{~nm}$. Carbohydrate content in the samples was then estimated by reference to the standard curve.

\subsection{Data analysis}

Data analysis was performed using IBM SPSS Statistics software (version 26.0.0.0). Tukey's fences (determined using the Inter-Quartile Range method) were used to identify outliers in the biological replicates of each dataset to validate the reliability of tests; however, no outliers were removed due to the relatively low biological replication for each time point. The field and experimental datasets were analyzed separately, and each physiological response variable was assessed for normality using the Shapiro-Wilk test $(\alpha=0.05)$ as well as visual assessment of standardized residual plots. The assumption of equal variances was assessed using Levene's Test for Homogeneity of Variances $(\alpha=0.05)$.

Data that met both assumptions of equal variance and normality were analyzed with a one-way Analysis of Variance ("ANOVA"; $\alpha=0.05$ ) to determine the presence of significant differences between groups, and then supplemented with a Tukey's post hoc test $(\alpha=0.05)$ with a $95 \%$ confidence interval $(\mathrm{CI})$ to identify which groups were significantly different from one another.

Data that violated the assumption of equal variance but met the assumption of normality were analyzed with the more robust Welch ANOVA $(\alpha=0.05)$ to test for differences between groups, and then supplemented with a Games-Howell post hoc test $(\alpha=0.05)$ with a $95 \%$ CI to identify the specific groups that were significantly different from one another.

Data that met the assumption of equal variance but violated the assumption of normality were $\log _{10}$ transformed, and then reassessed for equal variances and normality. If both met the assumptions, then a one-way ANOVA was performed on the log-transformed data, followed by Tukey's post hoc as mentioned 
above. However, if the log-transformed data met the assumption of normality but no longer passed the assumption of equal variances, a Welch ANOVA was performed on the data, followed by a Games-Howell post hoc as previously mentioned.

If a dataset violated both the assumptions of equal variance and normality, then it was also log-transformed and reassessed. If the log-transformed data also violated both assumptions of equal variance and normality, the non-parametric Kruskal-Wallis test was performed to supplement the original ANOVA, and Bonferroniadjusted significances were used to identify significant differences between groups.

As so many individual analyses had to be performed on the numerous datasets developed throughout this thesis, the possibility of a Type 1 error occurring (in which significant difference are reported when one may not actually exist) was considered; this was avoided in problematic datasets by supplementing group comparisons with adjusted significances, and testing at a lower significance level if needed. Details of each statistical test performed are outlined in Appendix 2.

\subsubsection{Field data}

This dataset was analysed with two separate general linear models: first, data were analysed by a one-way ANOVA which compared each physiological response variable between months $(\alpha=$ 0.05), then, the monthly data were pooled into seasons (Dec-Feb, Mar-May, Jun-Aug, Sep-Nov) and another one-way ANOVA was performed to compare each physiological response variable grouped by season $(\alpha=0.05)$. Relationships between water temperature, air temperature, and irradiance with each response variable were assessed visually, as the data were too complex and irregular to be analysed using conventional statistical analyses.

\subsubsection{Experimental data}

Initially, a two-way ANOVA with both time and treatment used as separate independent factors was attempted; however, most datasets were either heteroscedastic or followed non-normal distributions, and therefore required supplementary analyses that do not allow for multiple independent factors. As such, both time and treatment were combined into one independent variable (i.e. " 0.1 " for week 0 -treatment 1 , " 0.2 " for week 0 -treatment 2 , and so on...) so that the Welch ANOVA and non-parametric Kruskal-Wallis test were able to be performed. 


\section{Chapter 3: $\underline{\text { Results }}$}

\subsection{Field study}

There were significant seasonal and/or monthly effects for all response variables. Monthly data are presented below (Figures 3.1 and 3.2), and seasonal data are in Appendix 3.1.
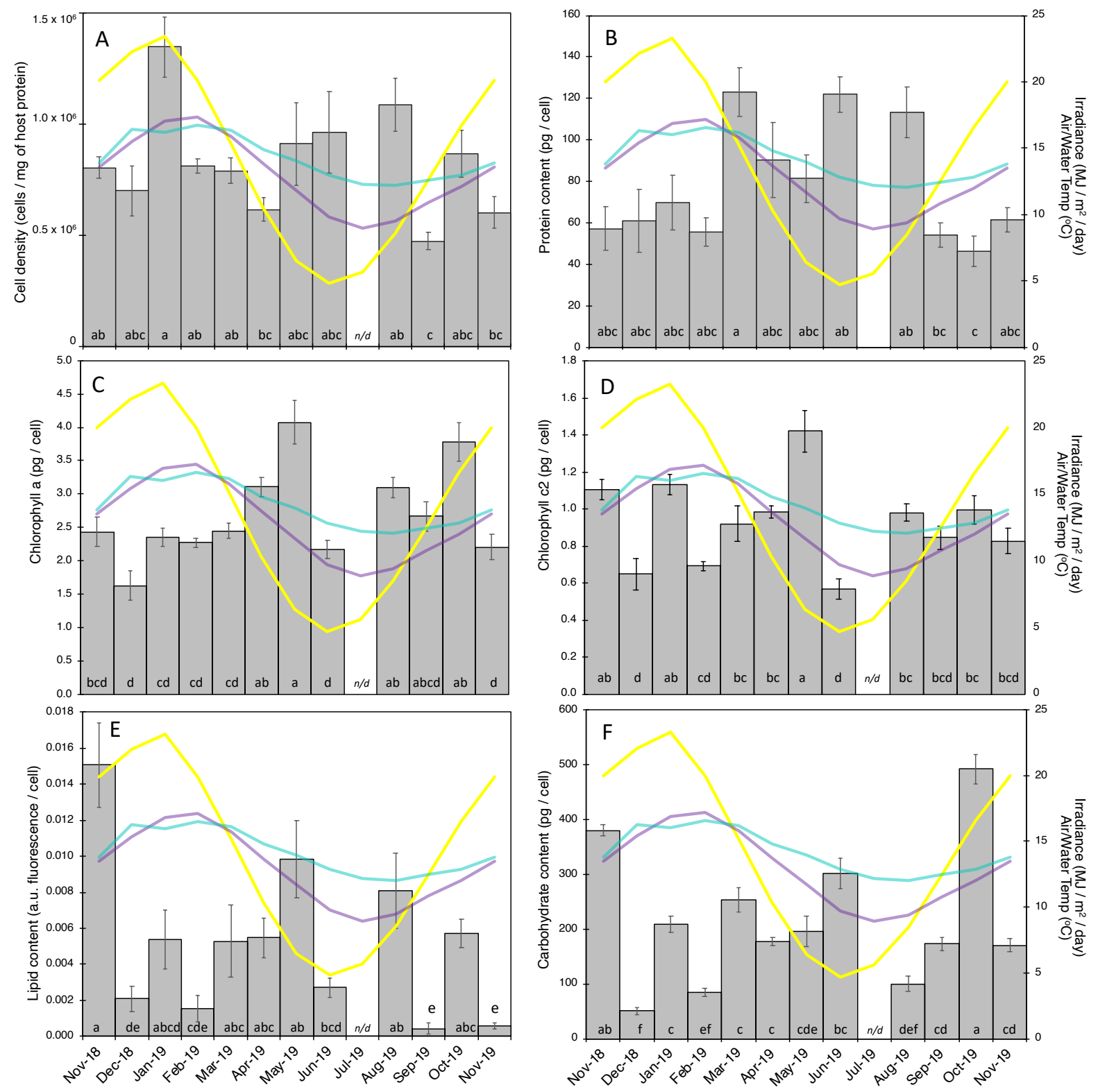

Figure 3.1: Monthly physiological assessment of Symbiodiniaceae cells isolated from the sea anemone Anthopleura aureoradiata. Bars represent monthly averages ( $\mathrm{n}=7$ per month; values presented are means \pm 1 S.E.) for the following physiological measurements: (A) cell density, (B) protein content, (C) chlorophyll $a$, (D) chlorophyll $c_{2}$, (E) lipid content, and (F) carbohydrate content. Significant differences between groups are indicated by letters at the base of each bar. Coloured lines represent average monthly values of environmental parameters (yellow $=$ irradiance $\left(\mathrm{MJ} / \mathrm{m}^{2} /\right.$ day $)$, purple $=$ air temperature $\left({ }^{\circ} \mathrm{C}\right)$, blue $=$ water temperature $\left.\left({ }^{\circ} \mathrm{C}\right)\right)$. 

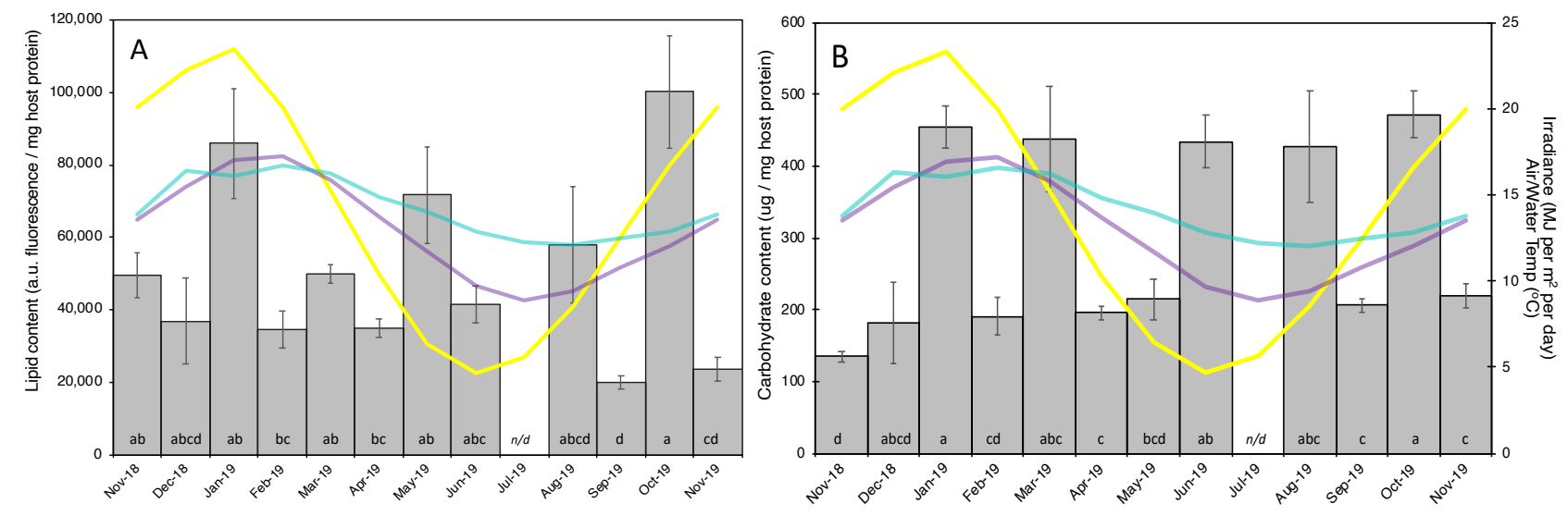

Figure 3.2: Monthly physiological assessment of host tissue for the sea anemone Anthopleura aureoradiata. Bars represent monthly averages $(\mathrm{n}=7$ per month; values presented are means \pm 1 S.E.) for the following physiological measurements: (A) lipid content, and (B) carbohydrate content. Significant differences between months are indicated by letters at the base of each bar. Coloured lines represent average monthly values of environmental parameters $\left(\right.$ yellow $=$ irradiance $\left(\mathrm{MJ} / \mathrm{m}^{2}\right)$, purple $=$ air temperature $\left({ }^{\circ} \mathrm{C}\right)$, blue $=$ water temperature $\left({ }^{\circ} \mathrm{C}\right)$ ).

\subsubsection{Symbiont cell density}

Symbiont cell density per milligram of host protein was highest in mid-summer (January) (Figure $3.1 \mathrm{~A}$ ), with an average of $1.35 \pm 0.14$ million cells $/ \mathrm{mg}$ host protein, corresponding with a peak in average solar irradiance. The following months experienced a steady decrease in both temperature and irradiance, which was reflected by a decrease in symbiont cell density, though the density did not markedly change throughout the months comprising autumn and winter (Welch ANOVA, Games-Howell post hoc, $\mathrm{p}>0.05$; but see below). Symbiont density experienced a significant decline (to only $0.47 \pm 0.04$ million cells $/ \mathrm{mg}$ host protein) from winter to early-spring (September), when the prolonged effects of winter had perhaps had a cumulative effect (one-way ANOVA, Tukey post hoc, $\mathrm{p}<0.05)$.

While the monthly analysis did not detect a pronounced, significant change in symbiont density for anemones collected between March 2019 and August 2019, analysis of the data pooled by season rather than month did detect a difference (Appendix 3, Figure A3.1.3). Of note, symbiont cell density was significantly higher in both summer and winter compared with spring (one-way ANOVA on log-transformed data, Tukey post hoc, $\mathrm{p}<0.05)$. Of potential relevance, the high symbiont density in pooled summer months coincides with peak irradiance, as previously mentioned, whereas the elevated winter symbiont density coincides with both low irradiance and temperature (and hence a possible indication of photoacclimation). 


\subsubsection{Biomass: Protein content}

Considered on a monthly basis, symbiont protein content, measured in picograms per cell, was relatively stable from November 2018 to February 2019 (late spring and summer, respectively); however, a noticeable spike occurred in March (early-autumn) with $133.38 \pm 11.77 \mathrm{pg} /$ cell (Figure 3.1B). The protein content then remained at similarly elevated levels for the next four months (April to July 2019; mid-autumn to mid-winter) before experiencing a decrease to more moderate levels for the remainder of the year, with the lowest protein content being in October 2019 (mid-spring), at only $40.30 \pm 7.32 \mathrm{pg} / \mathrm{cell}$, which was more than three times lower than the values observed in March 2019. These patterns were reflected by the seasonally-pooled data, with symbiont protein content in both spring and summer being similar to one another but lower than those in autumn and winter, which were likewise similar to each other (Appendix 3, Figure A3.1.3; one-way ANOVA, Tukey post hoc, $\mathrm{p}<0.05)$.

\subsubsection{Chlorophyll content}

On a monthly basis, chlorophyll $a$ and $c_{2}$ pigment content (in picograms per cell) were both rather variable throughout the year, although $c_{2}$ content was the more visually variable of the two (Figure 3.1E,F). There was a trend of steadily increasing cellular content of both chlorophyll $a$ and $c_{2}$ pigments from February to a peak in May (late summer to late autumn), which coincided with a decrease in temperature and irradiance as winter approached. Following this, both pigments experienced a significant drop during June 2019 before increasing again in the spring (one-way ANOVA, Tukey post hoc, $\mathrm{p}<0.05$; see Appendix 3, Figure A3.1.3 for seasonally-pooled data plots).

When data were pooled by season, both chlorophyll $a$ and $c_{2}$ pigment content reached lower levels in summer and winter than in spring and autumn, consistent with the monthly patterns described above (one-way ANOVA, Tukey post hoc, $\mathrm{p}<0.05$ ). However, the inter-seasonal difference was much more marked in the winter, when chlorophyll $a$ content was $22 \%$ higher than in summer (by comparison, chlorophyll $c_{2}$ content was $6 \%$ higher in summer than it was in winter) (Appendix 3, Figure A3.1.3). The ratio of chlorophyll a: $c_{2}$ pigments (Appendix 3, Figures A3.1.2 and A3.1.4) was relatively stable throughout the year, but there was a noticeable increase during the winter (particularly June of 2019) compared to all other seasons (one-way ANOVA, Tukey post hoc, $\mathrm{p}<$ $0.05)$. 


\subsubsection{Lipid content}

As a standard curve for lipid quantification could not be optimized for use in this thesis, analyses were performed on a comparative basis between samples; while this method yielded seeminglyconsistent results, any interpretations should still be considered with caution.

Symbiont | When considered with respect to monthly changes, the symbiont lipid content, measured in arbitrary units (a.u.) of fluorescence per symbiont cell, was highly variable throughout the sampling period, even from one month to the next. Particularly disparate monthly averages were observed between the late-spring November 2018 and 2019 sampling points (Figure 3.1C), with symbiont lipid content in November 2018 being approximately 25 times higher than the lipid content in November 2019. This monthly variability means that distinct seasonal patterns were not obvious; though analysis of the seasonally-pooled data indicated that symbiont lipid content was lowest in the summer (Appendix 3, Figure A3.1.3), this difference was not statistically significant (Welch ANOVA, Games-Howell post hoc, $\mathrm{p}>0.05$ ). Furthermore, while the anomalously-high value recorded during November 2018 increased the overall spring average, the symbiont lipid levels in September and November 2019 (early-and late-spring) were the lowest throughout the year, significantly lower, in fact, than almost every other month (with the exception of early- and late-summer months December and February 2019) (one-way ANOVA, Tukey post hoc, $\mathrm{p}<0.05$ ).

Host | Host lipid content, measured in a.u. fluorescence per milligram of host protein, fluctuated far less than that of the symbionts throughout the survey period, though there were still some marked differences between consecutive months (Figure 3.2A). For example, September 2019 exhibited by far the lowest recorded lipid content (only 19,972 \pm 1,860 a.u. fluorescence/mg host protein), while the highest host lipid content was recorded for the following month, October 2019, with a significant five-fold increase (Welch ANOVA, Games-Howell post hoc, $\mathrm{p}<0.05$ ). Such fluctuations lead to there being no significant effect of season (i.e. seasonally-pooled data) on host

lipid content (Welch ANOVA, Games-Howell post hoc, $\mathrm{p}>0.05$ ), though the highest monthly average was observed in the summer (Appendix 3, Figure A3.1.5). 


\subsubsection{Carbohydrate content}

Symbiont | Similarly to the aforementioned lipid content, when considered on a monthly basis, the symbiont carbohydrate content, measured in picograms per cell, was also highly variable even between consecutive months (Figure 3.1D). The lowest carbohydrate content was observed in December 2018, with 50.35 $\pm 6.08 \mathrm{pg} /$ cell, while the peak, recorded in October 2019, was almost ten-fold higher, at $491.71 \pm 27.09 \mathrm{pg} / \mathrm{cell}$. For extended periods of the year (e.g. March - June 2019), however, symbiont carbohydrate content was statistically stable, with no significant differences between months. On a seasonal scale (i.e. seasonally-pooled data), symbiont carbohydrate content was higher in spring than both summer and autumn (Welch ANOVA, GamesHowell post hoc, $\mathrm{p}<0.05$ )(Appendix 3, Figure A3.1.3) although this trend was skewed by the particularly high value measured in October 2019.

Host | Host carbohydrate content, measured in micrograms per milligram of host protein, showed even greater inter-monthly variability than symbiont carbohydrate content (Figure 3.2B). Values ranged from $134.53 \pm 6.55 \mu \mathrm{g} / \mathrm{mg}$ host protein in November 2018 (late-spring) to a peak of 471.96 $\pm 33.32 \mu \mathrm{g} / \mathrm{mg}$ host protein in October 2019 (mid-spring), with increases or decreases of two-fold or more seen between some months, including within the same season (Welch ANOVA, GamesHowell post hoc, $\mathrm{p}<0.05)$. When the seasonally-pooled data were considered, the anemones were found to contain significantly more carbohydrates during winter than in spring or summer (oneway ANOVA, Tukey post hoc, $\mathrm{p}>0.05$ ); however, it is important to note that this finding is based on data for just two winter months due to the inability to sample during July 2019. Due to this, seasonally-pooled winter data must be interpreted with extreme caution, as huge monthly variability within other seasons resulted in host carbohydrate content not differing significantly between seasons (one-way ANOVA, Tukey post hoc, $\mathrm{p}>0.05$ )(Appendix 3, Figure A3.1.5).

\subsection{Experimental study}

There was a significant effect of both time and treatment on the physiological response variables analysed (one-way ANOVA, Tukey post hoc, $\mathrm{p}<0.05$; confirmed by Kruskal-Wallis test with Bonferroni-adjusted significances). The most notable result from this experiment is that although all experimental anemones remained alive, when measurements of photosynthetic efficiency began at week 4, all anemones in both the low-temperature low-irradiance (LTLI) and low-temperature high-irradiance (LTHI) treatments were already registering very low $\mathrm{F}_{\mathrm{v}} / \mathrm{F}_{\mathrm{m}}$ values (Figure 3.3), in addition to becoming physically smaller and visibly paler. By the second sampling point at week 8 , symbiont densities were so low that reliable measures 
of photosynthetic efficiency could not be made, and there were too few symbionts for accurate cell counts or storage product determination; therefore, these treatments (LTLI and LTHI) were considered to have bleached. Therefore, comparative analyses of symbiont physiology were performed for the moderate and high temperature treatments only, though the data for the host fractions of the cold-treated anemones are also presented and discussed. Areas in each figure where a bar would have existed, should there have been data, have been labelled as " $n / d$ ".

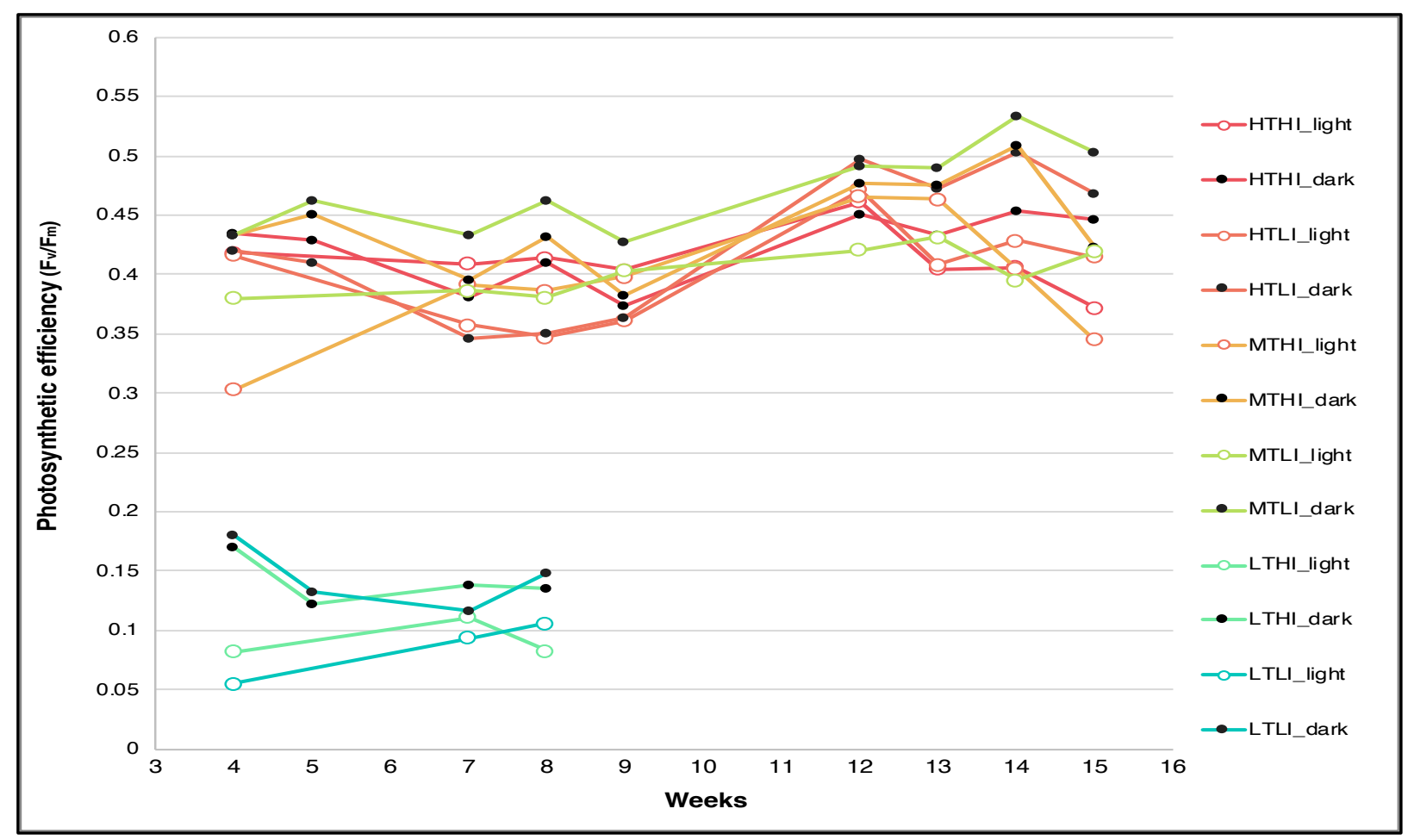

Figure 3.3: Photosynthetic efficiency of the intact Anthopleura aureoradiata-Symbiodiniaceae symbiosis under experimental conditions. Treatments are abbreviated as follows: $\mathrm{HTHI}=$ high temperature high irradiance, $\mathrm{HTLI}=$ high temperature low irradiance, $\mathrm{MTHI}=$ moderate temperature high irradiance, $\mathrm{MTLI}=$ moderate temperature low irradiance, LTHI = low temperature high irradiance, and LTLI = low temperature low irradiance. Each line represents either dark-adapted (black marker) or light-adapted (white marker) measurements for each treatment (specified in the data labels). Measurements of photosynthetic efficiency for the low temperature tanks ceased at week 8 as fluorescence values were too low for reliable detection, and anemones were determined to have bleached. 

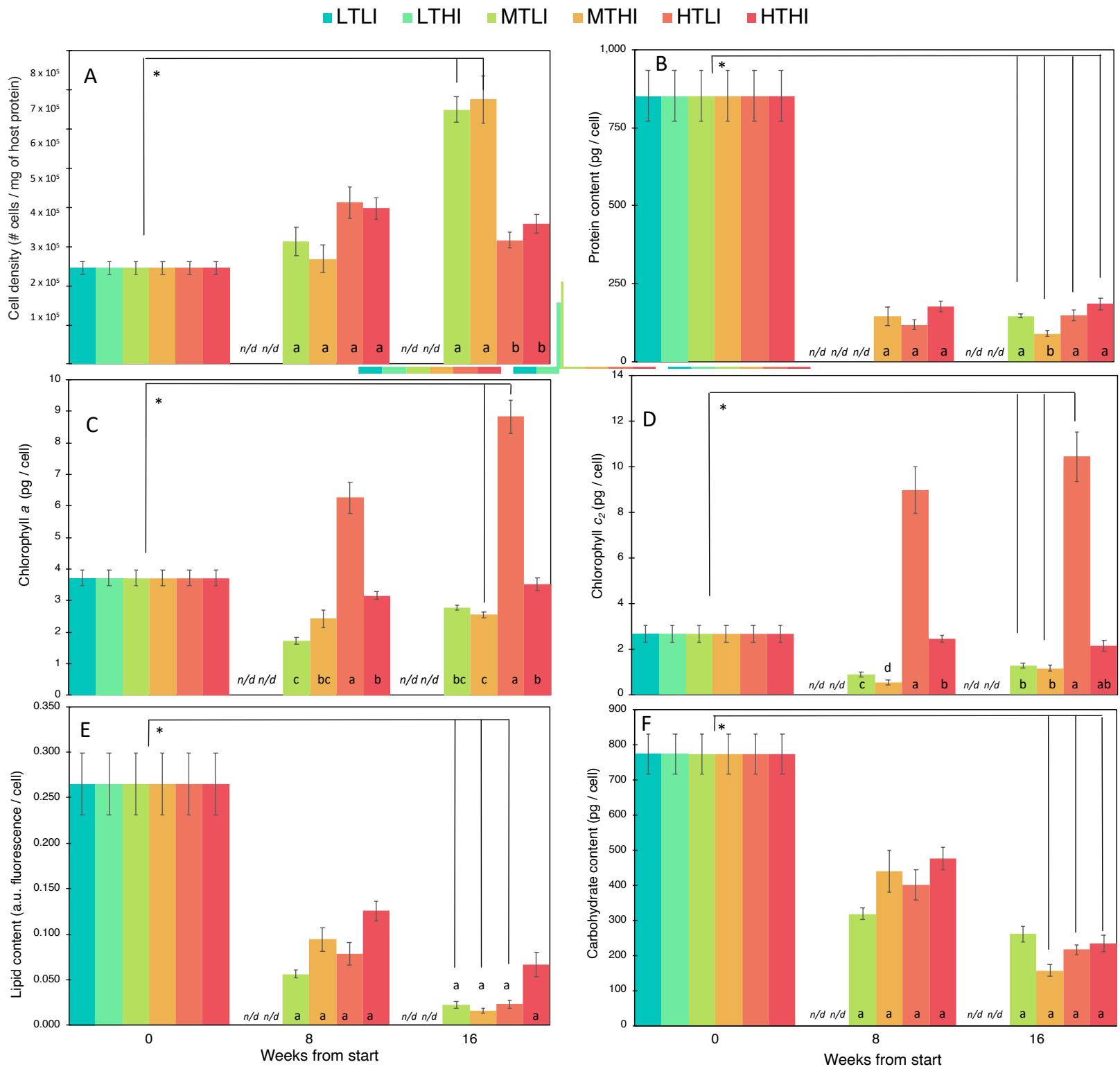

Figure 3.4: Physiology of Symbiodiniaceae isolated from the sea anemone Anthopleura aureoradiata maintained

in experimental conditions. Experimental study was conducted for 16 weeks. Treatments are abbreviated as follows: $\mathrm{HTHI}=$ high temperature high irradiance, $\mathrm{HTLI}=$ high temperature low irradiance, $\mathrm{MTHI}=$ moderate temperature high irradiance, MTLI = moderate temperature low irradiance, $\mathrm{LTHI}=$ low temperature high irradiance, and LTLI = low temperature low irradiance. Bars represent treatment averages $(\mathrm{n}=7$ per treatment per time point, except for MTHI at week 8 where $n=4$; values are means \pm 1 S.E.) for the following physiological measurements: (A) cell density, (B) protein, (C) lipid, (D) carbohydrate, (E) chlorophyll a, and (F) chlorophyll c2. Significant differences between treatments at each time point are indicated by letters at the base of each bar; same letters should not be interpreted as similarity across time points. Treatments that exhibited significant changes between weeks 0 and 16 are indicated by a line with an asterisk $(*)$. 


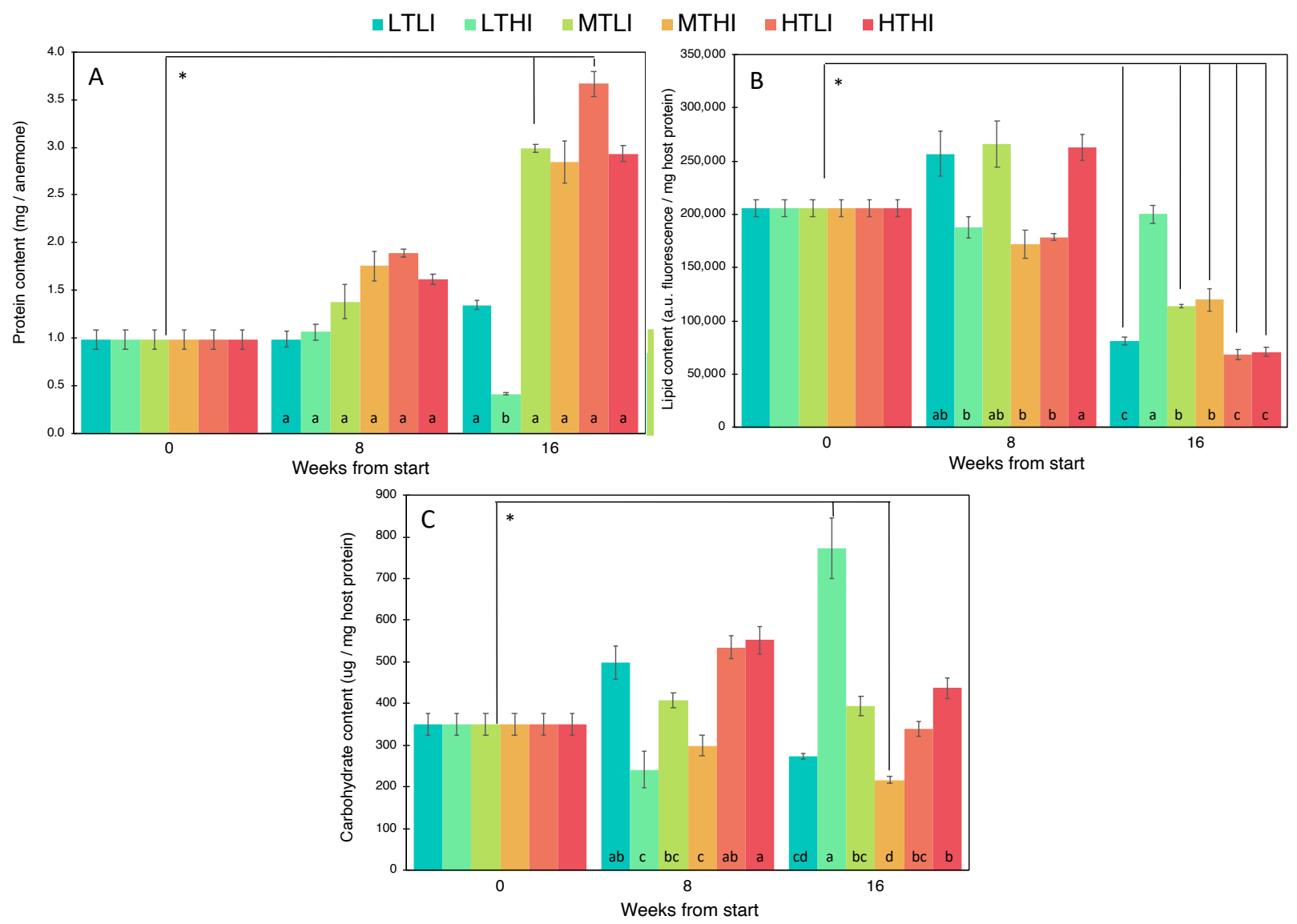

Figure 3.5: Physiology of host tissue in the sea anemone Anthopleura aureoradiata maintained in experimental conditions. Experimental study was conducted for 16 weeks. Treatments are abbreviated as follows: HTHI = high temperature high irradiance, $\mathrm{HTLI}=$ high temperature low irradiance, $\mathrm{MTHI}=$ moderate temperature high irradiance, MTLI $=$ moderate temperature low irradiance, $\mathrm{LTHI}=$ low temperature high irradiance, and LTLI $=$ low temperature low irradiance. Bars represent values ( $\mathrm{n}=7$ per sample period, values presented are means $\pm 1 \mathrm{SE}$ ) for the following physiological measurements: (A) protein content, (B) lipid content, and (C) carbohydrate content. Significant differences between treatments at each time point are indicated by letters at the base of each bar; same letters should not be interpreted as similarity across time points. Treatments that exhibited significant changes between weeks 0 and 16 are indicated by a line with asterisk $(*)$.

\subsubsection{Symbiont cell density}

As stated previously, low temperature caused anemones to bleach, with symbiont numbers too low to estimate density reliably. Anemones maintained at the moderate temperature, both low irradiance (MTLI) and high irradiance (MTHI) variants, experienced the greatest increases in symbiont cell density (measured in cell number per milligram of host protein) during the experiment (Figure 3.4A). Indeed, these treatments were the only ones that changed significantly between weeks 0 and 16 (Welch's ANOVA, Games-Howell post hoc, $\mathrm{p}<0.05$ ). In comparison, anemones maintained at 
high temperature, both low (HTLI) and high irradiance (HTHI), exhibited a slight, but insignificant, increase in symbiont cell density during the first eight weeks, but thereafter dropped back to levels similar to those seen at the start. Within each time point, irradiance levels had no discernible effect on symbiont density at either the moderate temperature or the high temperature (Welch's ANOVA, Games-Howell post hoc, $\mathrm{p}>0.05)$.

\subsubsection{Protein content}

Symbiont | Symbiont protein content, measured in picograms per cell, declined significantly over the course of the 16-week experiment in all moderate and high temperature treatments (Welch ANOVA, Games-Howell, $\mathrm{p}<0.05$ ) (Figure 3.4B). The only statistical difference between the treatments was observed in the significantly lower protein content in the MTHI treatment compared with all others at week 16 (Welch ANOVA, Games-Howell, $\mathrm{p}<0.05$ ). [*Note that the symbiont protein content in the week 8 MTLI treatment could not be detected, but given the remainder of the dataset it seems likely that this was due to technical error rather than being a real result; unfortunately, due to limited laboratory access during the COVID-19 lockdown, this sample set could not be re-analysed.]

Host | The most notable trend in host protein content, measured in milligrams per anemone, occurred in the LTHI treatment, which decreased over the course of the experiment, whereas in every other treatment, host protein content either remained stable or increased throughout the experiment (Figure 3.5A). However, the only significant changes in host protein content over time occurred in the MTLI and HTLI treatments, in which an increase was apparent at week 16, suggesting that irradiance deficits played a greater role than temperature in determining changes in protein content (Welch ANOVA, Games-Howell, $\mathrm{p}<0.05$ )

\subsubsection{Chlorophyll content}

Both chlorophyll $a$ and $c_{2}$ pigments, measured in picograms per cell, followed similar patterns throughout the experiment, with both pigments experiencing significant changes between weeks 0 and 16, but not under all treatments (Figure 3.4E,F). In particular, chlorophyll $a$ content declined significantly in the MTHI treatment (one-way ANOVA, Tukey post hoc, $\mathrm{p}<0.05$ ), and chlorophyll $c_{2}$ content declined significantly in both the MTLI and MTHI treatments (Welch ANOVA, GamesHowell post hoc, $\mathrm{p}<0.05$ ). Both chlorophyll pigments remained unchanged in the HTHI treatment throughout the experiment. In contrast, in the HTLI treatment, chlorophyll $a$ content increased by 
approximately three-fold between weeks 0 and 16 (one-way ANOVA, Tukey post hoc, $\mathrm{p}<0.05$ ), while chlorophyll $c_{2}$ content increased approximately five-fold at the same time (Welch ANOVA, Games-Howell post hoc, $\mathrm{p}<0.05)$. The chlorophyll $a: c_{2}$ ratio in this treatment was significantly lower than the ratio for all other treatments at both sampling time points, further indicating that the HTLI treatment had the greatest impact on chlorophyll content in this experiment (Appendix 3, Figure A3.2.1).

\subsubsection{Lipid content}

As previously stated, a standard curve for lipid quantification could not be optimized for use in this thesis, analyses were performed on a comparative basis between samples; while this method yielded seemingly-consistent results, any interpretations should still be considered with caution.

Symbiont | Much like the symbiont protein content, symbiont lipid content, measured in artificial units (a.u.) of fluorescence per cell, decreased throughout the experiment in both moderate and high temperature treatments, with all treatments except the HTHI treatment containing significantly less lipid by week 16 (one-way ANOVA, Tukey post hoc, $\mathrm{p}<0.05$ )(Figure 3.4C), and even then, symbionts in the HTHI treatment contained only approximately $25 \%$ of the lipid measured at the start of the experiment. Despite this, there were no significant differences in lipid content between any of the treatments at both weeks 8 and 16 (one-way ANOVA, Tukey post hoc, $\mathrm{p}>0.05$ ).

Host | Average host lipid content, measured in a.u. fluorescence per milligram host protein, experienced a slight increase in the LTLI, MTLI, and HTHI treatments, and a slight decrease in the other three treatments during the first eight weeks of the experiment (Figure 3.5B). However, by week 16, all treatments had experienced an overall decrease in the average host lipid content (Welch ANOVA, Games-Howell post hoc, $\mathrm{p}<0.05$ ), although the LTHI treatment was the only one to not exhibit a statistically significant decrease (Welch ANOVA, Games-Howell post hoc, $\mathrm{p}>0.05$ ).

\subsubsection{Carbohydrate content}

Symbiont | Similarly to both symbiont protein and lipid content, the carbohydrate content of the symbionts, measured in picograms per cell, declined markedly over the course of the experiment (one-way ANOVA, Tukey post hoc, $\mathrm{p}<0.05$ ), with the exception of the MTLI treatment, whose decline in content was not statistically significant (one-way ANOVA, Tukey post hoc, $\mathrm{p}>$ 0.05)(Figure 3.4D). Even then, carbohydrate content in the MTLI treatment was not significantly 
different from the contents measured in the other treatments at weeks 8 and 16, all of which were statistically the same throughout the experiment.

Host | Most treatments experienced a slight increase during the first eight weeks in host carbohydrate content (Figure 3.5C), measured in micrograms per milligram of host protein, followed by a decrease in the second eight weeks of the experiment; however, anemones in the LTHI treatment actually increased in carbohydrate content over the second half of the experiment, with a final carbohydrate content that was significantly higher than in all other treatments (one-way ANOVA, Tukey post hoc, $\mathrm{p}<0.05)$. Anemones in the MTHI treatment experienced the greatest overall decrease in host carbohydrate content throughout the experiment, declining by $41 \%$ over the course of sixteen weeks. 


\section{Chapter 4: Discussion}

This thesis provides insight into the cellular biology of temperate cnidarian-dinoflagellate symbioses, with a particular emphasis on the impacts of temperature and irradiance on symbiosis stability and the use of storage products in the New Zealand sea anemone Anthopleura aureoradiata and its endosymbiotic dinoflagellates (Philozoon spp., Symbiodiniaceae). I hypothesized that this temperate symbiosis would remain stable in response to both seasonal environmental changes and experimental treatment to a range of temperatures and irradiances that could be experienced in the field. Moreover, I hypothesized that the accumulation of storage products, both in the host and its symbionts, would change in response to environmental variables as a means of sustaining the symbiosis and contributing to its stability; these hypotheses were only partially supported by the findings of the present study. In particular, the symbiosis was seasonally robust (i.e. despite temporal variability, samples showed no signs of dysfunction or bleaching), with symbiont densities peaking in mid-summer in the field; however, extended experimental cold treatments induced bleaching in the laboratory. Notably though, other than holobionts exposed to prolonged experimental cold treatment, the symbiosis showed no signs of photo-physiological dysfunction in all other experimental treatments. Furthermore, concentrations of energy-rich lipids and carbohydrates in both host and symbionts - were highly variable in the field, although results of the experimental study provided evidence for their increased depletion in the symbionts under moderate and high temperature treatments in the lab, compared with the hosts who maintained relatively stable levels of storage products. These findings can be interpreted as evidence for the potential utilization of symbiont storage products under times of environmental change, contributing to maintenance of a stable holobiont. The implications of this finding in terms of the stability of temperate cnidarian-dinoflagellate symbioses, and why the symbiosis in the field exhibited no clear seasonal patterns of resource use, will be discussed here.

\subsection{Field study}

A. aureoradiata is capable of surviving under a wide variety of conditions, as demonstrated by its ability to maintain its symbiont population throughout all seasons in the field. This robustness is unsurprising, given that the intertidal habitat of this species is exposed to a variety of both aerial and aquatic conditions. However, the partnership did exhibit seasonal fluctuations, with a peak in symbiont density accompanied by a decline in cell-specific protein, lipid, and carbohydrate content during the summer. While another slight increase in symbiont density was observed during the winter as well, the cell-specific storage products did not decline consistently as in summer; rather, cell-specific protein was high while lipid and carbohydrate content varied too much to determine a distinct trend. Throughout the year, symbiont chlorophyll content was considerably seasonally variable, with levels slightly elevated during spring and autumn, but there were no indications of photophysiological dysfunction. 


\subsubsection{Symbiont biomass: cell density and protein content}

The symbiont cell densities measured from field-collected anemones were similar to those reported in previous studies of A. aureoradiata (Doherty, 2009; Cornwall, 2017), which ranged from 0.25$1.6 \times 10^{6}$ cells per milligram of host protein; this range is also similar to those reported for other Anthopleura species, such as A. ballii (Davy et al., 1996) and A. elegantissima (Verde and McCloskey, 2001, 2002, 2007). Perhaps interestingly, another study of $A$. aureoradiata from New Zealand (Bone, 2016) reported symbiont cell densities 2-3 times higher than the densities reported in the aforementioned studies, with an average of 3-4 x $10^{6}$ cells per mg host protein. These differences, while potentially due to separate sampling sites, may highlight the interannual variability experienced in this region that unfortunately could not be assessed within the time-frame of the current study.

The results of the current study suggest distinct seasonal effects on symbiont density, which reinforce the seasonal effects reported in previous studies of the temperate sea anemone $A$. elegantissima and the temperate soft coral Capnella gaboensis (Farrant et al., 1987; Verde and McCloskey, 2007; Bergschneider and Muller-Parker, 2008; Dimond et al., 2011). In particular, the current study found that symbiont cell density was similarly higher in the summer and winter than in the spring and autumn. This observation mirrors the findings of Bone (2016) who also reported similarly higher symbiont densities between summer and winter. This seasonal trend in symbiont cell density is consistent with the variations in the external environment, with summer and winter both characterized by annual 'extremes' in temperature and irradiance. However, of possibly greater relevance, a similar study to the present one reported that symbiont cell densities in $A$. aureoradiata in the Wellington region were actually significantly higher in the summer than in the winter (Gibbons, 2009), as did a study of A. elegantissima by (Saunders and Muller-Parker, 1997), who suggested that low winter irradiance limits the symbionts more than temperature. These contrasted findings suggest that temperate cnidarian-dinoflagellate symbioses are individually variable in their responses to seasonal changes, and that these responses are likely due to a myriad of factors. Exactly how variables such as ambient temperature and irradiance, microhabitat, local nutrient availability, and species-specific physiology interact to produce the patterns reported in the aforementioned studies is ultimately still unclear; yet it is apparent that symbiont density tends to increase in response to suboptimal conditions during summer and winter due to a combination of factors. 
Symbiont protein content per cell also showed a seasonal effect, being significantly higher during autumn and winter than spring and summer; this corresponds with the significantly lower irradiance in autumn and winter than in spring and summer, as well as a steady decrease in both air and water temperature. This suggests that symbiont protein content may be more affected by irradiance than by temperature, though other environmental factors undoubtedly also have an influence. It is unknown why the protein content per symbiont cell declines in the spring and summer, but it could be related to symbiont growth and proliferation rates, which are likely to increase in well-lit conditions (such as those characteristic of summer). Unfortunately, growth rate (e.g. mitotic index/percentage of cells in a state of division) was not measured in the present study, but such data would be beneficial in addressing seasonal changes in protein content for further work.

\subsubsection{Chlorophyll content}

Cell-specific levels of chlorophyll pigments $a$ and $c_{2}$ exhibited similar seasonal patterns, with higher content of both pigments observed in spring and autumn (with a particular spike in May 2019), compared to the lower values recorded during summer and winter. Given the identical annual trends in the content of both chlorophylls $a$ and $c_{2}$ throughout the study period, the pigment ratio of chlorophylls $a: c_{2}$ was relatively consistent throughout much of the year, though it did significantly increase during winter. These findings are in contrast with those reported for the temperate soft coral $C$. gaboensis, in which cell-specific chlorophyll $a$ content did not experience any seasonal changes (Farrant et al., 1987); this variation in responses between two temperate symbioses highlights the prevalence of symbiosis-specific differences. However, there are many examples of symbiotic cnidarians that photo-acclimate to changing irradiance environments, for example, those experienced at different depths, by adjusting chlorophyll synthesis rates and overall content. Moreover, the temperate sea anemone A. elegantissima was observed to undergo a decrease in chlorophyll content during the summer (similarly to this study), but an increase in winter (in contrast to this study)(Verde and McCloskey, 2007). These authors also report a peak in the chlorophyll $a: c_{2}$ ratio during the winter, consistent with the findings of the present study.

Both temperature and irradiance have the potential to impact cellular chlorophyll content, either through photo-acclimation, or light- or temperature-induced stress (Verde and McCloskey, 2002; Chakravarti and van Oppen, 2018; Jones et al., 2020). It is therefore possible that both of these environmental variables were interacting to produce the patterns of chlorophyll content observed in the present study. For example, during the summer, chlorophyll levels might reduce to optimize light capture while minimizing the chance of photodamage, as suggested by Verde and McCloskey 
(2007) for A. elegantissima. Alternatively, high irradiance and warm temperatures during the summer could also induce damage to photosystem II (Kemp et al., 2014), with this photosynthetic dysfunction causing a decline in chlorophyll synthesis and repair (Takahashi et al., 2008). In contrast, during the winter, it is plausible that low irradiance and temperature could induce physiological stress (Oakley and Davy, 2018) and limit the potential for chlorophyll synthesis, as results of the present study would support. However, the study of A. elegantissima reports that reduced irradiance causes an increase in pigments during the winter, with more chlorophyll being required to capture the decreased irradiance (Verde and McCloskey, 2007). Results of the present study suggest that $A$. aureoradiata may photo-acclimate to lower winter irradiance by increasing its symbiont cell density, rather than experiencing an increase in chlorophyll content.

Seawater nutrient levels and host heterotrophy (and thereby provision of nutrients to the symbionts) can also impact symbiont chlorophyll levels, as well as chloroplast size, by affecting the symbiont's nutrient status. Nutrient levels were not measured regularly enough in the current study to assess how they might interact with symbiont photosynthesis and productivity, but in a study of the temperate coral Plesiastrea versipora in Sydney Harbour, Australia, Davy et al. (2006) observed that the symbiotic dinoflagellates were nitrogen-sufficient during autumn, mildly nitrogen-deficient during the spring and winter, and most nitrogen-deficient during the summer. If such patterns are partly mirrored in Wellington Harbour, New Zealand, then they could certainly contribute to reduced chlorophyll synthesis in the summer and winter. Testing the nutrient status against seasonality for the symbionts of $A$. aureoradiata would be greatly beneficial in elucidating this trend, and provide a useful comparison with tropical cnidarian-dinoflagellate symbioses, which tend to be much more nutrient-deficient by default (Dubinsky et al., 1990; Cook et al., 1992; Falkowski et al., 1993). In fact, Davy et al. (2006) suggests that the more nutrient-replete state of temperate symbiotic algae may allow them to store nitrogen for use in times of limited environmental nutrient supply, and so contribute to the seasonal stability of the holobiont.

Along similar lines, Bergschneider and Muller-Parker (2008) noted a decline in symbiont chlorophyll content during the winter (and summer, which did not have significantly different pigment content than winter), speculating that symbionts might be meeting their metabolic needs from host-derived energy sources instead. Alternatively, temperate cnidarian hosts may engage in increased heterotrophy during the winter, as previously mentioned, in a similar manner to the increased planktonic feeding seen in tropical reef corals during bleaching events (Grottoli et al., 2018). Heterotrophic feeding often comes with the behavioral repetition of extending and 
withdrawing tentacles to capture prey; symbionts located within these tentacles will be exposed to far less and more variable light when tentacles are withdrawn into the body, which may play a role in decreased pigment content during the winter (Ferrier-Pagés et al., 2011; Haag and Dyson, 2014). While previous studies have suggested that temperate hosts rely more on heterotrophy during the winter (Gibbons, 2009; Ferrier-Pagés et al., 2011), when temperature and irradiance are characteristically suboptimal, a study of the temperate sea anemone $A$. elegantissima suggested that the presence of symbionts had no impact on host feeding behavior (Hiebert and Bingham, 2012). The extent to which $A$. aureoradiata adjusts its feeding strategy to allow for changes in its ambient environment throughout the year is an interesting topic for future research.

\subsubsection{Symbiont and host storage products: lipid and carbohydrate content}

Symbiont cell-specific lipid content was lowest in summer and highest in autumn, although these levels were not significantly different than their neighbouring seasons of spring and winter, respectively. This is contradictory to previous studies of seasonal effects on temperate cnidariandinoflagellate symbioses, in which it has been observed that lipid levels are lowest in the winter for the temperate gorgonian Eunicella singularis (Gori et al., 2012) and the tropical octocorals Pseudoplexaura crucis and Eunicea tourneforti (McCauley et al., 2018). On the other hand, Rossi (2006) reported maximum lipid contents of the temperate octocoral Paramuricea clavata in the winter, and declines in lipid content during summer and autumn months. These contrasting results suggest that seasonal patterns of lipid content could be due to a number of interacting factors. As previously discussed, symbiont cells experienced reduced protein content in both spring and summer relative to autumn and winter, so while the apparent decrease in lipid content could potentially be an artefact of decreased cell size given that lipid content was calculated per cell, adjusted calculations with lipid content normalized to symbiont protein content showed the same trend (data not shown). Alternatively, it is also possible that increased irradiance and temperature (and possible nutrient availability) during spring and summer stimulated metabolic activity and growth, causing the holobiont to draw upon its reserves more during these seasons than ather times of the year. Of particular relevance, Muller-Parker et al. (1996) used transmission electron microscopy to measure lipid stores in the symbiotic dinoflagellate of the sea anemone Exaiptasia pallida, observing that lipid accumulation was much greater when anemones were starved (regardless of ambient irradiance). These authors also measured starch (i.e. a carbohydrate) stores in response to the same nutrient/irradiance treatments, but in contrast to lipid content, starch abundance was only affected by irradiance (with more starch accumulation under high light than low light) and not feeding regime, suggesting that lipids are perhaps the primary storage product 
utilized in times of nutritional need. Interestingly, the present study showed the opposite effect on symbiont carbohydrates, with accumulation being lowest in the summer (when irradiance was high).

In the host, lipid and carbohydrate levels fluctuated greatly from month to month (carbohydrates even more so than lipids), though there were no clear seasonal effects. The only notable observations were that the highest host lipid content appears to occur during the summer (though this was not a statistically significant peak), while host carbohydrate content did significantly peak during the winter - however, this latter observation was based on too few datasets (only two winter month collections compared with three for all other seasons) to be considered reliable given the month-to-month variability observed throughout the rest of the year. In a comparable study, Rossi (2006) reported a decline in host lipid content of the temperate Mediterranean octocoral P. clavata during the summer-autumn in comparison with elevated levels in the winter-spring, suggesting that the summer decline was related to food limitation and the mobilization of stores generated during the spring. Mobilization of host stores in response to environmental change has also been reported for the A. elegantissima, which, contrary to the apparent trends in its symbiotic algae (see above), primarily catabolizes carbohydrates and stores lipids (Fitt and Pardy, 1981). If A. aureoradiata likewise prioritizes use of carbohydrates over lipids, then this could explain why carbohydrate levels fluctuated even more than lipids on a monthly scale in the present study.

The various trends in lipid and carbohydrate content seen across species and regions highlight the likely interplay between host physiology, symbiont performance, and a range of environmental variables in producing the patterns observed. Furthermore, the monthly variability seen in the current study suggests that short-term environmental change is having an almost immediate effect on storage product accumulation and utilization, though the manner in which this occurs was not clear from the temperature and irradiance data. It is likely that other variables not measured in this study, such as nutrient availability and reproductive cycles, were playing a major role. In particular, Rossi (2006) suggests that changes in lipid content can be impacted by reproductive cycle, reporting that increased lipids in $P$. clavata were correlated with spawning events; unfortunately, while $A$. aureoradiata is known to brood young which it releases from its oral cavity (L. Fracasso, personal observation), the reproductive patterns in this species were not analysed in this field study. Further investigation into the combined effects of seasonality and reproduction could provide key insights into the trends of storage product utilization in temperate cnidarian-dinoflagellate symbioses. 


\subsection{Experimental study}

It was clear that $A$. aureoradiata performed better at moderate and high temperatures than low temperature, as was evident by the rapid bleaching and decrease in size observed in anemones exposed to sustained low temperatures. However, even at moderate and high temperatures (both low and high irradiance), there was a general decrease in symbiont storage product content throughout the experiment; this was not as pronounced in the host tissues, where levels of storage products remained either relatively consistent or experienced only mild decreases. These patterns are consistent with the hypothesis that symbionts may be catabolizing their stored products for their own survival and/or releasing them to the host to support increased metabolic activity, as would be expected at elevated temperatures (Hillyer et al., 2016). In either scenario, utilization of these storage products would promote symbiosis stability. Most organisms experience physiological changes within a week or two of experiencing new conditions (Jones et al., 2020), although this study shows that physiological changes can continue to occur over several months. When considering the implications of storage product use, it would have been interesting to extend this experiment beyond the four-month period, in order to assess what happens with respect to symbiosis stability once these intracellular resources become limiting after prolonged exposure.

\subsubsection{Biomass: cell density and protein content}

As stated above, bleaching (i.e. loss of symbionts) was observed in the cold $\left(9 \pm 1^{\circ} \mathrm{C}\right)$ treatments. This was somewhat surprising, as $A$. aureoradiata regularly experiences temperatures ${ }^{\circ} 10^{\circ} \mathrm{C}$ or less in the field during the winter, especially when aerially exposed in the intertidal zone; indeed, the anemones collected during the winter months of this study experienced such conditions and did not exhibit signs of dramatic stress. While the cold-treated anemones in the experimental study did not die, the observed bleaching was a clear indicator of physiological stress of the host, symbiont, or both (Oakley and Davy, 2018). Additionally, the visual loss of host biomass indicates that the anemones were not receiving sufficient nutritional input from their symbionts, due to both the loss of symbionts and because low temperatures are shown to limit the photosynthetic potential of these particular symbiotic dinoflagellates (Gibbons, 2009; Howe, 2013). The reason for this experimental response may be due to the rate at which the ambient temperature declined for the anemones, since they were moved immediately from their pre-experimental acclimation temperature of $19^{\circ} \mathrm{C}$ to the treatment temperature of $9^{\circ} \mathrm{C}$, giving them little chance to acclimate. This dramatic decrease also caused a significant decline in photosynthetic efficiency $\left(\mathrm{F}_{\mathrm{v}} / \mathrm{F}_{\mathrm{m}}\right)$ of the symbionts within four weeks, to a value that is typically indicative of photosynthetic dysfunction $\left(F_{v} / F_{m}<0.25\right)$. Such a rapid thermal decline would not be experienced in the field, and if it were, such a low temperature would likely not persist for more than a few hours due to tidal activity. Cold-induced bleaching in 
the wild has never been documented for a temperate cnidarian-dinoflagellate symbiosis, highlighting that the response seen here is likely an experimental artefact. It is important to note, however, that both treatments with bleached anemones were maintained in the same water bath; the lack of water bath replication makes it impossible to determine whether this was due to the bath itself (although no obvious issues were observed), or a result of the temperature drop experienced by the anemones. Further study comparing the physiological response of $A$. aureoradiata to both rapid and gradual temperature changes would be valuable, as similar work in other cnidariandinoflagellate symbioses have shown the rate of temperature change have had a profound effect on stress levels (Oakley et al., 2017; Newson, 2019). In stark contrast to the observed response to cold treatment, the moderate temperature treatments caused a significant increase in symbiont density by week 16, at both low and high irradiance. Anemones in the high temperature treatments, on the other hand, maintained relatively unchanged symbiont population densities.

The response of anemones in the moderate temperature treatments suggests that this temperature is optimal (or close to it) for the symbiosis. Additionally, the stability of this symbiosis under prolonged high temperature could at first seem surprising given the vast amount of literature on thermal bleaching in corals (Gates, 1990; Brown, 1997; Fitt et al., 2001; Rob, 2004; Wagner et al., 2010; Oakley and Davy, 2018); however, it should be remembered that this treatment was based on warm summer temperatures experienced in the field, and was not intended to induce physiological stress or symbiosis dysfunction. Still, it is interesting that the symbiosis withstood four months at elevated temperatures without exhibiting any signs of instability (i.e. a decline in symbiont density). Moreover, neither low nor high irradiance caused any discernible symbiont density response in both the moderate and high temperature treatments; this is surprising, given that photo-acclimation would be expected (see earlier discussion). Along similar lines, Cornwall (2017) reported that symbiont density in A. aureoradiata was reduced in the dark compared to in the light, while light-deficiency in intertidal caves can cause A. elegantissima to bleach entirely and live without any symbionts (Secord and Muller-Parker, 2005; Bates et al., 2010). This once again suggests that the treatments used in the present study were not quite extreme enough to induce such differential responses.

Contrary to the relative stability in symbiont density observed at both moderate and high temperatures, the symbionts in these treatments (at both low and high irradiances) exhibited a drastic decrease in cell-specific protein content by week 8, which did not improve by week 16 . This could suggest physiological stress of the symbionts, and hence catabolic breakdown of proteins, 
consistent with the declines in lipid and carbohydrate content (see below). Alternatively, faster growth and proliferation at warmer temperatures may have led to an overall reduction in cell size, and hence protein content, which would be consistent with the increased symbiont density observed in the moderate temperature treatments at least (see earlier discussion of this relationship). However, the magnitude of the decline in symbiont protein content for all treatments seems somewhat unrealistic, suggesting a possible erroneous overestimate of the protein assay at the beginning of the experiment; unfortunately, the sample analysis could not be repeated due to restricted lab access during the COVID-19 lockdown. The host protein content, by contrast, increased significantly in the MTLI and HTLI treatments over the course of the experiment, while the high irradiance variants at these temperatures also increased, although not significantly, and neither temperature appeared to have a greater impact on host protein content than the other. Only the low temperature-treated anemones failed to grow, and anemones in the LTHI treatment even appeared to shrink in size. A study implementing similar seasonally-based experimental treatments on tropical octocoral-dinoflagellate symbioses by McCauley et al. (2018) reported that protein content did not differ significantly with changes in temperature and UV radiation, with only species-specific differences having an effect. However, it should be noted that the temperatures used in that study only differed by $3^{\circ} \mathrm{C}$ and effects were monitored for seven days, whereas the temperature range in the present study was far greater and lasted for a significantly longer time, likely exacerbating the effects. The slight differences between light treatments observed in the present study (which were not apparent when treatments were compared within each time point) can potentially be related to symbiont performance, as it may be that the higher irradiance caused a degree of photo-inhibition in the symbionts and so less photosynthate was being translocated to support the host (Hillyer et al., 2016). This was not indicated by the PAM fluorometry data, though, with both low and high irradiance treatments showing very little difference in photosynthetic efficiency (although other subtle physiological effects of the various treatments cannot be ruled out).

\subsubsection{Photophysiology: photosynthetic efficiency and chlorophyll content}

Photosynthetic efficiency $\left(\mathrm{F}_{\mathrm{v}} / \mathrm{F}_{\mathrm{m}}\right)$ of the in hospite symbionts at both moderate and high temperatures was comparable to values previously reported for A. aureoradiata (Bock, 2008; Howe, 2013) as well as numerous other symbiotic cnidarians (Dubinsky et al., 1990). This stability suggests that these anemones were not experiencing significant photo-stress at either irradiance variant of both moderate and high temperatures. This was in marked contrast to the cold-treated anemones, which showed evident signs of photosynthetic dysfunction by four weeks. Howe (2013) 
similarly reported a decline in photosynthetic efficiency at low temperatures in A. aureoradiata, though she also noted a decline at high irradiance, unlike the present study where irradiance had no obvious effect (except in the low temperature treatment, where anemones under low irradiance exhibited the strongest signs of photosynthetic dysfunction). The present study concludes that photosynthetic efficiency was similar among anemones in all treatments, regardless of temperature or irradiance, with the exception of the bleached anemones in the low temperature treatments.

The overall content of chlorophylls $a$ and $c_{2}$ exhibited considerably more between-treatment variation than any other symbiont cellular product measured. Chlorophyll content appeared elevated under higher temperatures, and, in particular, the content of both chlorophylls $a$ and $c_{2}$ was significantly higher in the HTLI treatment than all other treatments. Given that high, stressful temperatures can induce bleaching and loss of cellular chlorophyll in symbiotic cnidarians (Weis, 2008; Oakley and Davy, 2018), this increase in chlorophyll at high temperature in the present study is perhaps surprising. However, it is important to note that the high temperature used in this experiment induce no signs of photo-physiological stress (e.g. $\left.F_{v} / F_{m}\right)$ in the anemones, so loss of chlorophyll was unexpected; in fact, elevated temperature may have even aided chlorophyll synthesis. This, combined with reduced light stress in the low-irradiance treatment, could have contributed to the dramatic increase in both chlorophylls $a$ and $c_{2}$ in the HTLI treatment. However, detailed analysis of chlorophyll synthesis and repair under these treatments would be necessary to confirm the underlying mechanisms (Robison and Warner, 2006). Interestingly, despite the increases in both chlorophyll types, the chlorophyll $a: c_{2}$ ratio for the HTLI treatment was significantly lower than all other treatments at each time point. The reasons for this are unclear, as are the functional implications, though the two chlorophylls do have slightly different absorption maxima (420 and $660 \mathrm{~nm}$ for chlorophyll $a$; 445 and 625 for chlorophyll $c_{2}$; (Hall and Rao, 1999)), so there would likely be minor differences in light harvesting. Indeed, changes to the ratio of chlorophyll pigments is typically associated with photo-acclimatization (Titlyanov and Shaposhnikova, 1980; Helmuth et al., 1997; Apprill et al., 2007).

It is worth noting that the anemones maintained in the laboratory and then used for the experimental study all contained twice as much cell-specific chlorophyll content as the anemones that were collected in the field. This is possibly because these anemones were maintained under conditions of artificial lighting, which could never match the intensity of the sunlight received by anemones in the field, causing them to photo-acclimate to the reduced irradiance. 


\subsubsection{Symbiont and host storage products: lipid and carbohydrate content}

All of the treatments induced a marked decline in both symbiont and host lipid content over the sixteen-week experiment, suggesting the mobilization of these resources to support metabolism and growth. This was especially pronounced in the symbionts, which saw a large decline in lipid content by week eight, whereas a decline in the host lipid content was not apparent until week sixteen. Lipids are widely regarded as one of the primary storage products for Symbiodiniaceae (Rossi et al., 2006) and cnidarians (Shick, 2012), so increased metabolism would be expected to influence their abundance. The decline in lipid content of both partners during the experiment, even at moderate temperature and low irradiance, was unexpected, but it could suggest that a more regular feeding regime was needed to support the metabolic activity of the symbiosis than was provided during the experiment. Alternatively (or perhaps in addition to this), it could be that these laboratory treatments caused elevated respiratory activity in both partners, necessitating the use of internal stores to maintain the symbiosis; increased respiration is a typical response to stress by organisms, including symbiotic cnidarians (Starzak et al., 2014), and the experimental conditions in addition to weekly jar cleanings did potentially induce some stress. Measurement of respiration rate would help to address this knowledge gap, as would testing with a range of different feeding regimes.

Despite the decline in lipid content over the course of the experiment, there was no significant difference between any of the treatments, in either symbiont or host, at each sampling time point. I expected to see greater lipid utilization at higher temperatures due to elevated respiration, but this was not apparent. Similarly, I expected lipid levels in the high irradiance treatments to be greater than those under low irradiance, due to symbiont photosynthesis being a primary source of lipids for both partners (Hillyer et al., 2016; Matthews, 2017). Consistent with this latter finding, Cornwall (2017) reported that light did not have an effect on the lipid stores of A. aureoradiata; rather, the biggest difference was apparent in the cold-treated anemones under high irradiance, in which the host tissues suffered no decline in lipid content. However, this pattern was almost certainly because of the large decline in the biomass/protein content of these anemones, so that the lipid content per unit host protein increased, rather than less use of the stores to support host metabolism.

The symbiont carbohydrate content also decreased steadily over the course of the experiment, although the decrease in the MTLI treatment was not statistically significant. In contrast, host carbohydrate content remained relatively stable, with the exception of the LTHI and MTHI 
treatments, whose carbohydrate levels significantly increased and decreased, respectively, by week sixteen. The decline in symbiont carbohydrates is likely due to the same reasons suggested above for lipid decline, with the lack of an irradiance effect being, again, somewhat surprising. The general consistency of the hosts' carbohydrate stores did not mirror the pattern observed with respect to lipids, however, supporting the suggestion that lipids are the primary energy source of cnidarians (Shick, 2012), with lipids being catabolized in the first instance to support increased metabolic activity or nutritional shortages. By contrast, the significant decrease in carbohydrate content in the MTHI treatment seems anomalous and inconsistent with the other trends seen. The large increase in the LTHI treatment, however, once again may result from the shrinkage of the anemones in this treatment (i.e. reduced protein content), causing an increased carbohydrate content per unit protein, rather than an increase in carbohydrate synthesis or storage.

\subsection{Ecological implications}

Current global trends suggest that greater fluctuations will occur more frequently as climate change continues to wreak havoc on the stability of environmental conditions in certain regions (IPCC, 2014; Bindoff, 2019). Climate change is particularly relevant to the cnidarian-dinoflagellate symbiosis in the context of coral reefs, which support not only aquatic but also terrestrial (including human) populations. Excess atmospheric heat caused by increased $\mathrm{CO}_{2}$ emissions is eventually retained by the ocean, causing sea surface temperatures to rise to suboptimal and sometimes lethal temperatures for ocean inhabitants (Hoegh-Guldberg et al., 2007; Hughes et al., 2017). Tropical cnidarian-dinoflagellate symbioses are particularly sensitive to prolonged temperature increases, as they already inhabit regions where the average temperature is at the high end of their optimal range (Hoogenboom et al., 2012), and are suffering from increasingly frequent bleaching events as a result (Iglesias-Prieto et al., 1992; Brown, 1997; HoeghGuldberg and Jones, 1999; Hughes et al., 2003). This bleaching not only has direct consequences for mature coral growth, calcification, and survival, but also has deleterious effects on reproductive output and larval distribution, settlement, and development, so reducing the likelihood of ecosystem recovery (McCauley et al., 2018; Fisch et al., 2019; Hughes et al., 2019). It is predicted that global temperatures will continue to increase, exposing cnidarian-dinoflagellate symbioses around the world to conditions that will frequently exceed their tolerance limits, with mass loss of reefs predicted to occur by the end of this century (HoeghGuldberg et al., 2007; Pandolfi et al., 2011; Frieler et al., 2013). Therefore, it is imperative to gain a comprehensive and more detailed knowledge of the stability of both tropical and temperate cnidariandinoflagellate symbioses in order to mitigate the potential damage caused by inevitable climate change. 
The present study aimed to shed light on the cellular mechanisms responsible for the relative stability of temperate cnidarian-dinoflagellate symbionts, compared with their more sensitive tropical counterparts. In particular, the utilization of cellular energy storage products, such as lipids and carbohydrates, to support symbiosis stability under different temperature and irradiance conditions was investigated. I observed considerable seasonal symbiosis stability in the field, despite regular fluctuations in both symbiont and host storage product contents, while my experimental study suggested a partial role for storage product utilization in maintaining this stability even under relatively consistent elevated temperature. $A$. aureoradiata and its symbionts therefore seem well-adapted for dealing with projected climate change scenarios in New Zealand (Environment, 2018), consistent with previous studies of thermal tolerance in this sea anemone (Gibbons, 2009; Howe, 2013). A. aureoradiata did respond negatively to rapid exposure to low temperature (evident in bleaching and loss of host tissue) and persistent elevated temperature (evident in excessive use of lipid reserves by both symbionts and host) in my experiment, suggesting stress or at least increased metabolic activity, but these scenarios are unlikely to occur in the field, even with global climate change scenarios. In particular, temperate regions are characterized by considerable environmental variability, for example with respect to temperature, irradiance, and nutrient supply (MullerParker and Davy, 2001), so in the field, potentially low or high temperatures are likely to be moderated by regular fluctuations, as well as tidal activity in intertidal regions such as the field site used in the present study. In order to better understand how temperate symbioses might respond to climate change, it is crucial that we develop an understanding of the range of conditions that these symbioses are exposed to in the field, how these conditions may change over time, and how the range of environmental conditions already experienced might prepare temperate cnidarian-dinoflagellate symbioses for future climate scenarios. In fact, there is evidence that higher-latitude (both subtropical and warm-temperate) marine species populations are tolerant of a greater temperature range than populations of their tropical conspecifics (Conover et al., 2009; Gardiner et al., 2010). This likely results from phenotypic plasticity due to acclimatization or adaptation to more variable environmental conditions (Beger et al., 2014). High-latitude coral reefs are considered as possible refugia for corals under threat from climate change ((Beger et al., 2014; Camp et al., 2018), and other temperate cnidarian-dinoflagellate symbioses could also have a part to play in conservation efforts, so understanding their responses to our changing climate is imperative.

\subsection{Concluding remarks and future recommendations}

This thesis has provided much-needed information about the cellular biology underlying the remarkable stability of temperate cnidarian-dinoflagellate symbioses, by shedding light on the fate of commonlyutilized cellular energy storage products with respect to changes in environmental temperature and irradiance. My thesis confirmed the considerable stability of A. aureoradiata in the field, but also 
demonstrated a relationship between temperature (and secondarily irradiance) in the use of energy-rich storage products under experimental manipulation, thereby supporting (at least, in part) my original hypotheses. In particular, there was evidence that carbohydrates and lipids are catabolized to support the symbiosis in times of resource limitation or stressful conditions; however, further investigation is required to build a more comprehensive picture of the mechanisms that underlie the environmental tolerance of temperate cnidarian-dinoflagellate symbioses. For example, the applications of 'omics' technologies, such as transcriptomics, proteomics, and especially metabolomics, would allow us to decipher the biochemical changes that occur with environmental changes, whether in response to diel and seasonal weather patterns or global warming; such technologies have been used with tropical corals and other symbiotic cnidarians already (Hillyer et al., 2016; Matthews, 2017; Oakley et al., 2017; Matthews et al., 2018). Of particular value could be ${ }^{13} \mathrm{C}$-stable isotope studies, which allow for the tracking of photosynthetically-generated metabolites in the symbiont and host, and the metabolite fluxes between the two partners (Hillyer et al., 2017; Matthews et al., 2018). Such studies can be combined with other physiological measures, such as respiration $(\mathrm{R})$, photosynthetic rate $(\mathrm{P})$, and estimates of $\mathrm{P}: \mathrm{R}$ (a proxy for autotrophic potential of the symbiosis) (Davy et al., 1996; Starzak et al., 2014); these measures can inform interpretations of metabolic pathway shifts in response to environmental change.

A more detailed understanding of host life-history, and especially reproductive cycles, will also aid with interpretation of lipid and carbohydrate utilization, as will more frequent and consistent sampling of seawater nutrient levels and food availability; in the current study, nutrient levels were sampled too infrequently to be informative. It is also important to take into account the potential diversity of symbionts, as there is emerging evidence that $A$. aureoradiata hosts two different (yet closely related) species of dinoflagellate endosymbionts endemic to New Zealand (Philozoon gen. nov.; LaJeunesse, in submission). How this might have impacted my research is unknown, but assessing the influence of this genotypic diversity, and the potential for associated physiological diversity in terms of environmental resilience, would be an interesting topic for future studies. It cannot be denied that considerable progress has been made in terms of understanding the mechanisms of symbiosis stability in both tropical and temperate regions, but as Muller-Parker and Davy (2001) so aptly stated, there is still a lot to be learned. In particular, we still have much to learn about the cellular physiology of temperate hosts and symbionts, and the hostsymbiont communication and integration that enables a persistent symbiosis (Davy et al., 2012), before we can truly understand how these high latitude associations remain so resilient.

In addition, both current and potential responses to environmental variability and climate change need to be better understood. Longer-term studies that mimic environmental conditions at the present and under 
future scenarios would better allow for modelling the fate of high-latitude symbiotic associations. For example, in some North American Anthopleura species, some physiological responses of the symbiosis to environmental change are not apparent for days or even months (Saunders and Muller-Parker, 1997; Secord and Muller-Parker, 2005; Dimond et al., 2011). There are a few studies on the impact of environmental variability in corals and other symbiotic cnidarians, but comparison of the thermal resilience of $A$. aureoradiata across its full latitudinal range (spanning from subtropical northern New Zealand to the southern Stewart Island), and in response to predicted climate change scenarios, would be an interesting topic for the future. Likewise, other symbiotic cnidarians such as the North American A. elegantissima, which can be found from Alaska to Baja California (Muller-Parker and Davy, 2001) or the coral $P$. versipora (Rodriguez-Lanetty and Hoegh-Guldberg, 2002; Davy et al., 2006), which is found from the Coral Triangle to the coast of southern Australia (Victoria), could prove as valuable model species in this regard. Such information will ultimately aid in developing a better understanding of how temperate cnidarian-dinoflagellate symbioses survive in the present, whether they will persist into the future, and if so, what they can tell us about the potential of high latitude symbiotic cnidarians and their associated ecosystems to act as refugia at a time when the world's coral reefs are in massive jeopardy. 


\section{Appendices}

\section{Appendix 1. Method Optimization}

\section{A1.1. Sucrose gradient symbiont isolation}

It was hard to obtain a pellet free of debris, as Anthopleura aureoradiata host tissue is particularly gelatinous and adherent to symbiont cells, so a sucrose gradient method of isolation (Chen et al., 2015) was attempted to obtain cleaner symbiont pellets. Anemone homogenate was spun down in a centrifuge set to $4^{\circ} \mathrm{C}$ at $500 \mathrm{x}$ g for 5 minutes; the resulting supernatant was transferred to a new host tube. Four sucrose concentration aliquots were developed $(0 \%, 25 \%, 40 \%$, and $50 \%$ v:v), and $200 \mu \mathrm{L}$ of each were pipetted into a clean tube, creating a density gradient with the $50 \%$ solution added first and the $0 \%$ solution added last. The remaining homogenate was re-suspended in 200 $\mu \mathrm{L}$ FSW, and pipetted carefully into the top layer of the sucrose gradient. The tubes containing the symbionts and sucrose gradients were once again spun down in a centrifuge set to $4^{\circ} \mathrm{C}$ at $10,000 \mathrm{x}$ $\mathrm{g}$ for 5 minutes. Symbiodiniaceae cells formed a layer at the interfaces between the $25-40 \%$ and $40-50 \%$ sucrose concentrations; these were carefully pipetted out and transferred into a new tube. Each new symbiont-containing tube was then washed twice, consisting of $4^{\circ} \mathrm{C}$ centrifugation at 500 $\mathrm{x} g$ for 5 minutes and the addition/discard of $500 \mu \mathrm{L}$ FSW. The final symbiont pellet was suspended in $1000 \mu \mathrm{L} \mathrm{FSW}$, and pipetted onto a haemocytometer to determine cell density and assess for the presence of host debris. Both the sucrose gradient and the standard method of fractionation yielded similar results with respect to symbiont cell counts, and the sucrose gradient protocol did not result in a significantly cleaner pellet than standard isolation (Figure A1.1). Since the sucrose gradient protocol was more time-consuming, it was not pursued further and the standard isolation method of repeated centrifugation and washes was used for both field and experimental samples.
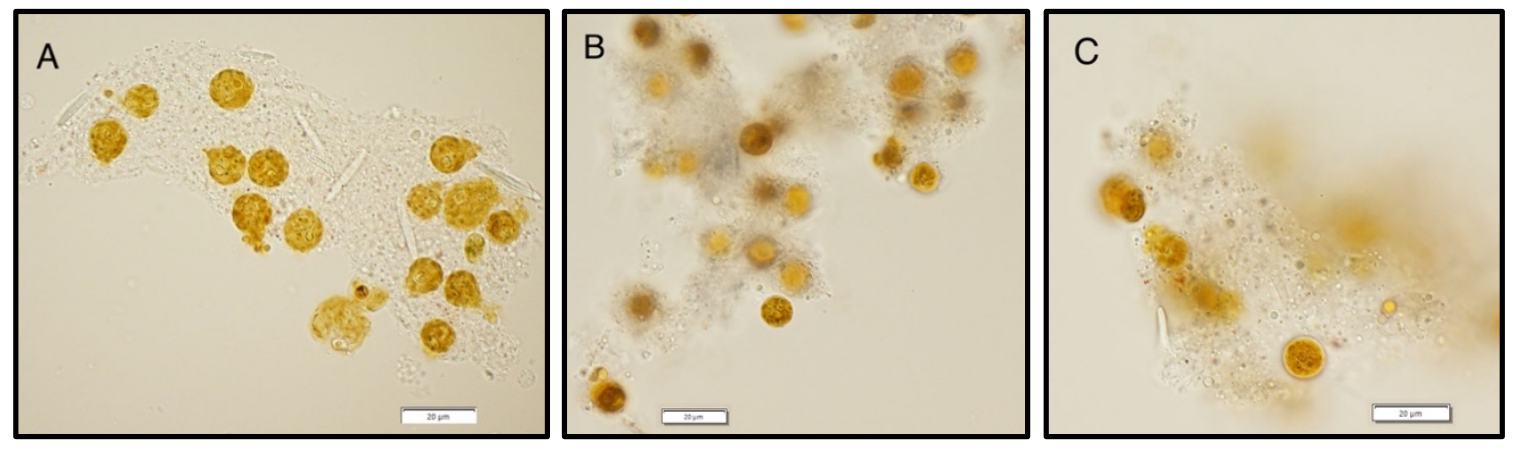

Figure A1.1: Comparison of symbiont isolation methods in the sea anemone Anthopleura aureoradiata.

(A) Symbionts isolated using standard centrifugation and washing method; (B-C) Photo of symbionts isolated using the sucrose gradient method, Photographs taken on a photomicroscope, magnification 40x. 


\section{A1.2. Lipid assay parameter optimization and standard development}

The original intention for the measurement of lipid content was to develop a colorimetric assay in which fluorescence of the samples stained by Nile Red lipophilic dye could be compared against a standard curve of known lipid content (Greenspan et al., 1985). The following section details the optimization steps taken in the development of this method. Unfortunately a protocol for standard comparison could not be optimized in the time frame of this study, due to the inability to get a standard lipid solution to fluoresce consistently in the correct emission range. The following optimization steps were performed, and while some results seemed promising, they could not be reproduced consistently.

Sample preparation | Anemones were homogenized and symbiont cells were isolated from host material, as described in Chapter 2, Section 2.4.1. The chlorophyll pigments were then extracted from symbiont samples, as described in Chapter 2, Section 2.4.3.1. (centrifuge at 2,000 x g for 5 minutes, discard supernatant, add $1 \mathrm{~mL}$ of ice cold ethanol, vortex, incubate under bright light $>100 \mu \mathrm{mol}$ photons $\mathrm{m}^{-2} \mathrm{~s}^{-1}$ for at least one hour to extract cell pigments, vortex, twice repeated wash), and the samples were washed with $3 x P B S$ to remove trace ethanol and pigments from samples.

Stain preparation | A $1,000 \mu \mathrm{g} / \mathrm{mL}$ stock of Nile Red stain (Sigma Aldrich, NZ) in 100\% DMSO was prepared in a dark fume hood and stored at $4^{\circ} \mathrm{C}$, wrapped in foil to prevent degradation of the stain by ambient light. This stock solution was aliquoted and diluted to a working concentration of $100 \mu \mathrm{g} / \mathrm{mL}$ in $100 \%$ DMSO prior to each use.

Lipid standard preparation | A 10,000 $\mu \mathrm{g} / \mathrm{mL}$ stock of Triolein oil (Sigma Aldrich, NZ) in isopropanol was prepared and stored at $-20^{\circ} \mathrm{C}$. This stock solution was aliquoted and diluted to a working concentration of $1,000 \mu \mathrm{g} / \mathrm{mL}$ in isopropanol prior to each use.

Optimization - Spectrophotometric parameters | The spectrophotometric parameters were optimized by developing a matrix of stepwise increases in both sample and stain concentrations to be spectrophotometrically analysed at several different excitation wavelengths; the optimal combination of the aforementioned variables would present as a distinct peak between $575-585 \mathrm{~nm}$, the emission range characteristic of neutral lipids for dinoflagellates (Bertozzini et al., 2011). Initial parameters were set without samples, using just blank medium (either FSW or 3xPBS) with stain and a lipid standard, and then all optimizations were repeated with samples replacing the blank medium. Each well 
contained $234 \mu \mathrm{L}$ of medium and $6 \mu \mathrm{L}$ of either DMSO (as a blank) or Nile Red (final concentration of $0-2 \mu \mathrm{g} / \mathrm{ml}$ ), to which $60 \mu \mathrm{L}$ of lipid standard (or isopropanol, as a blank) were added (final concentrations: $0,2.5,5,10,20 \mu \mathrm{g} / \mathrm{mL}$ ). The contents of each well were aspirated with a pipette to ensure proper mixing of all contents, and then the plate was incubated in the dark at $40^{\circ} \mathrm{C}$ for ten minutes. The plate was then inserted into a spectrophotometer (Perkin Elmer Enspire 2300 multi-label microplate reader) and a continuous emission scan was performed for the excitation wavelengths of $528 \mathrm{~nm}$ (Rosset et al., 2017) and $530 \mathrm{~nm}$ (Dagenais Bellefeuille et al., 2014), with an emission range of 550-700 nm (Chen et al., 2009; Bertozzini et al., 2011; Kou et al., 2013; Rosset et al., 2017). It was determined that an excitation wavelength of $530 \mathrm{~nm}$ with an emission of 580 $\mathrm{nm}$ was the most appropriate.

Optimization - DMSO concentration | DMSO acts to help the Nile Red stain permeate the cell well (Chen et al., 2009; Kou et al., 2013), but the concentration required for this varies between species. The optimal DMSO concentration was determined by performing repeated assays with a stepwise increase in the amount of DMSO per well ranging from 2.5 to $40 \%$ (Kou et al. 2013; Rosset et al. 2017). The optimal DMSO concentration was determined to be $5 \%$.

Optimization - Nile Red concentration | Insufficient Nile Red staining results in either no fluorescence, or presents as a peak corresponding only to chlorophyll pigment fluorescence, which has been reported to skew the emission peak away from that of neutral lipid bodies (Bertozzini et al., 2011). The optimal Nile Red stain concentration was determined by performing repeated assays with a stepwise increase in Nile Red concentration from 0.5 to $10 \mu \mathrm{g} / \mathrm{mL}$. It was determined that $2.5 \mu \mathrm{g} / \mathrm{mL}$ was the optimal stain concentration.

Optimization - Linearity | The linear relationship between cell density and fluorescence at different concentrations of Nile Red was attempted. Cell density ranged from $2.5 \times 10^{5}$ to $1 \times 10^{6}$ cells $/ \mathrm{ml}$, and Nile Red stain concentrations ranged from 0.5 to $4 \mathrm{ug} / \mathrm{mL}$ of stain. A blank and an unstained sample for each concentration were run as well, so that relative fluorescence intensity of each well could be calculated.

Optimization - Comparison standard equivalents | Both a standard curve and a standard addition curve were attempted, but neither were consistently successful (and in fact, 
standard addition of Triolein to samples effectively decreased their emission peaks, rather than making them more prominent as was described per Bertozzini et al. (2011).

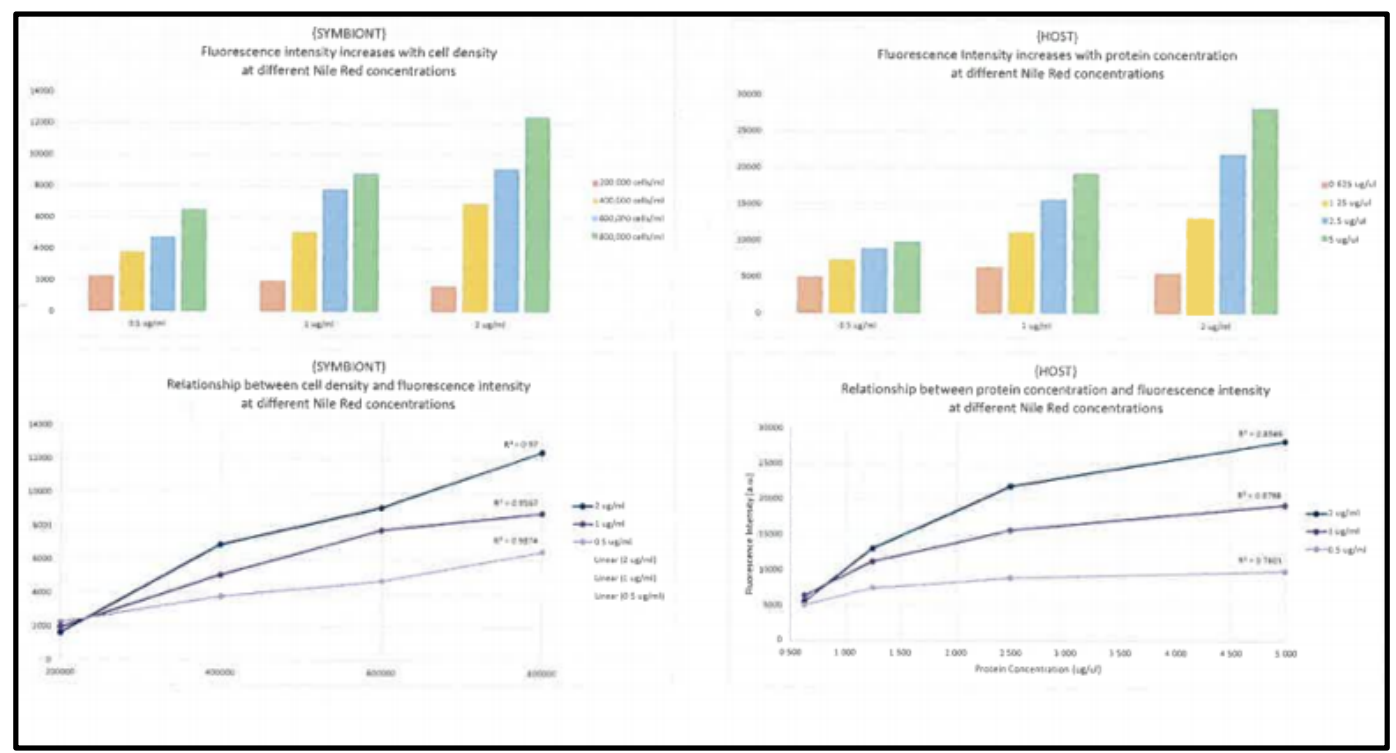

Figure A1.2: Nile Red lipid assay linearity optimization. Both symbiont and host fractions were assessed for linearity in fluorescence yields with varying sample dilutions and stain concentrations.

\section{A1.3. Starch granule staining}

Several studies have developed assays using hydrolysis extraction methods or commercial amylases to spectrophotometrically measure starch content in microalgae such as Chlorella sorokiniana (Souza et al., 2019), the dinoflagellate Lingulodinium polyedrum (Dagenais Bellefeuille et al., 2014) and Symbiodiniaceae spp. (Cornwall, 2017); however, the present study had insufficient biomass for such protocols so a simple staining method was attempted.

Lugol's Iodine has be used to indicate the presence of starch in the microalgae Chlamydomonas spp. (Toyoshima and Sato, 2015; Gifuni et al., 2017) and Parachlorella kessleri (Takeshita et al., 2015), by interacting with polysaccharides, staining them dark blue/violet. These protocols were adapted in an attempt to stain starch bodies in the microalgae used in this study, Symbiodiniaceae. Anemones were homogenized, and symbiont cells were isolated from host material, as described in Chapter 2, Section 2.4.1. Chlorophyll pigments were extracted from the symbiont fractions (Souza et al. 2019) as described in Chapter 2, Section 2.4.3.1. To the now pigment-free pellet of cells, 5-20 $\mu \mathrm{L}$ of Lugol's Iodine stain (Takeshita et al. 2015) were added, and the volume was topped up with medium to a final volume of $1 \mathrm{~mL}$. This solution was then vortexed and incubated (covered in foil to keep dark) at $4^{\circ} \mathrm{C}$ for 18 hours. Samples then underwent a series of washes, 
repeated until the supernatant was clear of dye (usually 2-3 repeats), which consisted of being centrifuged at 10,000 $\mathrm{x}$ g for 4 minutes, discarding the supernatant, and adding $1 \mathrm{~mL}$ of the same medium used when the stain was added (FSW/1xPBS/3xPBS). After sufficiently being washed of excess stain, samples were placed onto glass slides using a glass micropipette and viewed under a photomicroscope at 60-100x.

Optimization - Medium | FSW, 1xPBS, and 3xPBS were all tested as the medium which was added to the pigment-free symbiont cell pellet in an attempt to minimize cell lysing; none yielded any significantly different stain results from one another.

Optimization - Stain concentration | The Lugol's Iodine stain that was used in this project was of an unknown initial concentration (as it was handed down through the lab and the label had deteriorated); however, a stepwise gradient of stain volume to total volume ratio ( $5-20 \mu \mathrm{L}$ stain in $1000 \mu \mathrm{L}$ cell pellet and medium solution) was tested to determine whether an optimal relative concentration could be developed.

Optimization - Incubation temperature | Following the staining of the symbiont cell pellet, samples were either incubated at $4^{\circ} \mathrm{C}$ for $12-18$ hours, or at $90^{\circ} \mathrm{C}$ for $10-20$ minutes to see if either had a pronounced effect on the ability of the stain to penetrate the cell and adequately stain starch bodies.

Unfortunately, the results of this stain were too inconsistent to yield reliable measurements with reproducibility. Some cells appeared to be successfully stained; however, most cells lysed during the protocol, and were either not stained at all or too heavily stained for accurate measurement. Time constraints prevented the further optimization of this method for use in the present study.
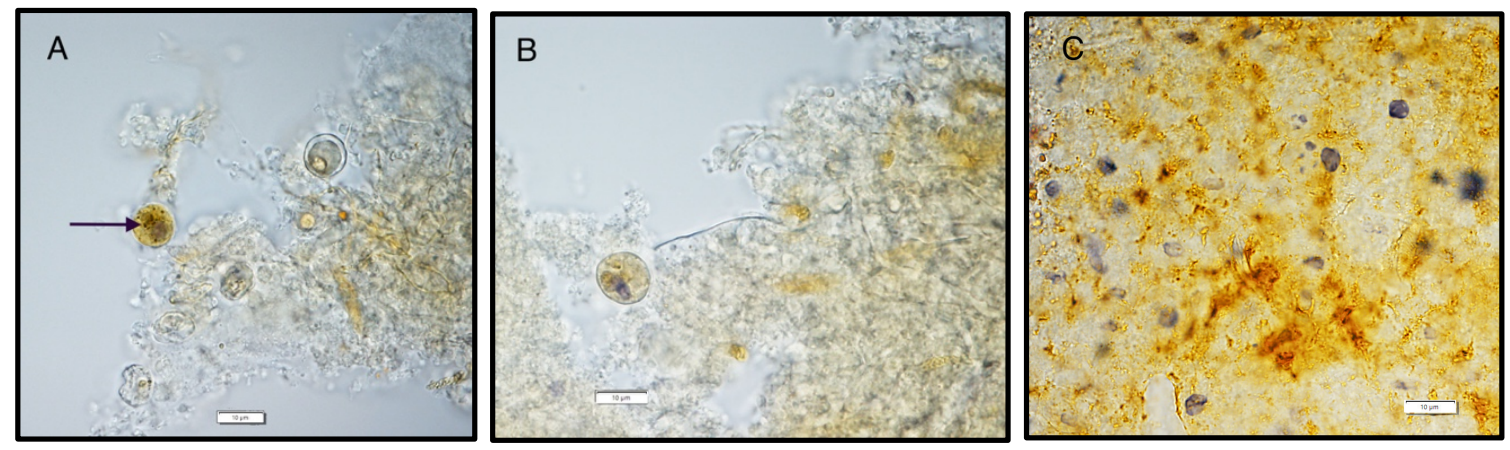

Figure A1.3: Attempts to identify starch bodies using Lugol's Iodine stain in the dinoflagellate Symbiodiniaceae. (A) Cell successfully stained, showing distinct dark bodies within an intact cell. (B) unsuccessful stain, cells lysed and only one stain detected, and (C) Unsuccessful stain, sample overstained. 


\section{Appendix 2. Statistical analyses}

\section{A2.1. Field Study - Environmental variable analysis}

Table A2.1: Statistical analyses of environmental variables for the field study site: Wellington Harbour, New Zealand. All environmental variables were tested against time factors: (A) month, and (B) season. All test statistics have been adjusted for ties, and all significance values have been adjusted for by the Bonferroni correction for multiple tests. Significance level is 0.05 .

\begin{tabular}{|c|c|c|c|c|}
\hline $\mathbf{A}$ & Response Variable & Test & Test Statistic & P-value \\
\hline \multirow{3}{*}{ 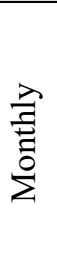 } & Irradiance & $\begin{array}{l}\text { Independent-Sample Kruskal- } \\
\text { Wallis }\end{array}$ & 83.000 & $<0.0001$ \\
\hline & Air Temperature & $\begin{array}{l}\text { Independent-Sample Kruskal- } \\
\text { Wallis }\end{array}$ & 83.000 & $<0.0001$ \\
\hline & Water Temperature & $\begin{array}{l}\text { Independent-Sample Kruskal- } \\
\text { Wallis }\end{array}$ & 83.000 & $<0.0001$ \\
\hline B & Response Variable & Test & Test Statistic & P-value \\
\hline \multirow{3}{*}{ 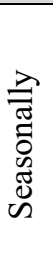 } & Irradiance & $\begin{array}{l}\text { Independent-Sample Kruskal- } \\
\text { Wallis }\end{array}$ & 67.891 & $<0.0001$ \\
\hline & Air Temperature & $\begin{array}{c}\text { Independent-Sample Kruskal- } \\
\text { Wallis }\end{array}$ & 64.313 & $<0.0001$ \\
\hline & Water Temperature & $\begin{array}{l}\text { Independent-Sample Kruskal- } \\
\text { Wallis }\end{array}$ & 70.640 & $<0.0001$ \\
\hline
\end{tabular}




\section{A2.2. Field Study - Physiological response variable analyses}

Table A2.2: Statistical analyses of physiological response variables for the sea anemone Anthopleura aureoradiata and its Symbiodiniaceae collected from the field. All response variables were tested against time factors: (A) month, and (B) season. Significance level is 0.05 .

\begin{tabular}{|c|c|c|c|c|}
\hline $\mathbf{A}$ & Response Variable & Test & Test Statistic ${ }^{a}$ & P-value ${ }^{b}$ \\
\hline \multirow{6}{*}{ 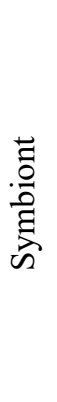 } & Cell density & Welch ANOVA ( $\log _{10}$ data) & 5.051 & $<0.0001$ \\
\hline & Protein content & Kruskal-Wallis & $41.938^{\mathrm{a}}$ & $<0.0001^{\mathrm{b}}$ \\
\hline & Lipid content & One-way ANOVA ( $\log _{10}$ data) & 14.151 & $<0.0001$ \\
\hline & Carbohydrate content & Welch ANOVA & 79.496 & $<0.0001$ \\
\hline & Chlorophyll $a$ content & Welch ANOVA & 9.466 & $<0.0001$ \\
\hline & Chlorophyll $c_{2}$ content & One-way ANOVA & 11.852 & $<0.0001$ \\
\hline \multirow{2}{*}{$\begin{array}{l}\overrightarrow{0} \\
\stackrel{0}{0}\end{array}$} & Lipid content & Welch ANOVA (log 10 data) & 9.939 & $<0.0001$ \\
\hline & Carbohydrate content & Welch ANOVA ( $\log _{10}$ data) & 30.467 & $<0.0001$ \\
\hline B & Response Variable & Test & Test Statistic ${ }^{a}$ & P-value ${ }^{b}$ \\
\hline \multirow{6}{*}{ 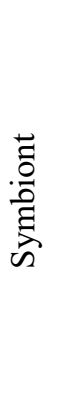 } & Cell density & One-way ANOVA ( $\log _{10}$ data) & 4.457 & 0.006 \\
\hline & Protein content & One-way ANOVA & 18.845 & $<0.0001$ \\
\hline & Lipid content & Welch ANOVA ( $\log _{10}$ data) & 9.546 & $<0.0001$ \\
\hline & Carbohydrate content & Welch ANOVA ( $\log _{10}$ data) & 10.336 & $<0.0001$ \\
\hline & Chlorophyll $a$ content & One-way ANOVA & 8.587 & $<0.0001$ \\
\hline & Chlorophyll $c_{2}$ content & One-way ANOVA & 7.550 & $<0.0001$ \\
\hline \multirow{2}{*}{$\stackrel{\overrightarrow{0}}{\stackrel{0}{I}}$} & Lipid content & Welch ANOVA ( $\log _{10}$ data) & 0.941 & 0.430 \\
\hline & Carbohydrate content & One-way ANOVA ( $\log _{10}$ data) & 4.677 & 0.005 \\
\hline
\end{tabular}

${ }^{a}=$ Test statistic has been adjusted for ties

$\mathrm{b}=$ Significance value has been adjusted by the Bonferroni correction for multiple tests. 


\section{A2.3. Experimental study - Physiological response variable analyses}

Table A2.3: Statistical analyses of physiological response variables for the sea anemone Anthopleura aureoradiata and its Symbiodiniaceae maintained under experimental conditions. All response variables were tested against a combined factor including both time and treatment. Significance level is 0.05 .

\begin{tabular}{|c|c|c|c|c|}
\hline & Response Variable & Test & Test Statistic ${ }^{\mathrm{a}}$ & P-value ${ }^{b}$ \\
\hline \multirow{7}{*}{ 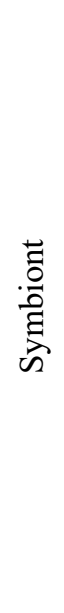 } & Cell density & Welch ANOVA & 16.742 & $<0.0001$ \\
\hline & Protein content & $\begin{array}{l}\text { Welch ANOVA } \\
\left(\log _{10} \text { data) }\right)\end{array}$ & 75.311 & $<0.0001$ \\
\hline & Lipid content & Kruskal-Wallis & $71.994^{\mathrm{a}}$ & $<0.0001^{\mathrm{b}}$ \\
\hline & Carbohydrate content & Kruskal-Wallis & $71.189^{\mathrm{a}}$ & $<0.0001^{\mathrm{b}}$ \\
\hline & Chlorophyll $a$ content & $\begin{array}{l}\text { Welch ANOVA } \\
\text { (log } \log _{10} \text { data) }\end{array}$ & 47.758 & $<0.0001$ \\
\hline & Chlorophyll $c_{2}$ content & $\begin{array}{c}\text { One-way ANOVA } \\
\left(\log _{10} \text { data }\right)\end{array}$ & 37.853 & $<0.0001$ \\
\hline & Chlorophyll $a: c_{2}$ ratio & $\begin{array}{l}\text { Welch ANOVA } \\
\text { ( } \log _{10} \text { data) }\end{array}$ & 23.143 & $<0.0001$ \\
\hline \multirow{3}{*}{$\begin{array}{l}\vec{w} \\
\overrightarrow{1}\end{array}$} & Protein content & $\begin{array}{l}\text { Kruskal-Wallis } \\
\left(\log _{10} \text { data }\right)\end{array}$ & $104.711^{\mathrm{a}}$ & $<0.0001^{\mathrm{b}}$ \\
\hline & Lipid content & $\begin{array}{l}\text { Welch ANOVA } \\
\left(\log _{10} \text { data }\right)\end{array}$ & 76.690 & $<0.0001$ \\
\hline & Carbohydrate content & $\begin{array}{c}\text { One-way ANOVA } \\
\left(\log _{10} \text { data }\right)\end{array}$ & 18.346 & $<0.0001$ \\
\hline
\end{tabular}

${ }^{\mathrm{a}}=$ Test statistic has been adjusted for ties

$\mathrm{b}=$ Significance value has been adjusted by the Bonferroni correction for multiple tests. 


\section{Appendix 3. Supplemental results}

\section{A3.1. Field study}

\section{A3.1.1. Environmental conditions: Temperature and irradiance}

As one might expect, the seasonal averages for water temperature, air temperature, and solar irradiance were highest in the summer and lowest in the winter, with averages during spring and autumn being similarly moderate (Figure A3.1.1). Irradiance was significantly higher in summer than all other seasons, while autumn and winter exhibited statistically similar low irradiances $(\mathrm{p}=0.557)$. Air temperature, on the other hand, was statistically similar during spring and autumn, but summer air temperature was warmer than all other seasons, and winter air temperature was colder than all other seasons $(<0.05)$. Water temperature exhibited the least seasonal change, with winter and spring being statistically similar to one another $(\mathrm{p}=0.587)$ and lower than the values during summer and autumn $(\mathrm{p}<0.001)$, which were statistically similar to one another $(\mathrm{p}=0.173)$.

Table A3.1: Recorded observations of field site environmental parameters.

\begin{tabular}{|c|c|c|c|c|c|}
\hline $\begin{array}{c}\text { Date } \\
(\mathrm{dd} / \mathrm{mm} / \mathrm{yy})\end{array}$ & Time & $\begin{array}{c}\text { Tide level } \\
(\mathrm{m})\end{array}$ & $\begin{array}{c}\text { Air Temp } \\
\left({ }^{\circ} \mathrm{C}\right)\end{array}$ & $\begin{array}{c}\text { Water Temp } \\
\left({ }^{\circ} \mathrm{C}\right)\end{array}$ & Weather \\
\hline $06 / 11 / 18$ & 10:50am & 0.6 & 17.3 & 15.5 & Partly cloudy \\
\hline $23 / 12 / 18$ & $12: 18 \mathrm{pm}$ & 0.5 & 16.6 & 17.0 & Sunny, minimal clouds \\
\hline $24 / 01 / 19$ & $3: 07 \mathrm{pm}$ & 0.5 & 18.8 & 15.5 & Sunny, minimal clouds \\
\hline $20 / 02 / 19$ & $12: 15 \mathrm{pm}$ & 0.5 & 16.8 & 16.0 & Partly cloudy \\
\hline $23 / 03 / 19$ & $2: 30 \mathrm{pm}$ & 0.6 & 15.9 & 16.5 & Sunny, minimal clouds \\
\hline $24 / 04 / 19$ & $2: 30 \mathrm{pm}$ & 0.6 & 13.2 & 16.0 & Cloudy \\
\hline $21 / 05 / 19$ & $1: 30 \mathrm{pm}$ & 0.6 & 12.3 & 15.0 & Sunny \\
\hline $21 / 06 / 19$ & $12: 00 \mathrm{pm}$ & 0.7 & 10.4 & 13.5 & Sunny \\
\hline $06 / 08 / 19$ & $1: 30 \mathrm{pm}$ & 0.5 & 8.6 & 13.0 & Partly cloudy \\
\hline $16 / 09 / 19$ & $1: 00 \mathrm{pm}$ & 0.7 & 10.2 & 13.5 & Cloudy \\
\hline $29 / 10 / 19$ & $12: 00 \mathrm{pm}$ & 0.5 & 11.1 & 15.5 & Sunny \\
\hline $28 / 11 / 19$ & $1: 00 \mathrm{pm}$ & 0.5 & 15.4 & 17.0 & Partly cloudy \\
\hline
\end{tabular}




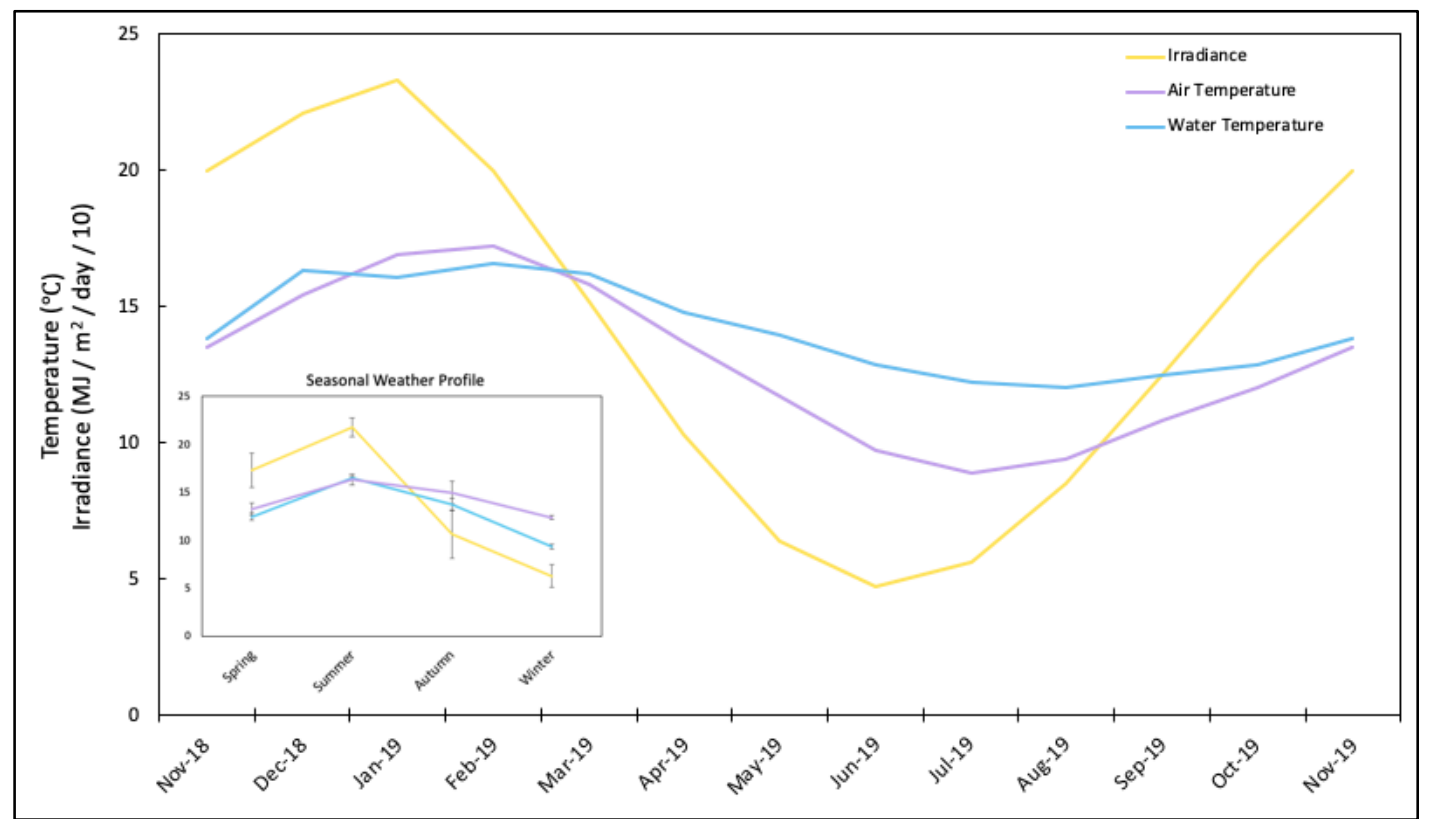

Figure A3.1.1: Average seasonal and monthly (inset) weather conditions for Wellington Harbour,

New Zealand. Irradiance $\left(\mathrm{MJ} / \mathrm{m}^{2} /\right.$ day $\left./ 10\right)$ and air temperature $\left({ }^{\circ} \mathrm{C}\right)$ values were obtained from NIWA online databases, which reports mean monthly values obtained throughout 1981-2010. Water temperature $\left({ }^{\circ} \mathrm{C}\right)$ was obtained from seatemperature.org, which reports average values from many years of compiled data. Values presented are means $\pm 1 \mathrm{SE}$ (where displayed).

\section{A3.1.2. Monthly chlorophyll $a: c_{2}$ ratio}

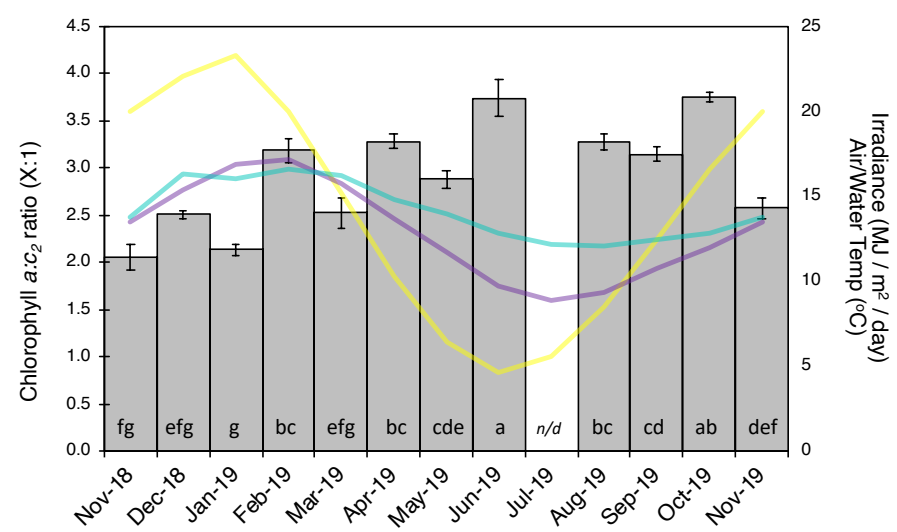

Figure A3.1.2: Monthly chlorophyll $a_{1} c_{2}$ of Symbiodiniaceae cells isolated from the sea anemone Anthopleura aureoradiata. Bars represent monthly averages ( $\mathrm{n}=7$ per month; values presented are means \pm 1 S.E.) for the following physiological measurements: (A) cell density, (B) protein content, (C) chlorophyll $a$, (D) chlorophyll $c_{2}$, (E) lipid content, and (F) carbohydrate content. Significant differences between groups are indicated by letters at the base of each bar. Coloured lines represent average monthly values of environmental parameters (yellow $=$ irradiance $\left(\mathrm{MJ} / \mathrm{m}^{2} /\right.$ day), purple $=$ air temperature $\left({ }^{\circ} \mathrm{C}\right)$, blue $=$ water temperature $\left.\left({ }^{\circ} \mathrm{C}\right)\right)$. 
A3.1.3. Seasonally-pooled physiology - Symbiont
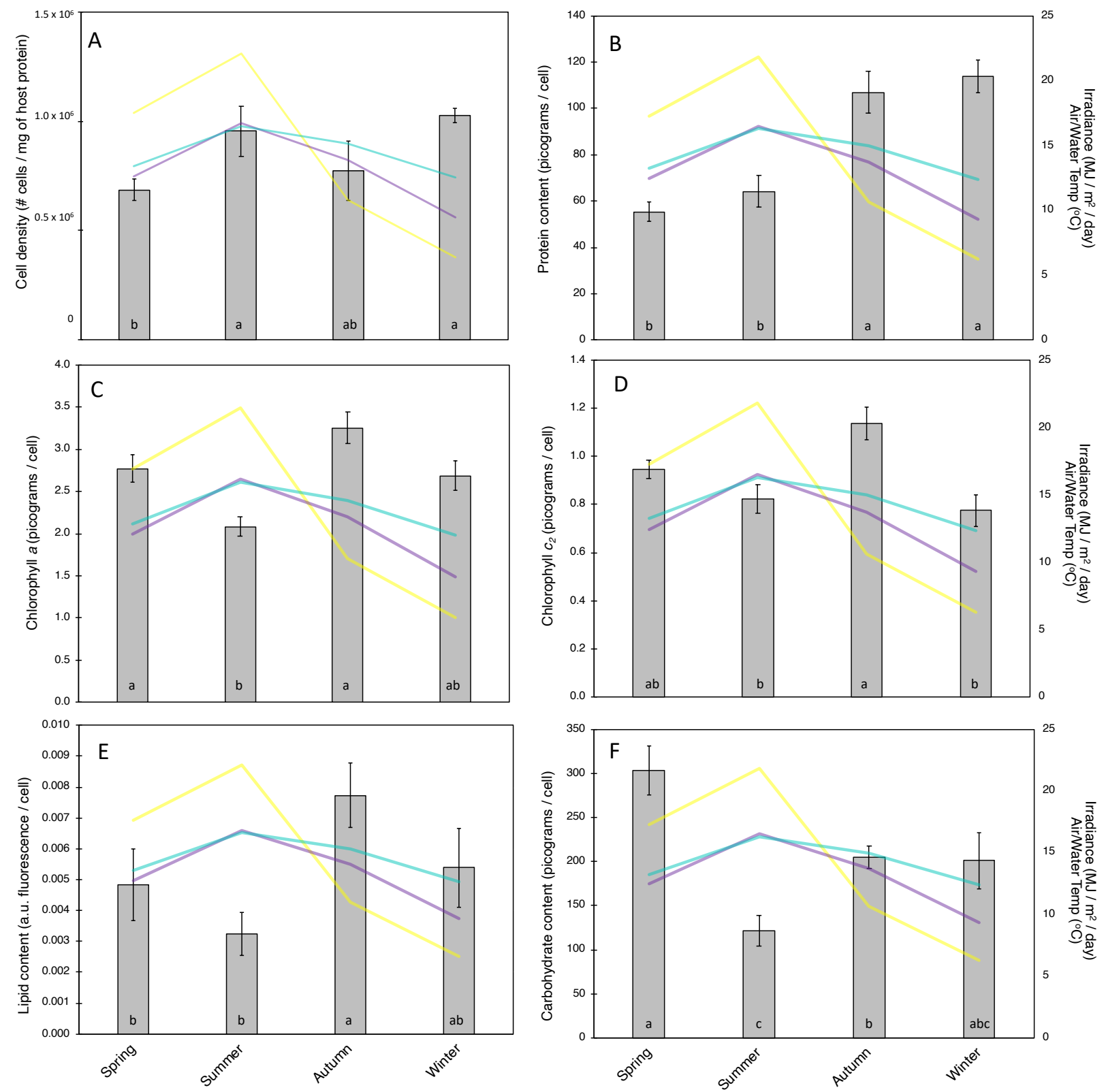

Figure A3.1.3: Seasonal physiology of symbionts isolated from Anthopleura aureoradiata collected from Shelly

Bay Lighthouse, NZ. Bars represent seasonal averages ( $\mathrm{n}=21$ per season, except for winter where $\mathrm{n}=14$ and spring where $n=28$; values presented are means \pm 1 S.E.) for the following physiological measurements: (A) cell density (cells per milligram host protein), (B) protein (picograms per cell), (C) chlorophyll a (picograms per cell), (D) chlorophyll $c_{2}$ (picograms per cell), (E) lipid (arbitrary units of fluorescence per cell), and (F) carbohydrate (picograms per cell). Significant differences between groups are indicated by letters at the base of each bar. Details of statistical tests can be found in the Appendices, Table A2.2. Coloured lines represent average monthly values of environmental parameters $\left(\right.$ yellow $=$ irradiance $\left(\mathrm{MJ} / \mathrm{m}^{2}\right)$, purple $=$ air temperature $\left({ }^{\circ} \mathrm{C}\right)$, blue $=$ water temperature $\left({ }^{\circ} \mathrm{C}\right)$ ). 


\section{A3.1.4. Seasonally-pooled physiology: Chlorophyll a:c2 ratio}

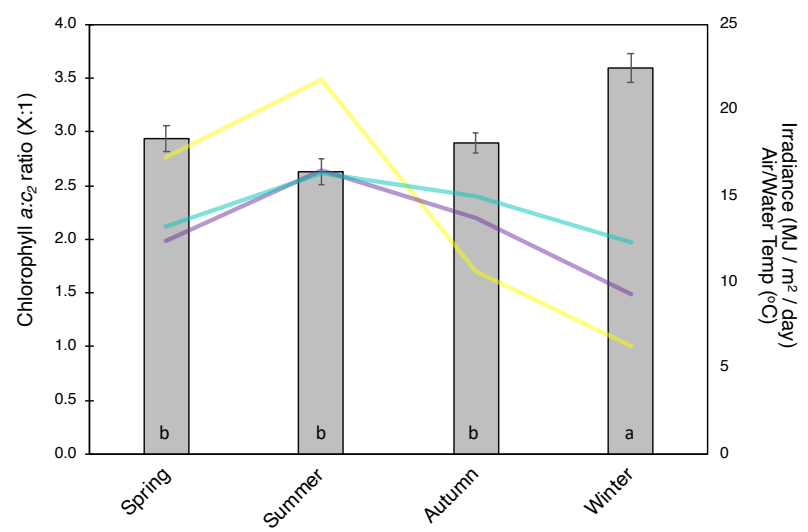

Figure A3.1.4: Seasonal chlorophyll $a: c_{2}$ ratio for symbionts isolated from Anthopleura aureoradiata collected from Shelly Bay Lighthouse, NZ between November 2018 and November 2019. Bars represent seasonal averages $(\mathrm{n}=21$ per season, except for winter where $\mathrm{n}=14$ and spring where $\mathrm{n}=28$; values presented are means \pm 1 S.E.) between Nov 2018 - Nov 2019. Significant differences between groups are indicated by letters at the base of each bar. Details of statistical tests can be found in the Appendices, Table A2.2. Coloured lines represent average monthly values of environmental parameters (yellow $=$ irradiance $\left(\mathrm{MJ} / \mathrm{m}^{2}\right)$, purple $=$ air temperature $\left({ }^{\circ} \mathrm{C}\right)$, blue $=$ water temperature $\left.\left({ }^{\circ} \mathrm{C}\right)\right)$.

\section{A3.1.5. Seasonally-pooled physiology - Host}
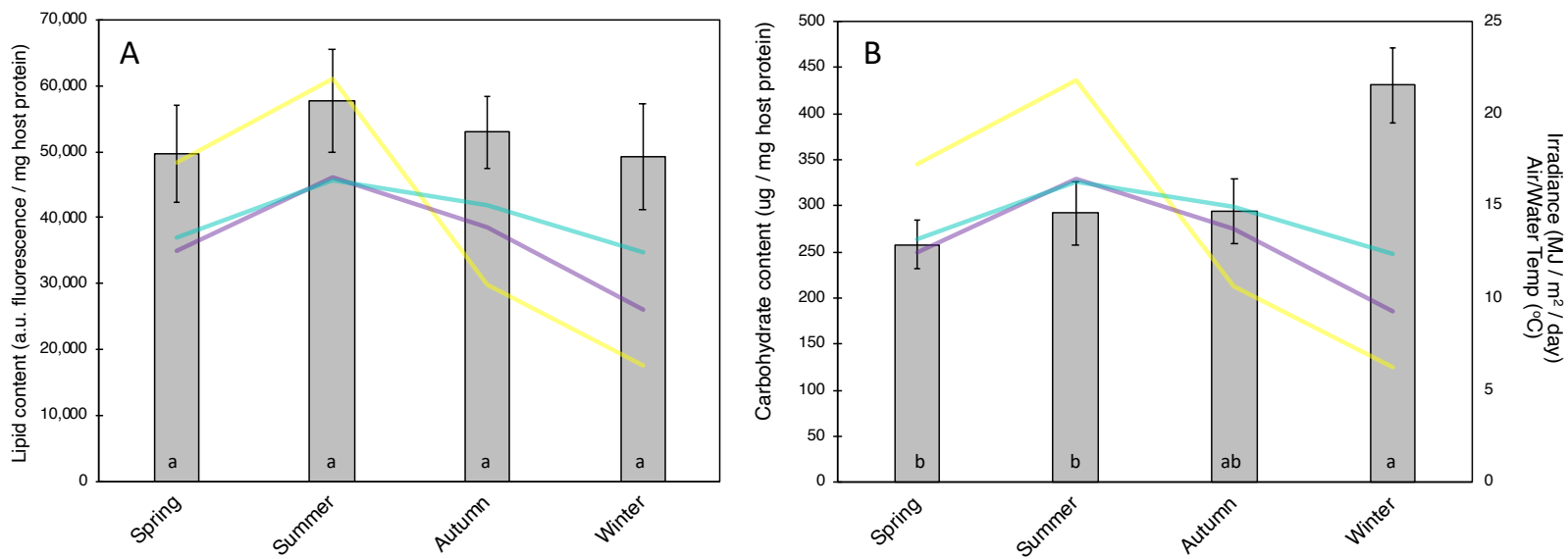

Figure A3.1.5: Seasonal physiology of Anthopleura aureoradiata host material, collected from Shelly Bay Lighthouse, NZ between November 2018 and November 2019. Bars represent seasonal averages $(\mathrm{n}=21$ per season, except for winter where $\mathrm{n}=14$; values presented are means \pm 1 S.E.) for the following physiological measurements: (A) lipid (arbitrary units of fluorescence per milligram host protein), and (B) carbohydrate (micrograms per milligram host protein). Significant differences between groups are indicated by letters at the base of each bar. Details of statistical tests can be found in the Appendices, Table A2.2. Coloured lines represent average monthly values of environmental parameters (yellow $=$ irradiance $\left(\mathrm{MJ} / \mathrm{m}^{2}\right)$, purple $=$ air temperature $\left({ }^{\circ} \mathrm{C}\right)$, blue $=$ water temperature $\left.\left({ }^{\circ} \mathrm{C}\right)\right)$. 


\section{A3.2. Experimental study -}

\section{A3.2.1. Chlorophyll a:c2 ratio - Symbiont}

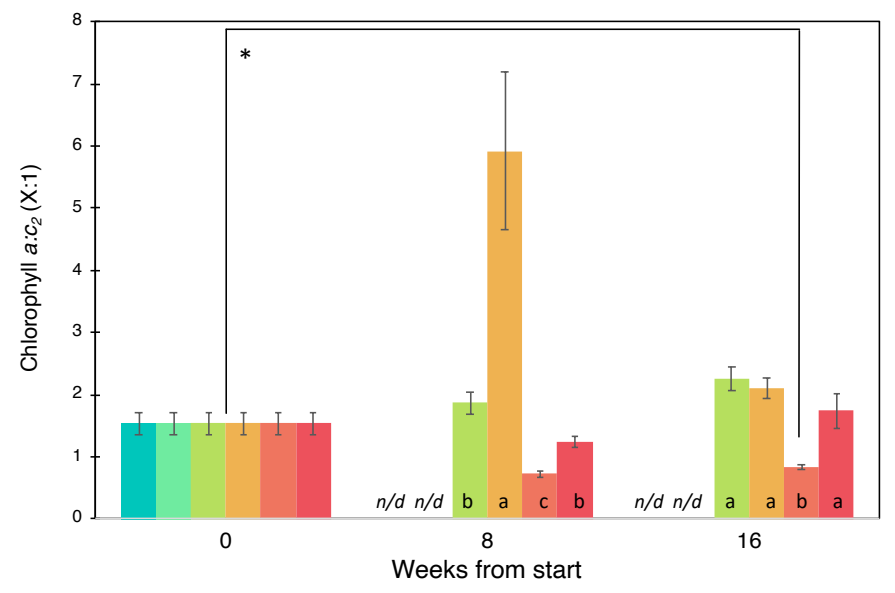

Figure A3.2.1: Chlorophyll a:c2 ratio of Symbiodiniaceae isolated from the sea anemone Anthopleura aureoradiata maintained in experimental conditions. Experimental study was conducted for 16 weeks. Treatments are abbreviated as follows: HTHI $=$ high temperature high irradiance, HTLI $=$ high temperature low irradiance, $\mathrm{MTHI}=$ moderate temperature high irradiance, $\mathrm{MTLI}=$ moderate temperature low irradiance, LTHI $=$ low temperature high irradiance, and LTLI $=$ low temperature low irradiance. Bars represent treatment averages ( $n=7$ per treatment per time point, except for MTHI at week 8 where $n=4$; values are means \pm 1 S.E.). Significant differences between treatments at each time point are indicated by letters at the base of each bar; same letters should not be interpreted as similarity across time points. Treatments that exhibited significant changes between weeks 0 and 16 are indicated by a line with an asterisk $\left(^{*}\right)$. 


\section{References}

Ainsworth, T, Fordyce, A, Camp, E. 2017. The Other Microeukaryotes of the Coral Reef Microbiome. Trends in Microbiology. 25:980-991.

Apprill, A, Bidigare, R, Gates, R. 2007. Visibly Healthy Corals Exhibit Variable Pigment Concentrations and Symbiont Phenotypes. Coral Reefs. 26:387-397.

Baghdasarian, G, Osberg, A, Mihora, D, Putnam, H, Gates, RD, Edmunds, PJ. 2017. Effects of Temperature and Pco2 on Population Regulation of Symbiodinium Spp. In a Tropical Reef Coral. The Biological Bulletin. 232:123-139.

Bates, AE, Mclean, L, Laing, P, Raeburn, LA, Hare, C. 2010. Distribution Patterns of Zoochlorellae and Zooxanthellae Hosted by Two Pacific Northeast Anemones, Anthopleura Elegantissima and A. Xanthogrammica. The Biological Bulletin. 218:237-247.

Beger, M, Sommer, B, Harrison, PL, Smith, SD, Pandolfi, JM. 2014. Conserving Potential Coral Reef Refuges at High Latitudes. Diversity and Distributions. 20:245-257.

Beinart, RA, et al. 2012. Evidence for the Role of Endosymbionts in Regional-Scale Habitat Partitioning by Hydrothermal Vent Symbioses. Proceedings of the National Academy of Sciences. 109.

Bergschneider, H, Muller-Parker, G1. 2008. Nutritional Role of Two Algal Symbionts in the Temperate Sea Anemone Anthopleura Elegantissima Brandt. The Biological Bulletin. 215:73-88.

Berkelmans, R. 2002. Time-Integrated Thermal Bleaching Thresholds of Reefs and Their Variation on the Great Barrier Reef. Marine Ecology Progress Series. 229:73-82.

Berkelmans, R, De'ath, G, Kininmonth, S, Skirving, W. 2004. A Comparison of the 1998 and 2002 Coral Bleaching Events on the Great Barrier Reef: Spatial Correlation, Patterns, and Predictions. Coral Reefs. 23:74-83. 
Berkelmans, R, van Oppen, MJH. 2006. The Role of Zooxanthellae in the Thermal Tolerance of Corals: A 'Nugget of Hope' for Coral Reefs in an Era of Climate Change. Proceedings of the National Academy of Sciences. 273:2305-2312.

Bertozzini, E, Galluzzi, L, Penna, A, Magnani, M. 2011. Application of the Standard Addition Method for the Absolute Quantification of Neutral Lipids in Microalgae Using Nile Red. Journal of Microbiological Methods. 87:17-23.

Bindoff, NL, W.W.L. Cheung, J.G. Kairo, J. Arístegui, V.A. Guinder, R. Hallberg, N. Hilmi, N. Jiao, M.S. Karim, L. Levin, S. O’Donoghue, S.R. Purca Cuicapusa, B. Rinkevich, T. Suga, A. Tagliabue, and P. Williamson. 2019. Ipcc Special Report on the Ocean and Cryosphere in a Changing Climate: Changing Ocean, Marine Ecosystems, and Dependent Communities. In press.

Blank, RJ, Trench, RK. 1985. Speciation and Symbiotic Dinoflagellates. Science.656-658.

Bock, T. 2008. The Control of Carbon Translocation in a Sea Anemone-Dinoflagellate Symbiosis from New Zealand. Master's Thesis. Victoria University of Wellington.

Bone, O. 2016. Impact of Environmental Stressors on the Metabolic Functioning of a Temperate CnidarianDinoflagellate Symbiosis. Master's Thesis. Victoria University of Wellington.

Bradford, MM. 1976. A Rapid and Sensitive Method for the Quantitation of Microgram Quantities of Protein Utilizing the Principle of Protein-Dye Binding. Analytical Biochemistry. 72:248-254.

Brown, BE. 1997. Coral Bleaching: Causes and Consequences. Coral Reefs. 16:S129-S138.

Buckley, BA, Szmant, A. 2004. Rna/DNA Ratios as Indicators of Metabolic Activity in Four Species of Caribbean Reef-Building Corals. Marine Ecology Progress Series. 282:143-149.

Burriesci, MS, Raab, TK, Pringle, JR. 2012. Evidence That Glucose Is the Major Transferred Metabolite in Dinoflagellate-Cnidarian Symbiosis. The Journal of Experimental Biology. 215:3467-3477.

Cacciapaglia, C, Woesik, R. 2016. Climate-Change Refugia: Shading Reef Corals by Turbidity. Global Change Biology. 22:1145-1154. 
Camp, EF, Schoepf, V, Mumby, PJ, Hardtke, LA, Rodolfo-Metalpa, R, Smith, DJ, Suggett, DJ. 2018. The Future of Coral Reefs Subject to Rapid Climate Change: Lessons from Natural Extreme Environments. Frontiers In Marine Science. 5:4.

Carlgren, O. 1950. A Revision of Some Actiniaria Described by A. E. Verrill. Journal of the Washington Academy of Sciences. 40:22-28.

Chakravarti, L, van Oppen, M. 2018. Experimental Evolution in Coral Photosymbionts as a Tool to Increase Thermal Tolerance. Frontiers In Marine Science. 5.

Chen, H-K, Song, S-N, Wang, L-H, Mayfield, AB, Chen, Y-J, Chen, W-N, Chen, C-S. 2015. A Compartmental Comparison of Major Lipid Species in a Coral-Symbiodinium Endosymbiosis: Evidence That the Coral Host Regulates Lipogenesis of Its Cytosolic Lipid Bodies: E0132519. PLoS ONE. 10.

Chen, W, Zhang, C, Song, L, Sommerfeld, M, Hu, Q. 2009. A High Throughput Nile Red Method for Quantitative Measurement of Neutral Lipids in Microalgae. Journal of Microbiological Methods. 77:41-47.

Coma, R, Ribes, M, Orejas, C, Gili, JM. 1999. Prey Capture by a Benthic Coral Reef Hydrozoan. Coral Reefs. 18:141-145.

Conover, DO, Duffy, TA, Hice, LA. 2009. The Covariance between Genetic and Environmental Influences across Ecological Gradients: Reassessing the Evolutionary Significance of Countergradient and Cogradient Variation. Annals of the New York Academy of Sciences. 1168:100-129.

Cook, CB, Muller-Parker, G, D'Elia, CF. 1992. Ammonium Enhancement of Dark Carbon Fixation and Nitrogen Limitation in Symbiotic Zooxanthellae: Effects of Feeding and Starvation of the Sea Anemone Aiptasia Pallida. Limnology and Oceanography. 37:131-139.

Cornwall, A. 2017. The Importance and Movement of Mud Bacterial Carbon within the Symbiosis of the New Zealand Sea Anemone Anthopleura Aureoradiata. Master's Thesis. Victoria University of Wellington. 
Dagenais Bellefeuille, S, Dorion, S, Rivoal, J, Morse, D, Lin, S. 2014. The Dinoflagellate Lingulodinium Polyedrum Responds to N Depletion by a Polarized Deposition of Starch and Lipid Bodies. PLoS ONE. 9.

Dahlhoff, E. 2004. Biochemical Indications of Stress and Metabolism: Applications for Marine Ecological Studies. Annual Review of Physiology. 66:183-207.

Davy, SK. 1994. The Specificity of Temperate Anthozoan-Dinoflagellate Symbioses. ProQuest Dissertations Publishing.

Davy, SK, Allemand, D, Weis, VM. 2012. Cell Biology of Cnidarian- Dinoflagellate Symbiosis. Microbiology and Molecular Biology Reviews. 76:229.

Davy, SK, Lucas, IAN, Turner, JR. 1996. Carbon Budgets in Temperate Anthozoan-Dinoflagellate Symbioses. International Journal on Life in Oceans and Coastal Waters. 126:773-783.

Davy, SK, Turner, JR. 2003. Early Development and Acquisition of Zooxanthellae in the Temperate Symbiotic Sea Anemone Anthopleura Ballii (Cocks). The Biological Bulletin. 205:66-72.

Davy, SK, Turner, JR, Lucas, IAN. 1997. The Nature of Temperate Anthozoan-Dinoflagellate Symbioses. Proceedings of the Eighth International Coral Reef Symposium. 2:1307-1312.

Davy, SK, Withers, KJT, Hinde, R. 2006. Effects of Host Nutritional Status and Seasonality on the Nitrogen Status of Zooxanthellae in the Temperate Coral Plesiastrea Versipora (Lamarck). Journal of Experimental Marine Biology and Ecology. 335:256-265.

De'ath, G, Fabricius, KE, Sweatman, H, Puotinen, M. 2012. The 27-Year Decline of Coral Cover on the Great Barrier Reef and Its Causes. Proceedings of the National Academy of Sciences. 109:1799517999.

DeSalvo, M, Estrada, A, Sunagawa, S, Medina, M. 2012. Transcriptomic Responses to Darkness Stress Point to Common Coral Bleaching Mechanisms. Coral Reefs. 31:215-228. 
Díaz-Almeyda, E, Thomé, P, El Hafidi, M, Iglesias-Prieto, R. 2011. Differential Stability of Photosynthetic Membranes and Fatty Acid Composition at Elevated Temperature in Symbiodinium. Coral Reefs. $30: 217-225$.

Dick, G. 2019. The Microbiomes of Deep-Sea Hydrothermal Vents: Distributed Globally, Shaped Locally. Nature Reviews. Microbiology. 17:271-283.

Dimond, J, Carrington, E. 2008. Symbiosis Regulation in a Facultatively Symbiotic Temperate Coral: Zooxanthellae Division and Expulsion. Coral Reefs. 27:601-604.

Dimond, JL, Bingham, BL, Muller-Parker, G, Wuesthoff, K, Francis, L. 2011. Seasonal Stability of a Flexible Algal-Cnidarian Symbiosis in a Highly Variable Temperate Environment. Limnology and Oceanography. 56:2233-2242.

Doherty, MD, Simon. 2009. Ocean Acidification: Comparative Impacts on the Photophysiology of a Temperate Symbiotic Sea Anemone

a Tropical Coral. Master's Thesis. Victoria University of Wellington.

Dubinsky, Z, Stambler, N, Ben-Zion, M, McCloskey, L, Muscatine, L, Falkowski, P. 1990. The Effect of External Nutrient Resources on the Optical Properties and Photosynthetic Efficiency of Stylophora Pistillata. Proceedings of the Royal Society of London. Series B. Biological Sciences. 239:231246.

DuBois, M, Gilles, KA, Hamilton, JK, Rebers, PA, Smith, F. 1956. Colorimetric Method for Determination of Sugars and Related Substances. Analytical Chemistry. 28:350-356.

Dykens, JA, Shick, JM. 1984. Photobiology of the Symbiotic Sea Anemone, Anthopleura Elegantissima: Defenses against Photodynamic Effects, and Seasonal Photoacclimation. The Biological Bulletin. 167:683-697.

Environment, Mft. 2018. Climate Change Projections for New Zealand: Atmosphere

Projections Based on Simulations from the Ipcc Fifth Assessment, 2nd Edition. Wellington: Ministry for the Environment. 
Fabricius, K, Mieog, J, Colin, P, Idip, D, Van Oppen, M. 2004. Identity and Diversity of Coral Endosymbionts (Zooxanthellae) from Three Palauan Reefs with Contrasting Bleaching, Temperature and Shading Histories. Molecular Ecology. 13:2445-2458.

Falkowski, PG, Dubinsky, Z, Muscatine, L, McCloskey, L. 1993. Population Control in Symbiotic Corals. BioScience. 43:606-611.

Falkowski, PG, Jokiel, PL, Kinzie, RA. 1990. Irradiance and Corals. Ecosystems of the World. 25:89-107.

Farrant, P, Borowitzka, MA, Hinde, R, King, R. 1987. Nutrition of the Temperate Australian Soft Coral Capnella Gaboensis . I. Photosynthesis and Carbon Fixation. Marine Biology. Berlin, Heidelberg. 95:565-574.

Ferrier-Pagés, C, Peirano, A, Abbate, M, Cocito, S, Negri, A, Rottier, C, Riera, P, Rodolfo-Metalpa, R, Reynauda, S. 2011. Summer Autotrophy and Winter Heterotrophy in the Temperate Symbiotic Coral Cladocora Caespitosa. Limnology and Oceanography. 56:1429-1438.

Fisch, J, Drury, C, Towle, EK, Winter, RN, Miller, MW. 2019. Physiological and Reproductive Repercussions of Consecutive Summer Bleaching Events of the Threatened Caribbean Coral Orbicella Faveolata. Coral Reefs. 38:863-876.

Fisher, P, Malme, M, Dove, S. 2012. The Effect of Temperature Stress on Coral- Symbiodinium Associations Containing Distinct Symbiont Types. Coral Reefs. 31:473-485.

Fitt, W, Brown, B, Warner, M, Dunne, R. 2001. Coral Bleaching: Interpretation of Thermal Tolerance Limits and Thermal Thresholds in Tropical Corals. Coral Reefs. 20:51-65.

Fitt, W, Pardy, R. 1981. Effects of Starvation, and Light and Dark on the Energy Metabolism of Symbiotic and Aposymbiotic Sea Anemones, Anthopleura Elegantissima. Marine Biology. 61:199-205.

Fitt, WK, et al. 2009. Response of Two Species of Indo-Pacific Corals, Porites Cylindrica and Stylophora Pistillata, to Short-Term Thermal Stress: The Host Does Matter in Determining the Tolerance of Corals to Bleaching. Journal of Experimental Marine Biology and Ecology. 373:102-110. 
Fitt, WK, McFarland, FK, Warner, ME, Chilcoat, GC. 2000. Seasonal Patterns of Tissue Biomass and Densities of Symbiotic Dinoflagellates in Reef Corals and Relation to Coral Bleaching. Limnology and Oceanography. 45:677-685.

Frankowiak, K, Wang, XT, Sigman, DM, Gothmann, AM, Kitahara, MV, Mazur, M, Meibom, A, Stolarski, J. 2016. Photosymbiosis and the Expansion of Shallow-Water Corals. Science Advances. 2:e1601122-e1601122.

Frieler, K, Meinshausen, M, Golly, A, Mengel, M, Lebek, K, Donner, S, Hoegh-Guldberg, O. 2013. Limiting Global Warming to 2 C Is Unlikely to Save Most Coral Reefs. Nature Climate Change. 3:165-170.

Gardiner, NM, Munday, PL, Nilsson, GE. 2010. Counter-Gradient Variation in Respiratory Performance of Coral Reef Fishes at Elevated Temperatures. PLoS ONE. 5:e13299.

Gates, R. 1990. Seawater Temperature and Sublethal Coral Bleaching in Jamaica. Coral Reefs. 8:193-197.

Gates, RD, Baghdasarian, G, Muscatine, L. 1992. Temperature Stress Causes Host Cell Detachment in Symbiotic Cnidarians: Implications for Coral Bleaching. The Biological Bulletin. 182:324-332.

Gerz, M, Guillermo Bueno, C, Ozinga, WA, Zobel, M, Moora, M. 2018. Niche Differentiation and Expansion of Plant Species Are Associated with Mycorrhizal Symbiosis. Journal of Ecology. 106:254-264.

Gibbons, CL. 2009. Carbon Flux in the Temperate Zooxanthellate Sea Anemone Anthopleura Aureoradiata. Master's Thesis. Victoria University of Wellington.

Gifuni, I, Olivieri, G, Pollio, A, Franco, T, Marzocchella, A. 2017. Autotrophic Starch Production by Chlamydomonas Species. Journal of Applied Phycology. 29:105-114.

Gori, A, Viladrich, N, Gili, JM, Kotta, M, Cucio, C, Magni, L, Bramanti, L, Rossi, S. 2012. Reproductive Cycle and Trophic Ecology in Deep Versus Shallow Populations of the Mediterranean Gorgonian Eunicella Singularis (Cap De Creus, Northwestern Mediterranean Sea). Coral Reefs. 31:823-837. 
Greenspan, P, Mayer, EP, Fowler, SD. 1985. Nile Red: A Selective Fluorescent Stain for Intracellular Lipid Droplets. Journal of Cell Biology. 100:965-973.

Grégoire, V, Schmacka, F, Coffroth, M, Karsten, U. 2017. Photophysiological and Thermal Tolerance of Various Genotypes of the Coral Endosymbiont Symbiodinium Sp. (Dinophyceae). Journal of Applied Phycology. 29:1893-1905.

Grottoli, AG, et al. 2018. Coral Physiology and Microbiome Dynamics under Combined Warming and Ocean Acidification. PLoS ONE. 13:e0191156.

Haag, E, Dyson, K. 2014. Trade-Off between Safety and Feeding in the Sea Anemone Anthopleura Aureoradiata. New Zealand Journal of Marine and Freshwater Research. 48:540-546.

Hall, DO, Rao, KK. 1999. Photosynthesis. Cambridge University Press, Cambridge.

Helmuth, BST, Timmerman, BEH, Sebens, KP. 1997. Interplay of Host Morphology and Symbiont Microhabitat in Coral Aggregations. Marine Biology. 130:1-10.

Hiebert, TC, Bingham, BL. 2012. The Effects of Symbiotic State on Heterotrophic Feeding in the Temperate Sea Anemone Anthopleura Elegantissima. Marine Biology. 159:939-950.

Hillyer, KE, Dias, DA, Lutz, A, Roessner, U, Davy, SK. 2017. Mapping Carbon Fate During Bleaching in a Model Cnidarian Symbiosis: The Application of 13c Metabolomics. The New Phytologist. 214:1551-1562.

Hillyer, KE, Tumanov, S, Villas-Bôas, S, Davy, SK. 2016. Metabolite Profiling of Symbiont and Host During Thermal Stress and Bleaching in a Model Cnidarian-Dinoflagellate Symbiosis. The Journal of Experimental Biology. 219:516.

Hinrichs, S, Patten, N, Allcock, R, Saunders, S, Strickland, D, Waite, A. 2013. Seasonal Variations in Energy Levels and Metabolic Processes of Two Dominant Acropora Species ( A. Spicifera and A. Digitifera ) at Ningaloo Reef. Journal of the International Society for Reef Studies. 32:623-635. 
Hoegh-Guldberg, O, Jones, R. 1999. Photoinhibition and Photoprotection in Symbiotic Dinoflagellates from Reef-Building Corals. Marine Ecology Progress Series. 183:73-86.

Hoegh-Guldberg, O, McCloskey, L, Muscatine, L. 1987. Expulsion of Zooxanthellae by Symbiotic Cnidarians from the Red Sea. Coral Reefs. 5:201-204.

Hoegh-Guldberg, O, Mumby, PJ, Hooten, AJ, Steneck, RS, Greenfield, P, Gomez, E, Harvell, CD, Sale, PF, Edwards, AJ, Caldeira, K. 2007. Coral Reefs under Rapid Climate Change and Ocean Acidification. Science. 318:1737-1742.

Hoogenboom, MO, Campbell, DA, Beraud, E, DeZeeuw, K, Ferrier-Pagès, C, Harmon, FG. 2012. Effects of Light, Food Availability and Temperature Stress on the Function of Photosystem Ii and Photosystem I of Coral Symbionts. PLoS ONE. 7.

Hopper, JV, Poulin, R, Thieltges, DW. 2008. Buffering Role of the Intertidal Anemone Anthopleura Aureoradiata in Cercarial Transmission from Snails to Crabs. Journal of Experimental Marine Biology and Ecology. 367:153-156.

Howe, JN. 2013. The Genetic and Physiological Characteristics of the Symbiodinium Spp. In the Endemic Anemone Anthopleura Aureoradiata. Master's Thesis. Victoria University of Wellington.

Hughes, AD, Grottoli, AG, Pease, T, Matsui, Y. 2010. Acquisition and Assimilation of Carbon in NonBleached and Bleached Corals. Marine Ecology Progress Series. 420:91-101.

Hughes, TP, et al. 2003. Climate Change, Human Impacts, and the Resilience of Coral Reefs. Science. 301:929-933.

Hughes, TP, Kerry, JT, Álvarez-Noriega, M, Álvarez-Romero, JG, Anderson, KD, Baird, AH, Babcock, RC, Beger, M, Bellwood, DR, Berkelmans, R. 2017. Global Warming and Recurrent Mass Bleaching of Corals. Nature. 543:373-377.

Hughes, TP, Kerry, JT, Baird, AH, Connolly, SR, Chase, TJ, Dietzel, A, Hill, T, Hoey, AS, Hoogenboom, MO, Jacobson, M. 2019. Global Warming Impairs Stock-Recruitment Dynamics of Corals. Nature. 568:387-390. 
Hunter, RL, LaJeunesse, TC, Santos, SR. 2007. Structure and Evolution of the Rdna Internal Transcribed Spacer (Its) Region 2 in the Symbiotic Dinoflagellates (Symbiotinium, Dynophyta). Journal of Phycology. 43:120-128.

Iglesias-Prieto, R, Matta, JL, Robins, WA, Trench, RK. 1992. Photosynthetic Response to Elevated Temperature in the Symbiotic Dinoflagellate Symbiodinium Microadriaticum in Culture. Proceedings of the National Academy of Sciences of the United States of America. 89:1030210305.

Iglesias-Prieto, R, Trench, R. 1997. Acclimation and Adaptation to Irradiance in Symbiotic Dinoflagellates. Ii. Response of Chlorophyll-Protein Complexes to Different Photon-Flux Densities. Marine Biology. 130:23-33.

IPCC. 2014. Climate Change 2014: Synthesis Report. Contribution of Working Groups I, Ii and Iii to the Fifth Assessment Report of the Intergovernmental Panel on Climate Change. Pages 151 in Core Writing Team RKP, and L.A. Meyer, ed. IPCC. Geneva, Switzerland.

Jacques, T, Marshall, N, Pilson, M. 1983. Experimental Ecology of the Temperate Scleractinian Coral Astrangia Danae . 2. Effect of Temperature, Light Intensity and Symbiosis with Zooxanthellae Onm Etabolic Rate and Calcification. Marine Biology. Berlin, Heidelberg. 76:135-148.

Jeffrey, SW, Humphrey, GF. 1975. New Spectrophotometric Equations for Determining Chlorophylls a, B, C1 and C2 in Higher Plants, Algae and Natural Phytoplankton. Biochemie und Physiologie der Pflanzen. 167:191-194.

Jones, R, Luter, H, Fisher, R, Duckworth, A. 2020. Responses of Corals to Chronic Turbidity. Scientific Reports (Nature Publisher Group). 10.

Kellogg, R, Patton, J. 1983. Lipid Droplets, Medium of Energy Exchange in the Symbiotic Anemone Condylactis Gigantea : A Model Coral Polyp. Marine Biology. Berlin, Heidelberg. 75:137-149. 
Kemp, DW, Hernandez - Pech, X, Iglesias - Prieto, R, Fitt, WK, Schmidt, GW. 2014. Community Dynamics and Physiology of Symbiodinium Spp. Before, During, and after a Coral Bleaching Event. Limnology and Oceanography. 59:788-797.

Kou, Z, Bei, S, Sun, J, Pan, J. 2013. Fluorescent Measurement of Lipid Content in the Model Organism Chlamydomonas Reinhardtii. Journal of Applied Phycology. 25:1633-1641.

LaJeunesse, TC. 2001. Investigating the Biodiversity, Ecology, and Phylogeny of Endosymbiotic Dinoflagellates in the Genus Symbiodinium Using the Its Region: In Search of a "Species" Level Marker. Journal of Phycology. 37:866-880.

LaJeunesse, TC, Parkinson, JE, Gabrielson, PW, Jeong, HJ, Reimer, JD, Voolstra, CR, Santos, SR. 2018. Systematic Revision of Symbiodiniaceae Highlights the Antiquity and Diversity of Coral Endosymbionts. Current Biology. 28:2570-2580.e2576.

LaJeunesse, TC, Pettay, DT, Sampayo, EM, Phongsuwan, N, Brown, B, Obura, DO, Hoegh-Guldberg, O, Fitt, WK. 2010. Long-Standing Environmental Conditions, Geographic Isolation and HostSymbiont Specificity Influence the Relative Ecological Dominance and Genetic Diversification of Coral Endosymbionts in the Genus Symbiodinium. Journal of Biogeography. 37:785-800.

Larson, P. 2017. Brooding Sea Anemones (Cnidaria: Anthozoa: Actiniaria): Paragons of Diversity in Mode, Morphology, and Maternity.(Report). Invertebrate Biology. 136:92.

Lesser, M, Farrell, J. 2004. Exposure to Solar Radiation Increases Damage to Both Host Tissues and Algal Symbionts of Corals During Thermal Stress. Coral Reefs. 23:367-377.

Masuko, T, Minami, A, Iwasaki, N, Majima, T, Nishimura, S-I, Lee, YC. 2005. Carbohydrate Analysis by a Phenol-Sulfuric Acid Method in Microplate Format. Analytical Biochemistry. 339:69-72.

Matthews, J. 2017. The Nutritional Implications of Partner Switching in the Cnidarian-Dinoflagellate Symbiosis. Master's Thesis. Victoria University of Wellington. 
Matthews, JL, Oakley, CA, Lutz, A, Hillyer, KE, Roessner, U, Grossman, AR, Weis, VM, Davy, SK. 2018. Partner Switching and Metabolic Flux in a Model Cnidarian-Dinoflagellate Symbiosis. Proceedings of the Royal Society of London. Series B. Biological Sciences. 285:20182336.

Mayfield, AB, Wang, YB, Chen, CS, Chen, SH, Lin, CY. 2016. Dual-Compartmental Transcriptomic + proteomic Analysis of a Marine Endosymbiosis Exposed to Environmental Change. Molecular Ecology. 25:5944-5958.

McCauley, M, Banaszak, A, Goulet, T. 2018. Species Traits Dictate Seasonal-Dependent Responses of Octocoral-Algal Symbioses to Elevated Temperature and Ultraviolet Radiation. Journal of the International Society for Reef Studies. 37:901-917.

Moberg, F, Folke, C. 1999. Ecological Goods and Services of Coral Reef Ecosystems. Ecological Economics. 29:215-233.

Morar, SR, Bury, SJ, Wilkinson, SP, Davy, SK. 2011. Sedimentary Nitrogen Uptake and Assimilation in the Temperate Zooxanthellate Sea Anemone Anthopleura Aureoradiata. Journal of Experimental Marine Biology and Ecology. 399:110-119.

Mouritsen, KN, Poulin, R. 2003. The Mud Flat Anemone-Cockle Association: Mutualism in the Intertidal Zone? Oecologia. 135:131-137.

Muller-Parker, G, Davy, SK. 2001. Temperate and Tropical Algal-Sea Anemone Symbioses. Invertebrate Biology. 120:104-123.

Muscatine, L, Falkowski, P, Porter, J, Dubinsky, Z. 1984. Fate of Photosynthetic Fixed Carbon in Lightand Shade-Adapted Colonies of the Symbiotic Coral Stylophora Pistillata. Proceedings of the Royal Society of London. Series B. Biological Sciences. 222:181-202.

Muscatine, L, Ferrier-Pagès, C, Blackburn, A, Gates, RD, Baghdasarian, G, Allemand, D. 1998. CellSpecific Density of Symbiotic Dinoflagellates in Tropical Anthozoans. Coral Reefs. 17:329-337.

Muscatine, L, Grossman, D, Doino, J. 1991. Release of Symbiotic Algae by Tropical Sea Anemones and Corals after Cold Shock. Marine Ecology Progress Series. 77:233-243. 
Muscatine, L, Hand, C. 1958. Direct Evidence for the Transfer of Materials from Symbiotic Algae to the Tissues of a Coelenterate. Proceedings of the National Academy of Sciences of the United States of America. 44:1259.

Newson, G. 2019. The Impact of Thermal Stress and Nutrient Availability on the Physiology and Proteome of Symbiotic Dinoflagellates. Master's Thesis. Victoria University of Wellington.

NIWA. 1981-2010. Climate Summaries: Daily Global Radiation, Daily Temperature, Monthly Temperature. (https://niwa.co.nz/education-and-training/schools/resources/climate)

NOAA. 2020. World Sea Temperatures. (https://www.seatemperature.org/australia-pacific/newzealand/wellington.htm)

Oakley, C, Davy, S. 2018. Cell Biology of Coral Bleaching. Pages 189-211. Coral Bleaching, Springer.

Oakley, CA, Durand, E, Wilkinson, SP, Peng, L, Weis, VM, Grossman, AR, Davy, SK. 2017. Thermal Shock Induces Host Proteostasis Disruption and Endoplasmic Reticulum Stress in the Model Symbiotic Cnidarian Aiptasia. Journal of Proteome Research. 16:2121-2134.

Pandolfi, JM, Connolly, SR, Marshall, DJ, Cohen, AL. 2011. Projecting Coral Reef Futures under Global Warming and Ocean Acidification. Science. 333:418-422.

Paracer, S. 2000. Symbiosis: An Introduction to Biological Associations. Oxford University Press.

Pascal, N, Allenbach, M, Brathwaite, A, Burke, L, Le Port, G, Clua, E. 2016. Economic Valuation of Coral Reef Ecosystem Service of Coastal Protection: A Pragmatic Approach. Ecosystem Services. 21:7280.

Pearse, V. 1974. Modification of Sea Anemone Behavior by Symbiotic Zooxanthellae:Expansion and Contraction. Biological Bulletin, Marine National Laboratory, Woods Hole. 147:641-651.

Pietra, F. 1995. Structurally Similar Natural Products in Phylogenetically Distant Marine Organisms, and a Comparison with Terrestrial Species. Chemical Society Reviews. 24:65-71. 
Revel, J, Massi, L, Mehiri, M, Boutoute, M, Mayzaud, P, Capron, L, Sabourault, C. 2016. Differential Distribution of Lipids in Epidermis, Gastrodermis and Hosted Symbiodinium in the Sea Anemone Anemonia Viridis. Comparative Biochemistry and Physiology. Part A: Molecular \& Integrative Physiology. 191:140.

Richardson, K, Beardall, J, Raven, JA. 1983. Adaptation of Unicellular Algae to Irradiance: An Analysis of Strategies. The New Phytologist. 93:157-191.

Ritchie, RJ. 2006. Consistent Sets of Spectrophotometric Chlorophyll Equations for Acetone, Methanol and Ethanol Solvents. Photosynth. Res. 89:27-41.

Rob, R. 2004. Coral Bleaching: Thermal Adaptation in Reef Coral Symbionts. Nature. 430:742.

Robison, JD, Warner, ME. 2006. Differential Impacts of Photoacclimation and Thermal Stress on the Photobiology of Four Different Phylotypes of Symbiodinium (Pyrrhophyta). Journal of Phycology. 42:568-579.

Rodriguez-Lanetty, M, Hoegh-Guldberg, O. 2002. The Phylogeography and Connectivity of the Latitudinally Widespread Scleractinian Coral Plesiastrea Versipora in the Western Pacific. Molecular Ecology. 11:1177-1189.

Rosado, PM, Leite, DC, Duarte, GA, Chaloub, RM, Jospin, G, da Rocha, UN, Saraiva, JP, Dini-Andreote, F, Eisen, JA, Bourne, DG. 2019. Marine Probiotics: Increasing Coral Resistance to Bleaching through Microbiome Manipulation. The ISME journal. 13:921-936.

Rosset, S, Wiedenmann, J, Reed, AJ, Angelo, C. 2017. Phosphate Deficiency Promotes Coral Bleaching and Is Reflected by the Ultrastructure of Symbiotic Dinoflagellates. Marine Pollution Bulletin. 118:180-187.

Rossi, S, Gili, J-M, Coma, R, Linares, C, Gori, A, Vert, N. 2006. Temporal Variation in Protein, Carbohydrate, and Lipid Concentrations in Paramuricea Clavata (Anthozoa, Octocorallia): Evidence for Summer-Autumn Feeding Constraints. Marine Biology. 149:643-651. 
Saunders, BK, Muller-Parker, G. 1997. The Effects of Temperature and Light on Two Algal Populations in the Temperate Sea Anemone Anthopleura Elegantissima (Brandt, 1835). Journal of Experimental Marine Biology and Ecology. 211:213-224.

Secord, D, Muller-Parker, G. 2005. Symbiont Distribution Along a Light Gradient within an Intertidal Cave. Limnology and Oceanography. 50:272-278.

Shick, JM. 2012. A Functional Biology of Sea Anemones. Springer Science \& Business Media.

Smith, GJ, Muscatine, L. 1999. Cell Cycle of Symbiotic Dinoflagellates: Variation in G1 Phase-Duration with Anemone Nutritional Status and Macronutrient Supply in the Aiptasia PulchellaSymbiodinium Pulchrorum Symbiosis. Marine Biology. 134:405-418.

Souza, M, Rodrigues, M, Bon, E, Freitas, S. 2019. Interference of Starch Accumulation in Microalgal Cell Growth Measurement. Journal of Applied Phycology. 31:249-254.

Spano, C, Häussermann, V. 2017. Anthopleura Radians, a New Species of Sea Anemone (Cnidaria: Actiniaria: Actiniidae) from Northern Chile, with Comments on Other Species of the Genus from the South Pacific Ocean. Biodiversity and Natural History. 3.

Sproles, AE, Kirk, NL, Kitchen, SA, Oakley, CA, Grossman, AR, Weis, VM, Davy, SK. 2018. Phylogenetic Characterization of Transporter Proteins in the Cnidarian-Dinoflagellate Symbiosis. Molecular Phylogenetics and Evolution. 120:307-320.

Starzak, D, Quinnell, R, Nitschke, M, Davy, S. 2014. The Influence of Symbiont Type on Photosynthetic Carbon Flux in a Model Cnidarian-Dinoflagellate Symbiosis. Marine Biology. 161:711-724.

Stat, M, Morris, E, Gates, R. 2008. Functional Diversity in Coral-Dinoflagellate Symbiosis. Proceedings of the National Academy of Sciences, USA. 105:9256-9261.

Steen, R, Muscatine, L. 1987. Low Temperature Evokes Rapid Exocytosis of Symbiotic Algae by a Sea Anemone. Biological Bulletin, Marine Biological Laboratory, Woods Hole. 17:246-263. 
Suggett, DJ, Warner, ME, Leggat, W. 2017. Symbiotic Dinoflagellate Functional Diversity Mediates Coral Survival under Ecological Crisis. Trends in Ecology \& Evolution. 32:735-745.

Takahashi, S, Whitney, S, Itoh, S, Maruyama, T, Badger, M. 2008. Heat Stress Causes Inhibition of the De Novo Synthesis of Antenna Proteins and Photobleaching in Cultured Symbiodinium. Proceedings of the National Academy of Sciences of the United States of America. 105:4203.

Takeshita, T, Takeda, K, Ota, S, Yamazaki, T, Kawano, S. 2015. A Simple Method for Measuring the Starch and Lipid Contents in the Cell of Microalgae. Cytologia. 80:475-481.

Tchernov, D, Gorbunov, MY, De Vargas, C, Yadav, SN, Milligan, AJ, Häggblom, M, Falkowski, PG, Field, CB. 2004. Membrane Lipids of Symbiotic Algae Are Diagnostic of Sensitivity to Thermal Bleaching in Corals. Proceedings of the National Academy of Sciences of the United States of America. 101:13531-13535.

Titlyanov, E, Shaposhnikova, M. 1980. Photosynthesis and Adaptation of Corals to Irradiance. I: Contents and Native State of Photosynthetic Pigments in Symbiotic Microalga. Photosynthetica.8.

Titlyanov, E, Titlyanova, T, Leletkin, V, Tsukahara, J, Yamazato, K. 1996. Degradation of Zooxanthellae and Regulation of Their Density in Hermatypic Corals. Marine Ecology Progress Series. Oldendorf. 139:167-178.

Tivey, TR, Parkinson, JE, Weis, VM. 2020. Host and Symbiont Cell Cycle Coordination Is Mediated by Symbiotic State, Nutrition, and Partner Identity in a Model Cnidarian-Dinoflagellate Symbiosis. mBio. 11.

Toyoshima, M, Sato, N. 2015. High-Level Accumulation of Triacylglycerol and Starch in Photoautotrophically Grown Chlamydomonas Debaryana Nies-2212. Plant and Cell Physiology. 56:2447-2456.

Trench, R. 1971. The Physiology and Biochemistry of Zooxanthellae Symbiotic with Marine Coelenterates I. The Assimilation of Photosynthetic Products of Zooxanthellae by Two Marine Coelenterates. Proceedings of the Royal Society of London. Series B. Biological Sciences. 177:225-235. 
Verde, EA, McCloskey, LR. 2001. A Comparative Analysis of the Photobiology of Zooxanthellae and Zoochlorellae Symbiotic with the Temperate Clonal Anemone Anthopleura Elegantissima (Brandt) I. Effect of Temperature. Marine Biology. 138:477-489.

Verde, EA, McCloskey, LR. 2002. A Comparative Analysis of the Photobiology of Zooxanthellae and Zoochlorellae Symbiotic with the Temperate Clonal Anemone Anthopleura Elegantissima (Brandt). Marine Biology. 141:225-239.

Verde, EA, McCloskey, LR. 2007. A Comparative Analysis of the Photobiology of Zooxanthellae and Zoochlorellae Symbiotic with the Temperate Clonal Anemone Anthopleura Elegantissima (Brandt). Iii. Seasonal Effects of Natural Light and Temperature on Photosynthesis and Respiration. Marine Biology. 152:775-792.

Wagner, DE, Kramer, P, Van Woesik, R. 2010. Species Composition, Habitat, and Water Quality Influence Coral Bleaching in Southern Florida. Marine Ecology Progress Series. 408:65-78.

Wakefield, T, Farmer, MA, Kempf, SC. 2000. Revised Description of the Fine Structure of in Situ "Zooxanthellae" Genus Symbiodinium. The Biological Bulletin. 199:76-84.

Wang, JT, Douglas, AE. 1999. Essential Amino Acid Synthesis and Nitrogen Recycling in an AlgaInvertebrate Symbiosis. Marine Biology. 135:219-222.

Wang, L-H, Lee, H-H, Fang, L-S, Mayfield, AB, Chen, C-S. 2013. Fatty Acid and Phospholipid Syntheses Are Prerequisites for the Cell Cycle of Symbiodinium and Their Endosymbiosis within Sea Anemones.(Research Article). PLoS ONE. 8:e72486.

Warner, ME, Fitt, WK, Schmidt, GW. 1999. Damage to Photosystem Ii in Symbiotic Dinoflagellates: A Determinant of Coral Bleaching. Proceedings of the National Academy of Sciences of the United States of America. 96:8007-8012.

Weis, VM. 2008. Cellular Mechanisms of Cnidarian Bleaching: Stress Causes the Collapse of Symbiosis. The Journal of Experimental Biology. 211:3059-3066. 
Whitehead, LF, Douglas, AE. 2003. Metabolite Comparisons and the Identity of Nutrients Translocated from Symbiotic Algae to an Animal Host. The Journal of Experimental Biology. 206:3149-3157.

Wietheger, A, Starzak, DE, Gould, KS, Davy, SK. 2018. Differential Ros Generation in Response to Stress in Symbiodinium Spp. The Biological Bulletin. 234:11-21.

Yadav, M, Verma, M, Chauhan, N. 2018. A Review of Metabolic Potential of Human Gut Microbiome in Human Nutrition. Archives of Microbiology. 200:203-217. 